\title{
An analytical investigation of the profitability of selected loyalty programs in a competitive environment
}

\author{
By
}

\author{
Amirhossein Bazargan \\ Master of Science, Industrial Engineering, University of Regina, Regina, Canada 2012 \\ Bachelor of Science, Mechanical Engineering, Islamic Azad University, Tehran, Iran 2001
}

\author{
A dissertation \\ Presented to Ryerson University \\ in partial fulfillment of the \\ requirements of the degree of \\ Doctor of Philosophy \\ in the Program of \\ Mechanical and Industrial Engineering
}

Toronto, Ontario, Canada, 2017

(c) Amirhossein Bazargan 2017 


\section{Author's Declaration}

I hereby declare that I am the sole author of this dissertation. This is a true copy of the dissertation, including any required final revisions, as accepted by my examiners.

I authorize Ryerson University to lend this dissertation to other institutions or individuals for the purpose of scholarly research.

I further authorize Ryerson University to reproduce this dissertation by photocopying or by other means, in total or in part, at the request of other institutions or individuals for the purpose of scholarly research. 


\begin{abstract}
An analytical investigation of the profitability of selected loyalty programs

in a competitive environment

Amirhossein Bazargan

Doctor of Philosophy

Mechanical and Industrial Engineering

Ryerson University
\end{abstract}

2017

This dissertation investigates the profitability of loyalty programs in a competitive environment. Loyalty programs are prevalent marketing tools that encourage repurchase intentions among customers, and increase long-term profitability of firms. However, there is no consensus among researchers regarding the effectiveness of these programs in a competitive environment. This thesis responds to this line of research by developing game theoretic models that incorporate customers' valuations of reward and time, two factors that have not been considered simultaneously in previous studies on the profitability of loyalty programs. The results show that for firms offering undifferentiated products (e.g., coffee shops), offering loyalty programs is a dominant and profitable strategy for the competing firms only when customers highly value rewards, but not time.

After assessing the profitability of loyalty programs, the thesis investigates LP design issues related to the effectiveness of restricting redemption. This aspect of loyalty program design has received minimal attention in the literature. Nine sub-games between two competing firms are 
solved in which each firm applies one specific restriction level on redemption (unrestricted, low restricted, or high restricted), and optimal decision variables are obtained for each scenario. Based on the Nash equilibria of the sub-games, the main game is solved in which the firms decide about the level of restriction on their loyalty programs, which maximizes their profit.

The results show that firms should follow highly restrictive policies at equilibrium, but not when customers highly value time over reward. When the latter is the case, a prisoner dilemma occurs. Firms should react by applying redemption policies that are the least restrictive at equilibrium. Furthermore, when customers do not highly value neither time nor reward, a prisoner dilemma arises that suggests the firms to offer a low restricted redemption policy at equilibrium. In addition to these findings, this thesis contributes to the literature by developing comprehensive analytical models, that are stochastic and competitive, and that incorporate psychological theories. 


\section{Acknowledgements}

I would like to express my sincere appreciation to my supervisors, Professor Saeed Zolfaghari and Professor Salma Karray. Without their guidance and support, it was impossible to complete this thesis. Their patience made my $\mathrm{PhD}$ studies a productive and gratifying experience.

I would also like to express my gratitude and appreciation to the members of my examination committee, Dr. Mohamad Jaber, Dr. Mohamed Wahab Ismail, Dr. Ahmad Ghasempoor, Dr. David Martin, and Dr. Ozhand Ganjavi.

I am deeply grateful to my parents for their unending supports and love, and inspiring me throughout my life.

I owe special thanks to my beloved wife, without whose patience and support, this journey was not bearable. 


\section{Dedication}

To Delbar, my devoted and patient wife;

Soosan and Ebrahim, my beloved parents;

Amirali and Yasaman, my dearest siblings 


\section{Table of contents}

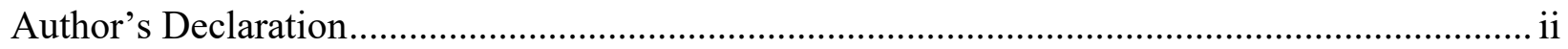

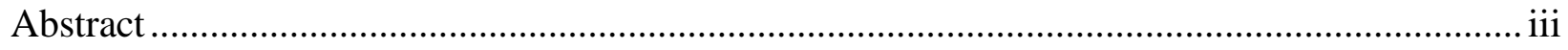

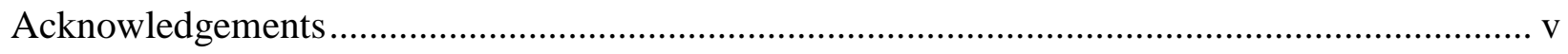

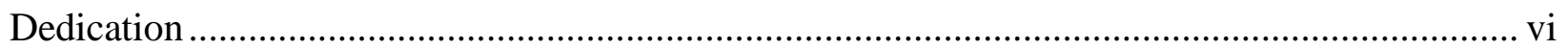

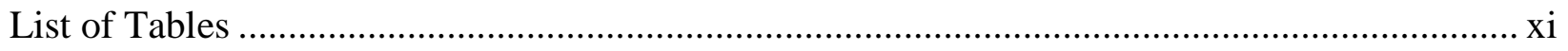

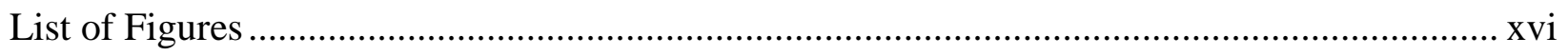

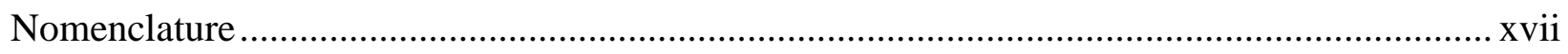

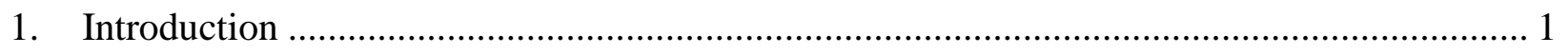

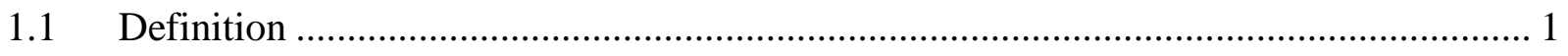

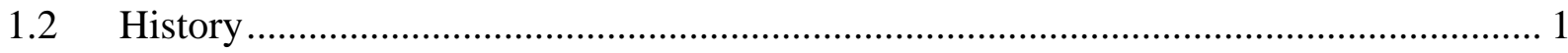

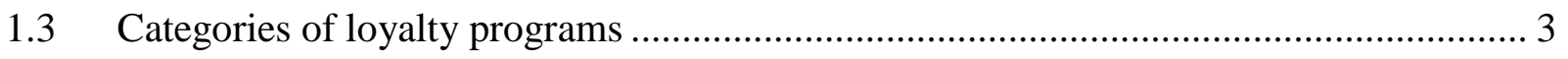

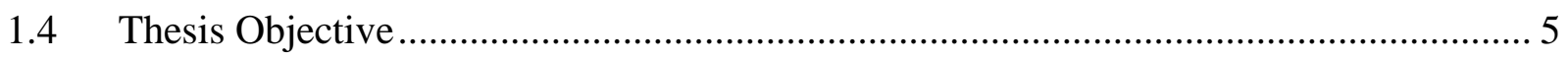

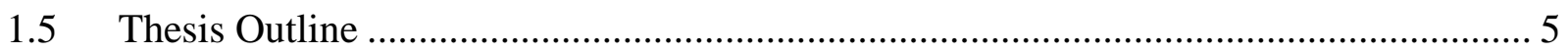

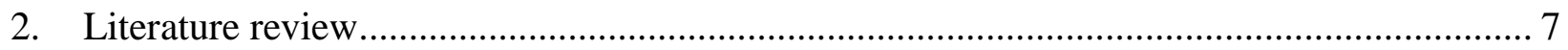

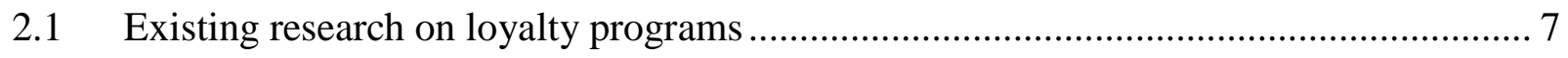

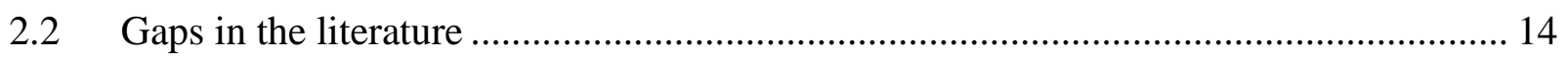

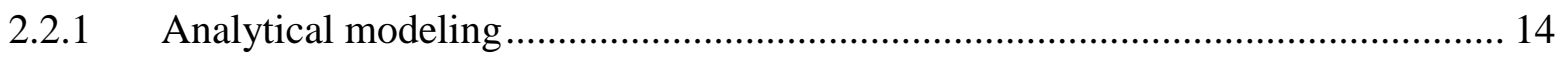

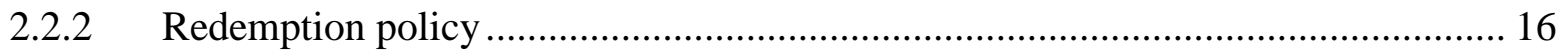


3. Loyalty programs' profitability in a competitive environment ...................................... 18

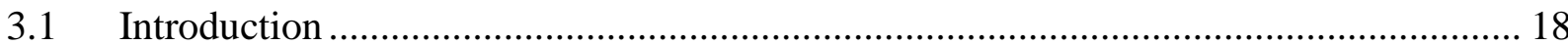

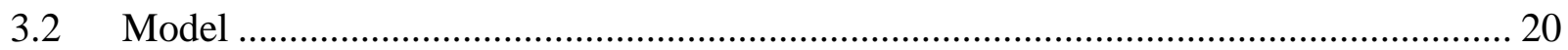

3.2.1 Assumptions and definitions .................................................................. 20

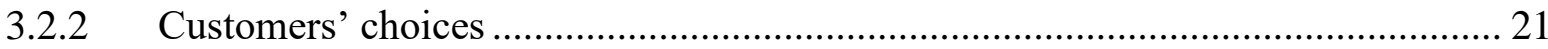

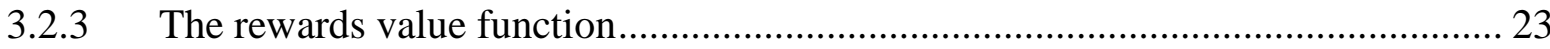

3.2.4 Deterministic components of customer's utilities......................................... 24

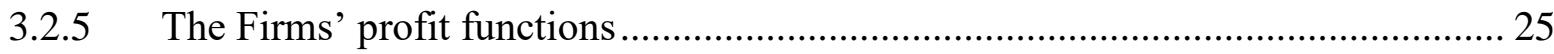

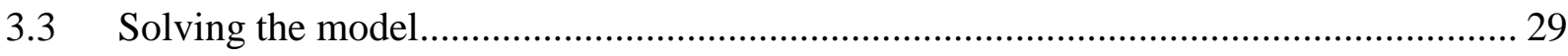

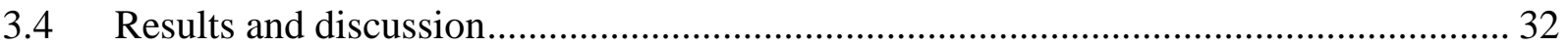

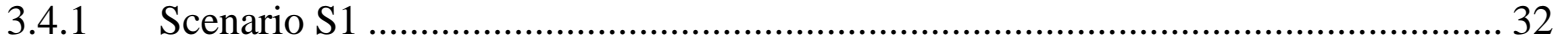

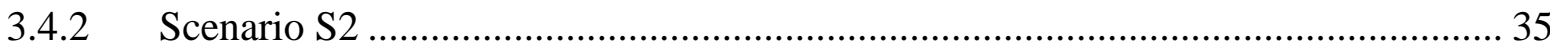

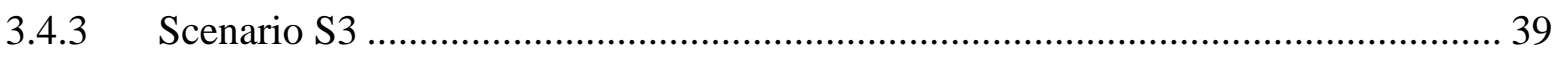

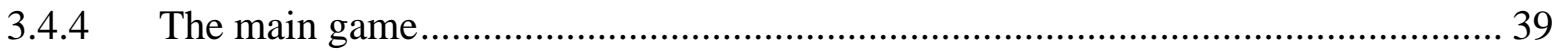

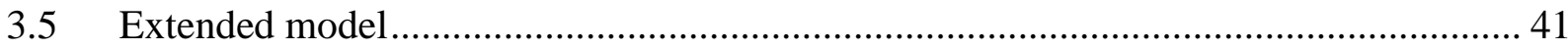

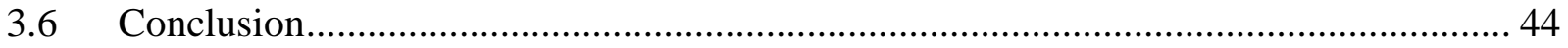

4. Profitability of restricted redemption in loyalty programs .......................................... 46

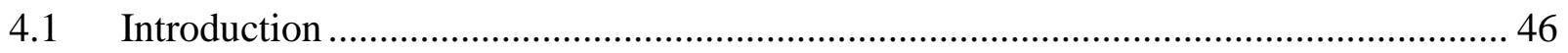

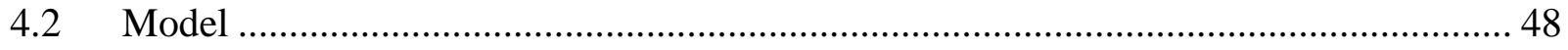

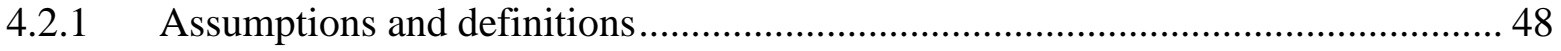




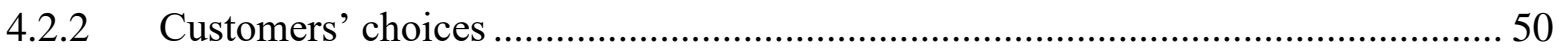

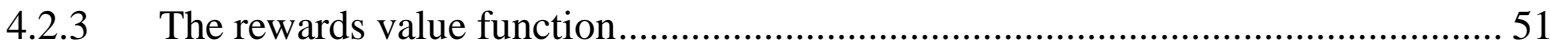

4.2.4 Deterministic components of customer's utilities................................................ 51

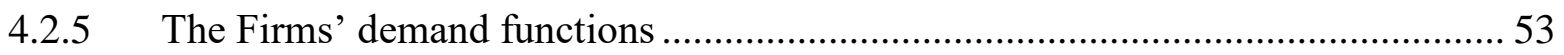

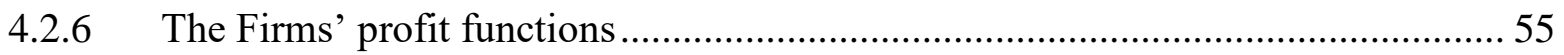

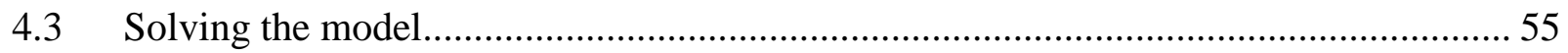

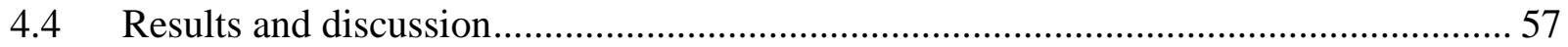

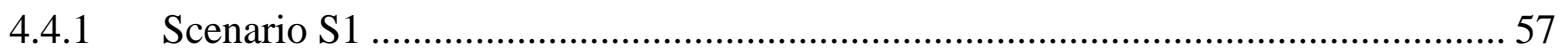

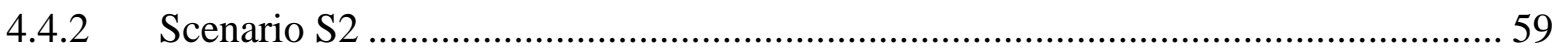

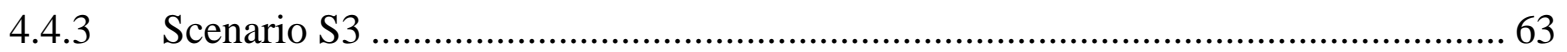

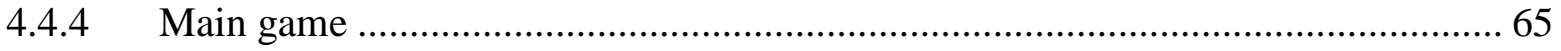

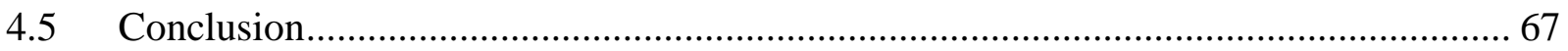

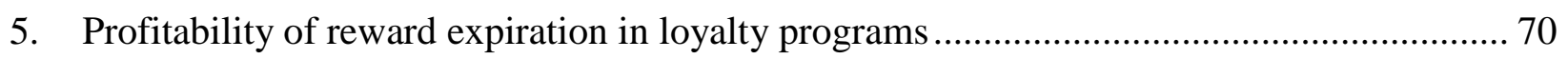

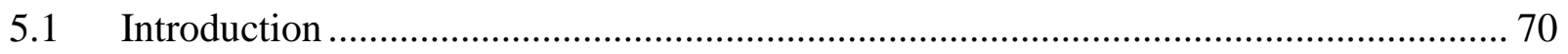

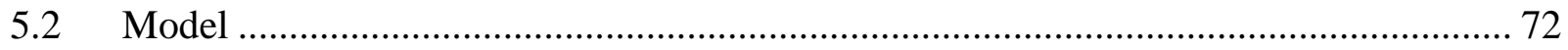

5.2.1 Assumptions and definitions ....................................................................... 72

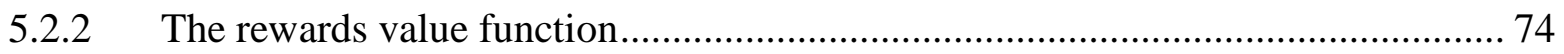

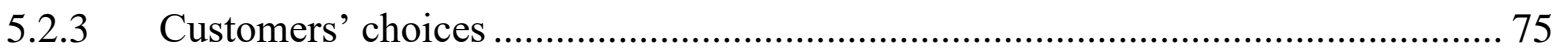

5.2.4 Deterministic components of customer's utilities................................................... 76

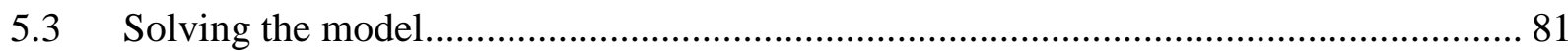




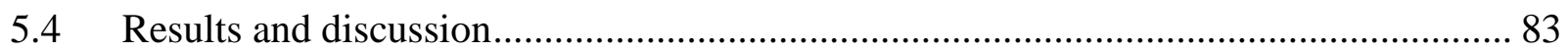

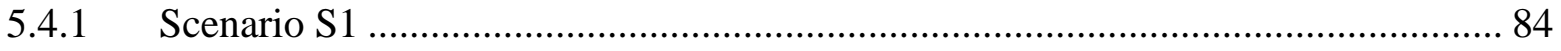

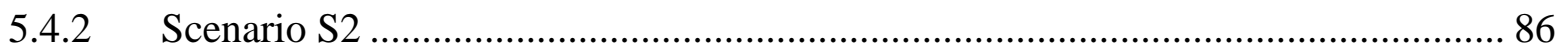

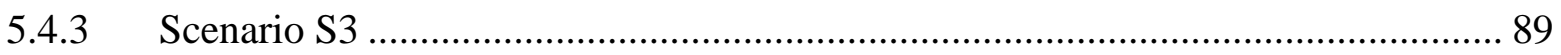

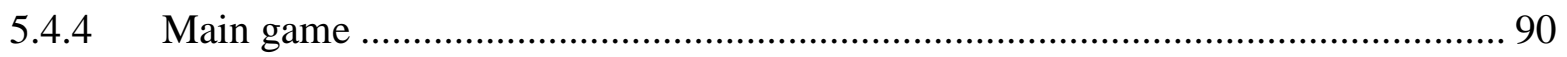

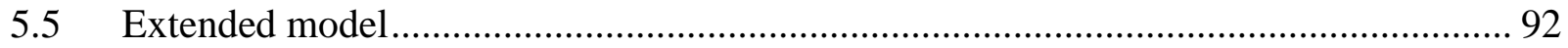

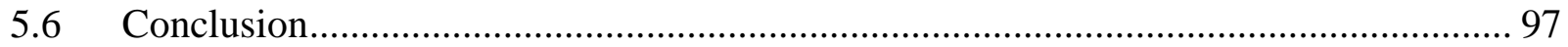

6. Conclusion, contributions and future research ........................................................ 99

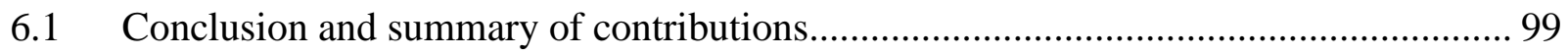

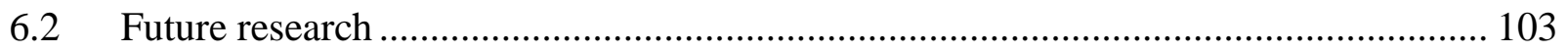

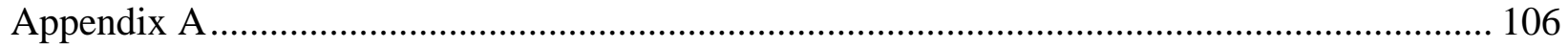

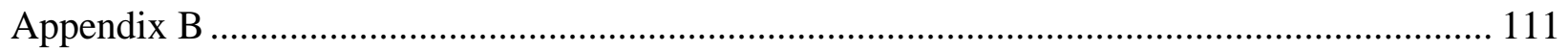

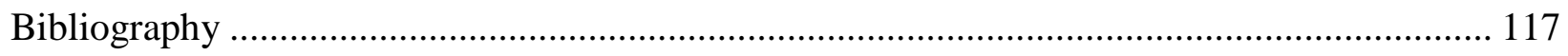




\section{List of Tables}

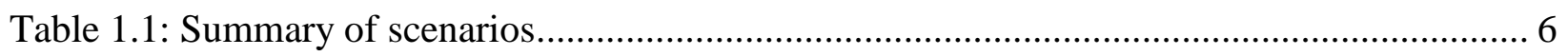

Table 2.1: Summary of analytical models in the literature ........................................................ 13

Table 3.1: Scenario definitions and firms' decision variables ................................................. 30

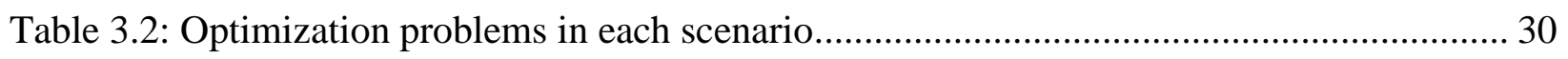

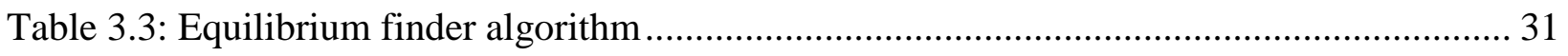

Table 3.4: Optimal reward timing (required number of purchases before redemption) in Scenario

S1 of the game between LP and No-LP for combinations of mental parameters ......................... 33

Table 3.5: Optimal price in Scenario S1 of the game between LP and No-LP for combinations of

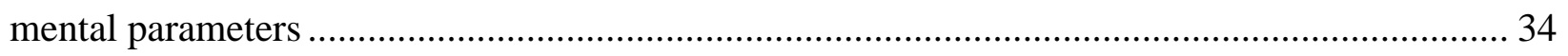

Table 3.6: Optimal profit in Scenario S1 of the game between LP and No-LP for combinations of

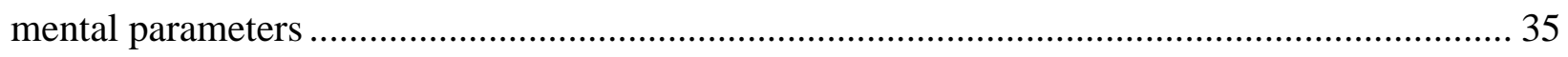

Table 3.7: Firm a's optimal reward timing (number of required purchases before redemption) in Scenario S2 of the game between LP and No-LP for combinations of mental parameters ........... 36 Table 3.8: Firm a's optimal price in Scenario S2 of the game between LP and No-LP for

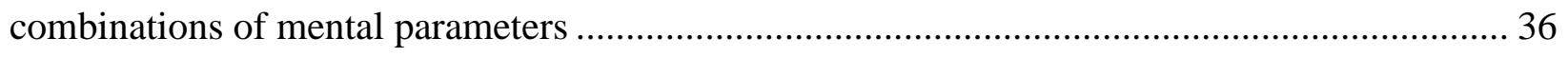

Table 3.9: Firm a's optimal profit in Scenario S2 of the game between LP and No-LP for

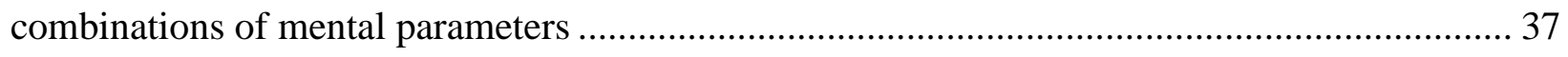

Table 3.10: Firm b's optimal price in Scenario S2 of the game between LP and No-LP for

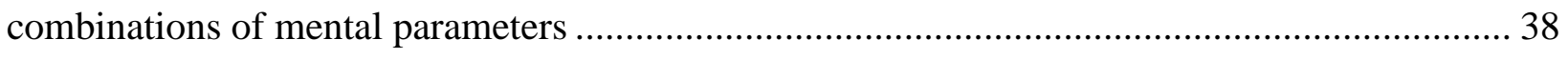

Table 3.11: Firm b's optimal profit in Scenario S2 of the game between LP and No-LP for

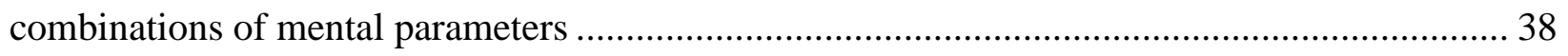


Table 3.12: Different regions of the game between LP and No-LP policies for combinations of mental parameters

Table 3.13: Different regions of the game between LP and No-LP considering an outside good for combinations of mental parameters 44

Table 4.1: Firms' optimal decision variables in Scenario S1 of the game between restricted and unrestricted redemption policies for combinations of mental parameters 58 Table 4.2: Firms' optimal profit in Scenario S1 of the game between restricted and unrestricted redemption policies for combinations of mental parameters 59

Table 4.3: Firm $a$ 's optimal decision variables in Scenario S2 of the game between restricted and unrestricted redemption policies for combinations of mental parameters 60 Table 4.4: Firm $a$ 's optimal profits in Scenario S2 of the game between restricted and unrestricted redemption policies for combinations of mental parameters

Table 4.5: Firm $b$ 's optimal decision variables in Scenario S2 of the game between restricted and unrestricted redemption policies for combinations of mental parameters 62 Table 4.6: Firm b's optimal profits in Scenario S2 of the game between restricted and unrestricted redemption policies for combinations of mental parameters

Table 4.7: Comparison of firms' profits in Scenario S2 of the game between restricted and unrestricted redemption policies for combinations of mental parameters

Table 4.8: Firms' optimal decision variables in Scenario S3 of the game between restricted and unrestricted redemption policies for combinations of mental parameters 64 Table 4.9: Firms' optimal profits in Scenario S3 of the game between restricted and unrestricted redemption policies for combinations of mental parameters 64 
Table 4.10: Different regions of the game between restricted and unrestricted policies for combinations of mental parameters

Table 5.1: Scenario definitions and firms' decision variables for the reward expiry problem..... 74

Table 5.2: Optimal decision variables in Scenario S1 of the game between expiry and no expiry policies for combinations of mental parameters

Table 5.3: Optimal profits in Scenario S1 of the game between expiry and no expiry policies for combinations of mental parameters 85

Table 5.4: Firm $a$ 's optimal decision variables in Scenario S2 of the game between expiry and no expiry policies for combinations of mental parameters 87

Table 5.5: Firm $a$ 's optimal profit in Scenario S2 of the game between expiry and no expiry policies for combinations of mental parameters 87 Table 5.6: Firm $b$ 's optimal decision variables in Scenario S2 of the game between expiry and no expiry policies for combinations of mental parameters 88

Table 5.7: Firm b's optimal profit in Scenario S2 of the game between expiry and no expiry policies for combinations of mental parameters 88

Table 5.8: Optimal decision variables in Scenario S3 of the game between expiry and no expiry policies for combinations of mental parameters 89 Table 5.9: Optimal profit in Scenario S3 of the game between expiry and no expiry policies for combinations of mental parameters 90 Table 5.10: Different regions of the game between expiry and no expiry policies for combinations of mental parameters. 92

Table 5.11: Firm $a^{\prime}$ optimal decision variables in Scenario S2e for combinations of mental parameters 94 
Table 5.12: Firm $a^{\prime}$ optimal profits in Scenario S2e for combinations of mental parameters ..... 95 Table 5.13: Firm b's optimal decision variables in Scenario S2e for combinations of mental

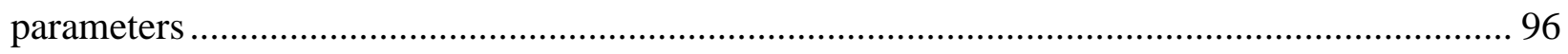

Table 5.14: Firm $b$ 's optimal profit in Scenario S2e for combinations of mental parameters ..... 96 Table 5.15: Comparison of firms' profits in Scenario S2e for combinations of mental parameters 97

Table 6.1: Different regions in the game between three levels of restriction redemption policies for combinations of mental parameters 103

Table A.1: Optimal reward timing (required number of purchases before redemption) in Scenario S1 of the game between LP and No-LP with an outside good 106 Table A.2: Optimal price in Scenario S1 of the game between LP and No-LP with outside goods for combinations of mental parameters. 107 Table A.3: Optimal profit in Scenario S1 of the game between LP and No-LP with outside goods for combinations of mental parameters. 107 Table A.4: Firm $a$ 's optimal reward timing (required number of purchases before redemption) in Scenario S2 of the game between LP and No-LP with an outside good for combinations of mental parameters 108

Table A.5: Firm $a$ 's optimal price in Scenario S2 of the game between LP and No-LP outside goods for combinations of mental parameters ..... 108 Table A.6: Firm $a$ 's optimal profit in Scenario S2 of the game between LP and No-LP with outside goods for combinations of mental parameters ...... 109

Table A.7: Firm b's optimal price in Scenario S2 of the game between LP and No-LP with outside goods for combinations of mental parameters 109 
Table A.8: Firm b's optimal profit in Scenario S2 of the game between LP and No-LP with outside goods for combinations of mental parameters ........................................................... 110

Table B.1: Scaled payoff matrices of the game between "LP" and "No-LP" policies for ......... 112 Table B.2: Scaled payoff matrices of the game between "LP" and "No-LP" policies with outside goods for combinations of mental parameters ............................................................ 113 Table B.3: Scaled payoff matrices of the game between restricted and unrestricted redemption policies for combinations of mental parameters .......................................................... 114 Table B.4 : Scaled payoff matrices of the game between low restricted (without expiry) and highly restricted (with expiry) redemption policies for combinations of mental parameters Table B.5: Scaled payoff matrices of the game between unrestricted, low restricted, and highly restricted redemption policies for combinations of mental parameters 116 


\section{List of Figures}

Figure 1.1: Sequence of emerging LPs in different industries.............................................. 2

Figure 1.2: LP's popularity in different sectors .......................................................... 3

Figure 3.1: Flow chart of two subsequent purchasing periods in Scenario S1 of the game between

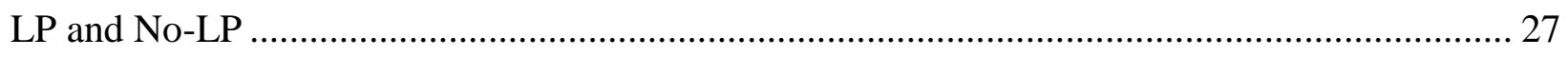

Figure 3.2: Flow chart of two subsequent purchasing periods in Scenario S2 of the game between

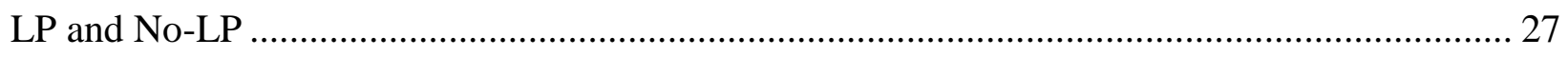

Figure 3.3: Flow chart between two subsequent periods in Scenario S1 of the game between LP

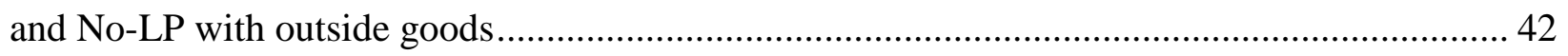

Figure 3.4: Flow chart between two subsequent periods in Scenario S2 of the game between LP

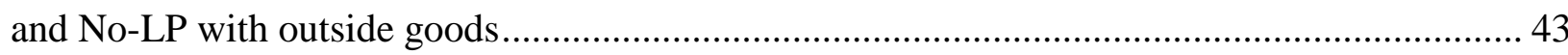

Figure 4.1: Flow chart between two subsequent purchasing periods in a market including restricted

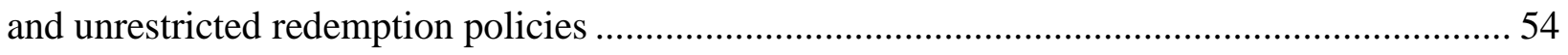

Figure 5.1: Flow chart between two subsequent purchasing periods for the game between expiry

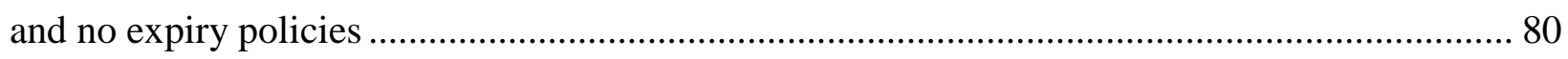




\section{Nomenclature}

A0 Alternative of purchasing from firm A and not redeeming

A1 Alternative of purchasing from firm A and redeeming

B0 Alternative of purchasing from firm B and not redeeming

B1 Alternative of purchasing from firm B and redeeming

C Alternative of purchasing outside goods

$\alpha_{v} \quad$ Customers' reward valuation coefficient

$\alpha_{d} \quad$ Discount rate

$p_{i} \quad$ Firm $i$ 's product price

$N_{i} \quad$ Required number of purchases to be eligible to receive a Firm $i$ 's free product as reward

$R(\%) \quad$ Reward percentage

$U_{z}^{j} \quad$ Customer $j$ 's utility of choosing alternative $z$

$D_{z}^{j} \quad$ Deterministic part of customer $j$ 's utility of choosing alternative $z$

$\varepsilon_{z}^{j} \quad$ Random part of customer $j$ 's utility of choosing alternative $z$

$T_{i} \quad$ Expiry time of Firm $i$ 's reward

$T_{\max } \quad$ Maximum expiry length

$q_{z}^{j} \quad$ Probability of choosing alternative $z$ by customer $j$

$v_{i}^{j} \quad$ Value of Firm $i$ 's product for customer $j$

$O_{i}^{r} \quad$ Firm $i$ 's optimal response in iteration $r$

$n_{i} \quad$ Number of purchases from Firm $i$ after the last redemption 
$\tau_{i}^{j} \quad$ Customer $j$ 's distance (number of periods) to the Firm $i$ 's reward expiry

$I_{i}^{S} \quad$ Firm $i$ 's profit in the stationary demand condition (in Scenario S)

$V(x, t) \quad$ Value function of $x$ dollars reward after $t$ periods $\begin{array}{ll}W\left(x, t_{1}, t_{2}\right) & \begin{array}{l}\text { Value function of } x \text { dollars reward that can be redeemed after } t_{1} \text { and before } t_{2} \\ \text { periods }\end{array}\end{array}$

$Y(x, t) \quad$ Loss function of $x$ dollars reward what will be expired after $t$ periods, when the customer gets one period closer to the expiry

$Q_{z}^{S}\left(n_{a}, n_{b}, \tau_{a}, \tau_{b}\right) \quad$ Probability function of choosing alternative $z$ in Scenario $S$ by the customers whose variables are $n_{a}, n_{b}, \tau_{a}$, and $\tau_{b}$

$M^{S}\left(n_{a}, n_{b}, \tau_{a}, \tau_{b}\right)$ Set of customers whose variables are $n_{a}, n_{b}, \tau_{a}$, and $\tau_{b}$ in Scenario $\mathrm{S}$

$\Pi^{S}\left(n_{a}, n_{b}, \tau_{a}, \tau_{b}\right) \quad$ Number of customers whose variables are $n_{a}, n_{b}, \tau_{a}$, and $\tau_{b}$ in Scenario $\mathrm{S}$ 


\section{Introduction}

\subsection{Definition}

Loyalty programs (LPs) have been studied in various fields, including marketing, management and economics. Several definitions exist for LPs in the literature. For instance, Bijmolt et al. (2012) define LPs as "continuity incentive programs offered by a retailer to reward customers and encourage repeat business". They emphasize that an LP is a membership-based program that is structured and based on collections and redemption rules.

LPs are designed by firms offering products or services with the objective to attract and retain customers (Dick, 1994; Uncles, 2003). Outcomes might include decreasing customer price sensitivity, building customer advocacy, extending the duration of the relationship with the firm, developing customer community, and increasing firm performance (McCall \& Voorhees, 2010). The long-term profitability remains however to be the primary objective for LPs (Sharp \& Sharp, 1997).

As discussed in Chapter 2, despite the widespread use of loyalty program, the literature has not reached a consensus about whether LPs are effective in establishing buying behaviour (even improving the relationship between firms and customers), and in the firm's long-term profitability.

\subsection{History}

Liu (2007) cites AAdvantage, American Airlines' frequent-flyer program, as the first contemporary loyalty program (LP) launched in 1981. Since that time, LPs have flourished in several sectors, including retail, accommodation, hospitality, transportation, food services, and 
finance. Figures 1.1 and 1.2 show the evolution of LPs over time (Kumar, 2008; Gandomi, 2012) and their popularity by sector according to 2015 COLLOQUY census.

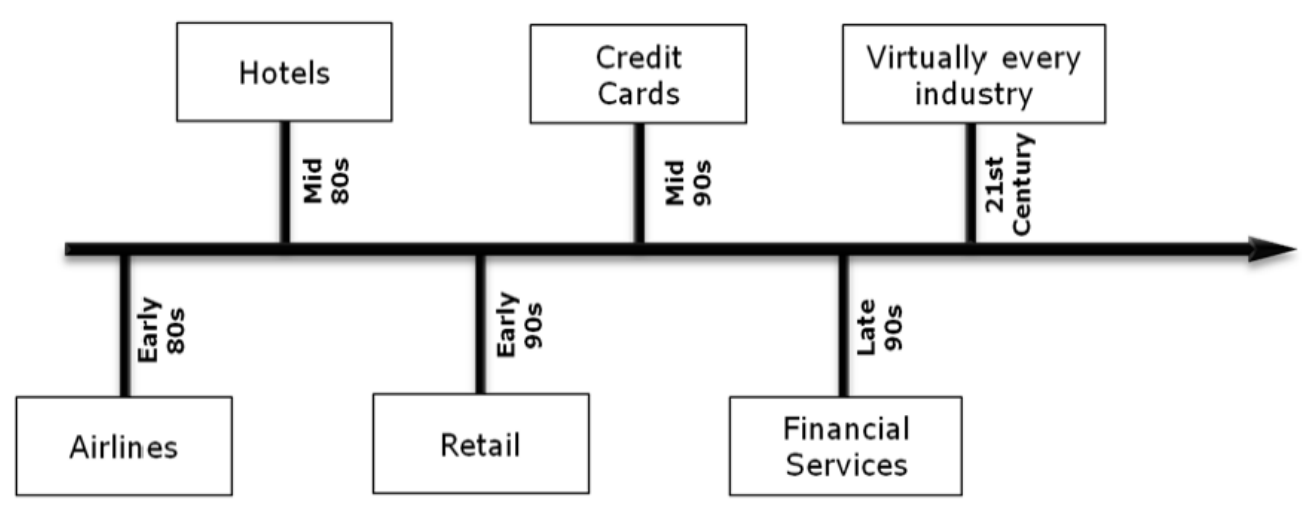

Figure 1.1: Sequence of emerging LPs in different industries (Kumar 2008, p.13; Gandomi 2012, p.7)

COLLOQUY census shows that LP memberships in the US exceeded 3.3 billion in 2014 averaging 29 per household (Berry, 2015). In Canada, AIR MILES® memberships, which is the largest coalition LP, exceeded two-thirds of Canadian households (Cao et al., 2015). The increasing popularity of loyalty programs among customers has caused many firms to increase their investment in LPs as their primary strategy to increase repeat business. Indeed, a recent Gallup study found that US companies collectively spend \$2 billion each year on LPs (Ott, 2011). 


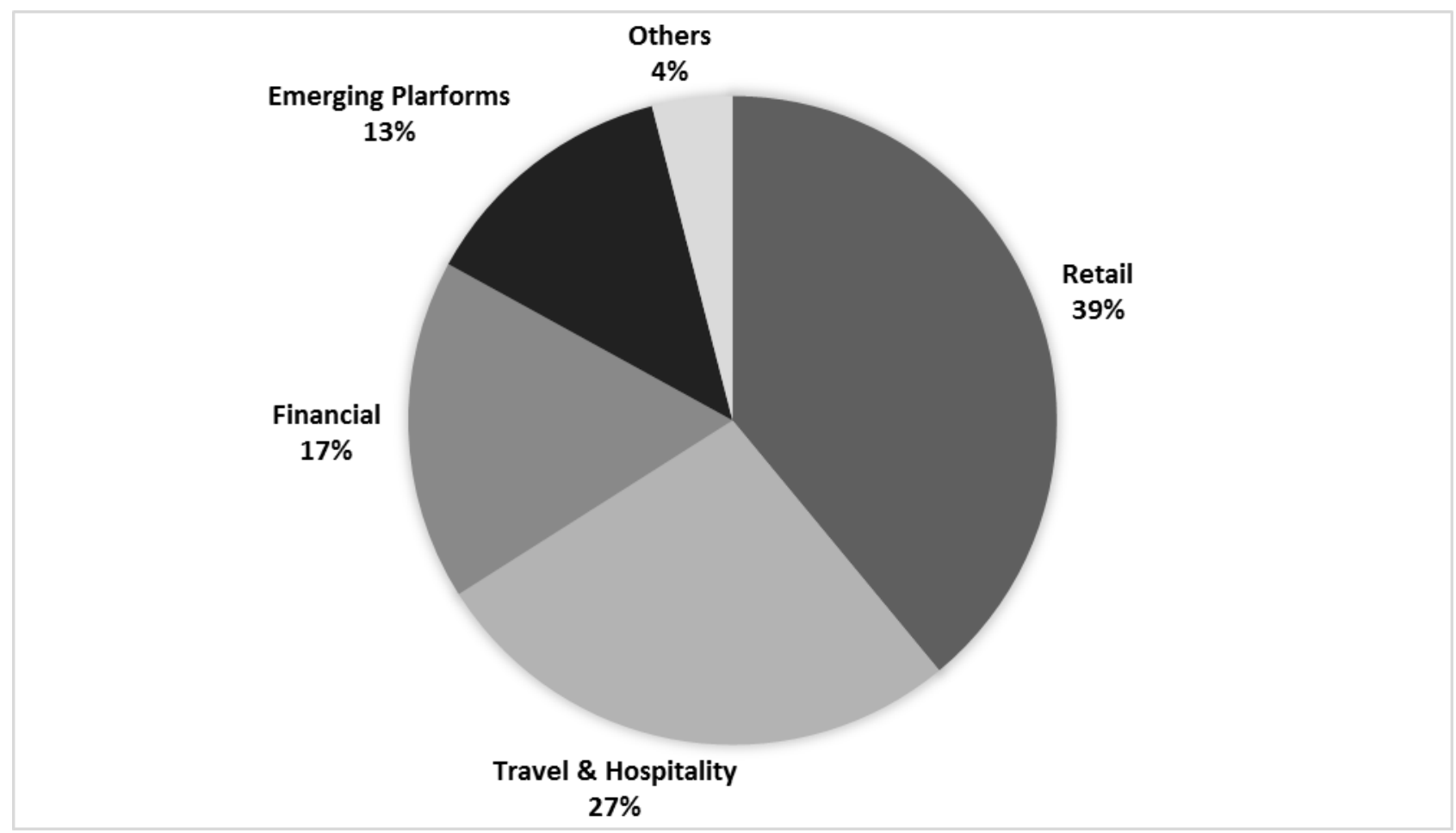

Figure 1.2: LP's popularity in different sectors ${ }^{1}$

\subsection{Categories of loyalty programs}

The literature categorizes LPs in terms of structure, type of reward, and redemption policy.

\section{Structure}

LPs have a linear or a non-linear structure. In linear LPs, each point has a fixed value (Stourm et al., 2015), and stockpiling points does not increase their values. It also does not require a minimum amount of points for redemption. Linear LPs can be attractive to customers who can easily redeem as little as one point without the hassle of complicated rules. Examples of such loyalty programs include Capital One's Journey credit card, Amazon's Rewards credit card, and Tesco's club card.

\footnotetext{
${ }^{1}$ COLLOQUY Loyalty Census 2015, p.5
} 
Non-linear LPs group customers into tiers of their purchasing history or the value of stockpiled points. Rewards accumulate more frequently than in linear LPs. Their value to customers increases in higher tier levels (e.g., the Optimum ${ }^{\circledR}$ Reward Program offered by SHOPPERS DRUG MART and the Aeroplan ${ }^{\circledR}$ program offered by Air Canada). Non-linear LPs offer additional incentives to customers. For example, the value of points may double when a customer acquires a pre-determined level of purchases.

\section{Types of rewards}

LPs offer different types of benefits and rewards to customers. Rewards can be monetary, such as discounts, coupons, rebates, and cash, or non-monetary and related to psychological and emotional benefits, such as entertainment, upgrades, and access to special events (Jones et al., 2006; Mimouni-Chaabane \& Volle, 2010). Furthermore, rewards can be direct, i.e., related to the focal firm, or indirect (Bijmolt et al., 2012). Another important characteristic of loyalty rewards is their redemption timing as rewards can either be immediate or delayed, with or without expiry.

\section{Redemption policies}

Redemption policies usually differ along two factors: the amount of rewards that can be redeemed and the time allowed for redemption to occur. They range from very restrictive to not restrictive. Examples of restrictive policies are coffee shops' reward cards (e.g., "buy 10, get one free") and some hotels' promotional offers (e.g., "stay 10 nights and earn one night free"). An expiry date on the accumulated rewards is another commonly used restriction in LPs. Conversely, Capital One's Journey credit card is an example of an LP with few restrictions on redemption. 


\subsection{Thesis Objective}

This thesis aims at studying the profitability of loyalty programs, and their optimal design, specifically the optimal level of restricting redemption policy. The thesis has the following objectives:

- Develop a comprehensive model based on customer behaviour, which reflects the behavioural theories of mental accounting theory (Thaler, 1985) and the goal-gradient theory (Kivetz et al., 2006).

- Investigate the profitability of loyalty programs for two competing firms: one offering a loyalty program while the other does not.

- Study the impact of restricting redemption policy on the LPs' profitability by considering three restriction levels (unrestricted, low restricted and high restricted).

\subsection{Thesis Outline}

The remainder of this thesis is arranged as follows: Chapter 2 presents a brief literature review about loyalty programs. Chapter 3 evaluates the effectiveness of a selected LP under different customers' behavioural aspects, by solving a game between two firms (denoted as $a$ and $b$ ) that decide to either offer or not offer LP. The selected LP studied in this chapter offers a free product after a certain number of purchases. Chapter 3 extends this game by adding an outside source (denoted as outside goods) besides Firm $a$ and Firm $b$, from which customers can also purchase. Chapter 4 studies a competition between the LP policy studied in Chapter 3, as an LP that restricts the redemption by setting a minimum number of purchasing, and an unrestricted redemption LP. Chapter 5 extends the level of restriction on redemption by adding an expiry date for redemption 
as well as setting a minimum required number of purchasing. In this chapter, the studied LPs in Chapter 4 (denoted as unrestricted and low restricted) compete with a highly restricted one (which applies both minimum purchasing and expiry).

To solve each of the mentioned games, all possible pairwise combinations of those competing policies (denoted as "scenarios") are studied. Table 1.1 summarizes all studied scenarios and their associated chapters. In this table, "N/A" stands for Not Applicable, the first entry in parentheses is for Firm $a$, and the second entry is for Firm $b$.

Based on the results of all scenarios studied in Chapters 4 and 5, Chapter 6 solves a game between three redemption policies of unrestricted, low restricted, and high restricted. Chapter 6 also concludes and summarizes the main findings, and proposes future research ideas.

Table 1.1: Summary of scenarios

\begin{tabular}{c|cccc}
\hline Scenario & $\begin{array}{c}\text { Outside } \\
\text { goods }\end{array}$ & LP & $\begin{array}{c}\text { Min. } \\
\text { Purchase }\end{array}$ & Expiry \\
\hline Ch. 3-S1 & No & (Yes, Yes) & (Yes, Yes) & (No, No) \\
Ch. 3-S2 & No & (Yes, No) & (Yes, N/A) & (No, N/A) \\
Ch. 3-S3 & No & (No, No) & (N/A, N/A) & (N/A, N/A) \\
Ch. 3, Ext. - S1 & Yes & (Yes, Yes) & (Yes, Yes) & (No, No) \\
Ch. 3, Ext. - S2 & Yes & (Yes, No) & (Yes, N/A) & (No, N/A) \\
Ch. 3, Ext. - S3 & Yes & (No, No) & (N/A, N/A) & (N/A, N/A) \\
& & & & \\
Ch. 4-S1 & No & (Yes, Yes) & (Yes, Yes) & (No, No) \\
Ch. 4-S2 & No & (Yes, Yes) & (Yes, No) & (No, No) \\
Ch. 4-S3 & No & (Yes, Yes) & (No, No) & (No, No) \\
Ch. 5-S1 & No & (Yes, Yes) & (Yes, Yes) & (No, No) \\
Ch. 5-S2 & No & (Yes, Yes) & (Yes, Yes) & (No, Yes) \\
Ch. 5-S3 & No & (Yes, Yes) & (Yes, Yes) & (Yes, Yes) \\
Ch. 5, Ext. - S2e & No & (Yes, Yes) & (No, Yes) & (Yes, Yes) \\
\hline
\end{tabular}




\section{Literature review}

As a consequence of the widespread use of LPs and the high rate of growth of investment in them, researchers have shown increasing interest in this area. The following sections present a brief review of existing research on LPs and outstanding questions in the literature.

\subsection{Existing research on loyalty programs}

Many different theoretical approaches have been adopted in the LP literature. The primary differences in these approaches are summarized below.

\section{Research objectives in the LP literature}

In terms of research objectives, there are two main streams of research about LPs. Some researchers focus on the primary goals of LP, and explore the effects of LPs on customers' buying behaviour (e.g., Sharp \& Sharp, 1997). The second stream of research investigates the profitability of LPs from the firm's perspective.

Although the literature acknowledges the ubiquity of LPs, the effectiveness of LPs in establishing buying behaviour is still a controversial subject among researchers. Some researchers believe LPs have a positive effect (Leenheer et al., 2007; Lal \& Bell, 2003; Lewis, 2004; Taylor \& Neslin, 2005; Kopalle et al., 2012), while others claim that LPs are unlikely to change an established buying behaviour (Mägi, 2003; Sharp \& Sharp, 1997; Dowling \& Uncles, 1997).

Researchers are also yet to reach a consensus on LPs' long-term profitability, considering the large investments some companies make in their LPs. In this regard, some researchers question LPs' competitive advantage in an environment where they are offered by all companies, since they 
cannot distinguish these firms while increasing their marketing costs (Shugan, 2005; Singh et al., 2008).

In order to account for these conflicting reports, some researchers propose that the intuitive assumptions that underlie the design of an LP influence its effectiveness (e.g., Kivetz \& Simonson, 2002; Roehm et al., 2002; Yi \& Jeon, 2003). This has led some researchers to study the different factors of LP design (Kopalle et al., 2012). In this regard, the literature offers several insights into consumer reactions to monetary versus non-monetary rewards (Jones et al., 2006; Noble et al., 2014), and to linear versus non-linear LPs (Wagner et al., 2009), the effects of varying reward offerings (Pauler \& Dick, 2006), and of reward redemption timing (Roehm \& Roehm Jr., 2010).

For instance, Drèze and Nunes (2009) investigate the advantages of non-linear LPs. They show that the number of tiers offered in non-linear programs has a large impact on customer satisfaction, so that a three-tier program is more satisfying than a two-tier program, and those customers at higher levels of loyalty are more satisfied when they are the relative minority in the firms' customer population. Furthermore, Gandomi (2012) shows that a low level of customer sensitivity to rewards and time results in suboptimal revenues in a three-tier reward scheme.

Research about the effectiveness of different kinds of rewards shows that direct rewards are preferred by customers (Verhoef, 2003), while indirect rewards have a considerable impact on the quality of the relationship between the firm and its customers (DeWulf et al., 2001). Furthermore, empirical studies show that monetary rewards are the most effective kind of direct rewards (Yi \& Jeon, 2003; Kivetz, 2005). For customers who are not motivated to build a viable relationship with a firm, immediate rewards are preferred, even if they are of lesser value (Yi \& Jeon, 2003; Kivetz, 2003; Kivetz, 2005). 


\section{Research concepts in the LP literature}

Research on loyalty programs can be conceptually categorized into two main groups: behavioural and attitudinal research.

The behavioural approach focuses on understanding customers' purchase behaviour by measuring the recency, frequency, and monetary values of LPs (e.g., Blattberg \& Sen, 1974; Kahn et al., 1988; Ehenberg et al., 1990; Lewis, 2004; Liu, 2007; Zhang et al., 2010).

The attitudinal approach incorporates psychological theories and considers implicit factors in the customers' decision process about LPs (e.g., Oliver, 1999; Butcher et al., 2001; BustosReyes \& González-Benito, 2008). While the attitudinal approach is conceptually richer than the behavioural approach, it is also more difficult to measure, and consequently less frequently used in the literature (Uncles, 2003). Mental accounting and goal-gradient are two of the most common theories used in the literature to explain customer behaviour.

The mental accounting theory indicates that customers' valuations of gains and losses differ depending on whether they relate to loyalty rewards or to cash (Thaler, 1985). This is because customers' increased utility from a gain, or disutility (pain) from a loss (payment), can vary depending on which currency (cash or reward) is being exchanged for the payment (Soman, 2003; Drèze \& Nunes, 2009). This theory explains customers' decisions to redeem or accumulate gains (in cash or in reward points). In fact, at every purchasing occasion, customers have to weigh their gain (either from accumulating points or from receiving a cash discount on price) versus their loss (either from redeemed rewards or from the missed opportunity of price savings).

Goal-gradient theory, on the other hand, indicates that customers accelerate their purchasing process as they progress towards earning a particular reward (Kivetz et al., 2006). This theory is especially important in understanding consumer redemption for restricted loyalty 
programs. It explains that the closer a customer gets to redeeming his/her rewards, the more he/she will feel the pressure to accumulate points, and the more likely that he/she will purchase the product of the firm offering the restricted loyalty program.

\section{Research perspectives in the LP literature}

Research about LPs can be divided into three perspectives: a firm perspective, a customer perspective, and a social perspective (Bijmolt et al., 2012).

Firm perspective research focuses on LPs' profitability for firms and their effectiveness in enhancing customer loyalty. The literature reports divergent findings in this regard (McCall \& Voorhees, 2010). Some studies indicate a positive impact from using LPs (Liu, 2007; Leenheer et al., 2007), while others find a minor effect or even no impact (Meyer-Waarden \& Benavent, 2006; Sharp \& Sharp, 1997). To study the profitability of LPs, the literature compares a firm that offers an LP to a firm that offers a lower price instead of a loyalty reward (i.e., an every-day-low-price strategy) such as Easy Jet, Ryanair, Southwest Airlines, Aldi, Lidl, and Wal-Mart (Supermaket News, 2010).

Customer perspective research investigates the efficacy of LPs in changing customers' buying behaviour. It compares the benefit of heavy users (i.e., those customers who have a purchasing history) and light users (i.e., customers with no purchasing experience), and studies the conditions under which customers may not fully benefit from the rewards or leave them unredeemed (Dekay et al., 2009; Mauri, 2003; Stourm et al., 2015).

Societal perspective research mostly discusses the benefits of LPs in different environments, specifically in small and large firms. Reports show that LPs mainly benefit largeshare brands and those firms with a previously established competitive advantage (Sharp \& Sharp, 1997; Meyer-Waarden \& Benavent, 2006; Leenheer et al., 2007). 


\section{Research methodologies in the LP literature}

Turning to the methodologies used in the literature to study loyalty programs, two main approaches can be recognized: empirical research (e.g., Sharp \& Sharp, 1997; Kivetz, 2003; Yi \& Leon, 2003; Lewis, 2004; Liu, 2007; Mayer-Waarden, 2007, 2008; McCall \& Voorhees, 2010; Kumar et al., 2013), and analytical research (e.g., Kim et al., 2001; Singh et al., 2008; Gandomi \& Zolfaghari, 2013). While the literature shows a significant growth in empirical research on LPs over the past two decades, there are only a few analytical studies in the field. Most of the existing analytical studies do not have attitudinal approach. There are few attempts in the literature in which the mathematical model incorporates psychological theories explaining consumer choices.

Empirical research is based on real data and uses statistical methods to analyze them. Analytical research, on the other hand, develops a mathematical model to explain the market conditions and firms' decisions by defining different factors and variables. To solve these mathematical models, two main methods are used: algebraic methods (e.g., Singh et al., 2008; Gandomi \& Zolfaghari, 2013), and numerical methods (e.g., Kopalle \& Neslin, 2003). Furthermore, some analytical studies use a game-theoretic approach (e.g., Caminal \& Matutes, 1990; Klemperer, 1995; Kim et al., 2001; Singh et al., 2008), while others have looked at optimization problems for one firm (Chun, et al., 2015; Gandomi \& Zolfaghari, 2011, 2013; Stourm et al., 2015). The mathematical models used in analytical studies are further divided into stochastic (e.g., Gandomi, 2012; Gandomi \& Zolfaghari, 2013) and deterministic models (e.g., Kim et al., 2001; Singh et al., 2008).

Below is a summary of some of the mentioned analytical studies which most closely resemble the present work. 
- Klemperer (1987b) studies the impact of customers' switching costs by modeling a duopoly in which products are homogeneous, and firms decide about setting a low price to capture market share, and setting a high price to harvest profits. Studying different types of switching costs such those created by loyalty programs, he shows that switching costs reduce the market's competitiveness.

- Caminal and Matutes (1990) improve Klemperer's work by considering endogenous switching cost. Assuming that customers randomly change their preferences over time, they show that if firms offer the same price to their loyal customers in two subsequent periods, the equilibrium profits decline, but if they pre commit to a discount (reward), then firms gain higher profits at equilibrium.

- Kim et al. (2001) use a game-theoretic model to investigate the profitability of a linear loyalty program in which a specific discount is offered to loyal customers. They use a deterministic model with two firms as decision makers (players) and two periods of purchasing. In an effort to extend Klemperer's study, they consider two groups of customers: heavy users (i.e., customers who have a purchasing history) and light users (i.e., customers without a previous experience of purchasing) and allow customers in each group to have a different price sensitivity level. Their results show that it is optimal for firms to offer cash rewards when the heavy user segment is small and is much more sensitive to price than the light user segment. Alternatively, it is optimal for firms to offer their products as rewards when the heavy user segment is large or is not sensitive to price.

- Singh et al. (2008) improve Kim et al.'s work by including an asymmetric scenario where only one firm offers a loyalty program. For both symmetric and asymmetric scenarios, they obtain equilibrium prices that maximize the firms' profit in each period, as a function of 
loyalty reward and percentage of light users. They show that firms might be better off with no loyalty program even if the competitor is offering one.

- Chun et al. (2015) model a monopoly market to study the dynamic management of LPs. Their model covers multiple purchasing periods and includes stochastic terms. They assume that the firm sells a single type of product over a finite time horizon, and offers reward points that can be redeemed by customers at the next purchases for additional products. The firm decides about the price and point value to maximize profit or cash flow. Chun et al. show that the fair value of loyalty points acts as inventory and that price and point value should be adjusted according to a "base-stock, list price" policy.

- Gandomi and Zolfaghari (2013) develop a stochastic model that studies the impact of customer satisfaction on a single firm's revenue. Similar to Singh's model, they also model two periods of purchasing and heavy and light users. They obtain an algebraic solution and show that if the firm manages to maintain satisfaction among customers, it will not profit from offering loyalty rewards.

Table 2.1 summarizes some of the models used in these analytical studies and compares them with the one developed in this thesis.

Table 2.1: Summary of analytical models in the literature

\begin{tabular}{c|ccccccc}
\hline Features & $\begin{array}{c}\text { Singh et al. } \\
(2008)\end{array}$ & $\begin{array}{c}\text { Gandomi and } \\
\text { Zolfaghari } \\
(2013)\end{array}$ & $\begin{array}{c}\text { Kim et al. } \\
(2001)\end{array}$ & $\begin{array}{c}\text { Chun et al. } \\
(2015)\end{array}$ & $\begin{array}{c}\text { Klemperer } \\
(1987 b)\end{array}$ & $\begin{array}{c}\text { Caminal and } \\
\text { Matutes } \\
(1990)\end{array}$ & $\begin{array}{c}\text { This } \\
\text { thesis }\end{array}$ \\
\hline Competitive & Yes & No & Yes & No & Yes & Yes & Yes \\
Stochastic & No & Yes & No & Yes & No & No & Yes \\
Multi-scenario & Yes & No & No & No & No & No & Yes \\
Attitudinal & No & Yes & Yes & No & No & No & Yes \\
Endogenous & Yes & Yes & Yes & Yes & No & Yes & Yes \\
switching cost & & & & & & &
\end{tabular}




\subsection{Gaps in the literature}

Next, we study the gaps in the analytical literature about LPs' redemption policies.

\subsubsection{Analytical modeling}

As discussed in Section 2.1, the empirical literature about LPs usually focuses on a specific design of LP in a specific environment (customers behaviour and market conditions), and therefore the results that emerge from this literature may not be applicable for other designs and environments (Zhang \& Breugelmans, 2012). On account of this deficiency, many researchers are turning to analytical approaches. In this kind of research, a mathematical model of the market is developed to represent different aspects of LP design and different environments.

By including various aspects of the design and environment, analytical research provides the possibility of studying different designs in various environments. Models play a central role in this approach, since the more representative of the problem and context under study a model is, the more trustworthy the results it provides. This fact was marked by Kim et al. (2001), the first published analytical research on optimizing loyalty programs, who introduce their work "as an initial step, and clearly far removed from the ideal model in which the implications directly translate into managerial practice" (p.113). Despite these advances under the analytical approach, a number of limitations and gaps remain.

- While analytical models can be categorized into different groups such as deterministic (e.g., Singh et al., 2008; Kim et al., 2001; Stourm et al., 2015) versus stochastic (e.g., Gandomi \& Zolfaghari, 2011, 2013), competitive (e.g., Singh et al., 2008; Kim et al., 2001) versus noncompetitive (e.g., Gandomi \& Zolfaghari, 2011, 2013; Stourm et al., 2015), along with consumer based (e.g., Stourm et al., 2015) versus vs. firm based (e.g., Singh et al., 2008; Kim 
et al., 2001), we are unaware of the existence of a stochastic competitive model in which consumers perspective has been adopted to reflect the psychological factors that affect consumers evaluations of LPs.

- In most analytical models in the literature (e.g., Singh et al., 2008; Kim et al., 2001; Gandomi \& Zolfaghari, 2011, 2013), it is assumed that a certain number of customers (called light users) leaves the market after their first purchase and therefore miss the loyalty reward that is given on their second purchase. In these studies, the fraction of light users is considered as an exogenous parameter. In reality, the firm's decisions (price and reward) affect the number of customers who leave the market. This is especially important in the context of loyalty programs, which are used purposefully to influence the size of these segments.

- Although the effects of LPs are time dependent, the literature often evaluates them at a single point without considering temporal effects (Lewis, 2004; Liu, 2007). This way of investigating LPs' profitability may result in wrong conclusions since it usually takes time for LPs to form a relationship between the firm and its customer or to establish a particular purchasing behaviour (Morales, 2005; Palmatier et al., 2009). For example, Henderson et al. (2011) argue that a short-term horizon can elaborate the impact of price discounting, while the benefits of habit-based loyalty may emerge only after a long time. This study departs from earlier ones in that limited periods are not modelled. On the contrary, we consider a stationary demand condition under which there are constant market shares, and the LP has been thoroughly established.

- Besides design and structure, the environment in which LPs are applied is a determinant in their effectiveness. This environment can include market conditions and behavioural factors. Specifically, researchers have become increasingly interested in considering behavioural 
theories explaining consumers' choices. However, modeling all these theories and conditions at once significantly increases the computational complexity of the problem. Therefore, researchers usually focus on some aspects related to the research at hand (Henderson et al., 2011). For example, Drèze and Nunes' (2009) investigation is from a status perspective, Rosenbaum et al. (2005) examine LPs from a relationship perspective, Stourm et al.'s (2015) study looks at linear LPs using the prospect theory, and Kivetz et al., (2006) suggest the goal gradient theory.

\subsubsection{Redemption policy}

Redemption policy is an important aspect in managing LPs because it directly impacts their financial performance. In fact, many companies (e.g., airlines) report financial losses due to the high costs of rewards, which can cause them to make their redemption policies more stringent (Maynard \& Dash, 2005). Despite this fact, reward redemption policies have received minimal attention in the literature. Companies can restrict their redemption policies mainly by restricting the amount of redemption, or by limiting redemption time, e.g., defining a required number of pre purchasing and/or setting a limited time to redeem (expiry).

Although recent empirical research shows that restricted redemption policies for monetary LP rewards result in increased customer loyalty (Noble et al., 2014), the literature does not effectively address how and why such limitations on redemption policies impact firms' profits.

Empirical research shows divergent findings about the use of expiry as a common way of limiting redemption policies, which may cause more confusion than guidance to managers. Some find that reward expiry may decrease customers' satisfaction and motivation and create frustration (Stauss et al., 2005), and claim that the fear of such negative effects may have encouraged some LPs to stretch their reward expiry periods or to set no expiry (Bijmolt et al., 2012). Recently, 
Dorotic et al. (2014) use data about 3,000 LP members' redemptions and find that imposing reward expiry can negatively impact purchase behaviour. Another stream of research takes the opposite stand and argues that expiry creates a time pressure mechanism that results in increasing consumer purchases (e.g., Kopalle \& Neslin, 2003; Drèze \& Nunes, 2009). Finally, Noble et al. (2014) find that reward expiry leads to higher levels of consumer commitment to the firm when non-monetary rewards are offered, whereas no expiry is more effective when rewards are monetary. Thus, it is not clear whether reward expiry brings in more profit to the firm or not.

This discussion shows that one of the gaps in the existing literature on loyalty programs is the lack of analytical research on the implications of restricting redemption policies for the firm's profitability. This gap will be addressed in this Thesis. 


\section{Loyalty programs' profitability in a competitive}

\section{environment}

\subsection{Introduction}

Despite the ubiquity of LPs and the large budgets that some companies spend on these programs, academics have not reached a consensus about their profitability. One of the main criticisms of LPs is their inability to provide a competitive advantage in an environment in which all companies offer LPs, and thereby they may only increase marketing costs without attracting additional customers and revenues (Shugan, 2005; Singh et al., 2008).

Some researchers believe that the design of LPs plays a critical role in this regard (Kivetz \& Simonson, 2002; Kivetz, 2003; Leenheer et al., 2007; Liu \& Yang, 2009; Kumar \& Reinartz, 2006), such that one particular design may be effective and another design may not. Consequently, it becomes increasingly important to examine different LP designs in order to study their effectiveness (Zhang \& Breugelmans, 2012). On the other hand, customers' behavioural aspects are pivotal factors in the success of LPs, and consequently, recent research has begun to consider behavioural theories in the analysis of LP implications and strategies (Henderson et al., 2011).

Analytical research has gradually become established in the literature that examine different aspects of LP designs using mathematical models of the market. As discussed before, models play a central role in analytical research, since the more accurate the model is, the more trustworthy the results that are achieved by that model.

Although LP models used in recent research have considerably been improved since the

first work by Kim et al. (2001), they are still in an early stage of development (Gandomi \& 
Zolfaghari, 2011). This thesis builds on the existing literature by studying the profitability of "Buy $N$ times, get one free" loyalty programs in a competitive environment. In particular, we attempt to answer the following research questions: Should competing firms offer loyalty programs? If yes, then under what market conditions? To answer these questions, we solve three stochastic Nash games. Two of these games are symmetric in which both firms either offer or do not offer LPs. In the third game, the companies' policies are asymmetric so that one firm offers a loyalty program and the other does not. Comparison of equilibrium outputs across these games provides insights into the profitability of offering an LP in a competitive setting.

This thesis mainly focuses on LPs that offer rewards after a certain number of purchases. These programs are commonly used by companies in the food and entertainment industries (e.g., Starbucks, Second Cup, McDonald's, 7-Eleven, AMC). In these sectors, firms usually do not change their prices (Henderson et al., 2011; Kumar \& Shah, 2004; Nunes \& Drèze, 2006) and therefore LPs are considered an important managerial tool to increase profits.

To the best of our knowledge, this is the first attempt to study of the profitability of these LPs in a competitive environment. This thesis also contributes to the existing literature by developing a stochastic competitive model that extends previous studies in many ways. First, our model represents two important psychological theories that explain customers' evaluations of rewards. Second, our model considers the number of customers who leave the market as an endogenous variable, thereby relaxing previous restrictive assumptions made in the literature.

The rest of this chapter is arranged as follows: Section 3.2 presents the model, Section 3.3 explains the method used to solve the three games, Section 3.4 presents results with discussion, Section 3.5 presents and studies an extended model, and Section 3.6 summarizes and concludes. 


\subsection{Model}

\subsubsection{Assumptions and definitions}

Our model considers two competing firms (named $a$ and $b$ ), which sell similar products at prices $p_{a}$ and $p_{b}$. Firms decide about offering or not offering LPs, and in each case, they choose their own price and reward (if applicable). The game played by the competing firms is assumed to be static. The firms set their strategies simultaneously at the beginning of the selling horizon, and do not change them afterwards. This is a reasonable assumption in many businesses, such as restaurants and movie theatres.

In order to investigate the profitability of LPs in a competitive environment, we find the Nash equilibrium solution in three different scenarios (named S1, S2, and S3) separately. In the symmetric Scenario S1, both firms offer LPs and decide about their own price and reward. In asymmetric Scenario S2, only one firm (Firm $a$ ) offers an LP. In this case, Firm $a$ decides about its price and reward and Firm $b$ decides only about its price. Scenario $\mathrm{S} 3$ is a symmetric scenario in which neither of the firms offers LP, and therefore each decides only its price.

In this research, we focus on the commonly used LPs in the food and entertainment industries, which offer a free product after a certain number of purchases. The firm that offers a loyalty program decides about the number of purchases required for the customer to receive a free product, which is denoted by $N_{i}$ for Firm $i \in\{a, b\}$.

In our model, customers are allowed to switch between firms in all periods of purchasing without any extra charge. They are also assumed to be rational and forward-looking when making their decisions so that each customer chooses the alternative that maximizes his/her utility. Utility is equivalent to the decision maker's (customer) payoff, which is his gains minus losses (Haurie, 
et al., 2012). Therefore, a negative value of utility means a higher value of losses than gains. Under this condition, the consumer does not choose that good/service. In this thesis, following other studies (e.g., Singh et al., 2008; Gandomi \& Zolfaghari, 2013; Caminal \& Matutes, 1990; Kim et al., 2001), it is assumed that customers' utilities are always positive. Customers are rational and forward-looking so that they choose the alternative that provides them with the maximum utility.

Finally, following the literature (e.g., Singh et al., 2008; Gandomi \& Zolfaghari, 2013), the market size is normalized to 1 unit and kept constant in order to exclude the impact of market expansion.

\subsubsection{Customers' choices}

In the model presented in this chapter, in each period of purchasing, customers select the firm from which they purchase and decide either to redeem or not to redeem their cumulated rewards (if any). Customers are allowed to switch between firms in all periods of purchasing without any extra charge. Consequently, a customer who is eligible to receive both firms' reward has the highest number of alternatives to choose from. In this case, he or she should choose one of four options:

- Purchasing from Firm $a$ and not redeeming (denoted by A0),

- Purchasing from Firm $a$ and redeeming (denoted by A1),

- Purchasing from Firm $b$ and not redeeming (denoted by B0), and

- Purchasing from Firm $b$ and redeeming (denoted by B1).

In Scenarios S2 and S3, Firm $b$ does not offer a loyalty program, so B1 is not a possible alternative in these scenarios. Similarly, A1 is not a choice available to customers in S3 since Firm $a$ does not offer LP in this scenario.

Since customers are rational and forward-looking when making their purchasing and redemption decisions, any customer $j$ will choose the alternative $z \in\{\mathrm{A} 0, \mathrm{~A} 1, \mathrm{~B} 0, \mathrm{~B} 1\}$ if his/her 
utility (payoff) obtained from choosing this alternative (denoted by $U_{z}^{j}$ ) is greater than his/her utility obtained from choosing any other alternative. In each alternative $z$, we model consumer utility as the sum of a deterministic expression (denoted by $D_{z}^{j}$ ) and a random part (denoted by $\varepsilon_{z}^{j}$ ). The latter captures the unknown part of these utilities. Therefore, customer $j$ 's utility in choosing alternative $z$, is $U_{z}^{j}=D_{z}^{j}+\varepsilon_{z}^{j}$.

As per the commonly used multinomial logit model (Ben-Akiva \& Lerman, 1985), if we assume that the random parts of all the utilities $\left(\varepsilon_{z}^{j}\right)$ follow independent and identical Gumbel distributions, the probability of choosing alternative $z$ by customer $j$ (denoted by $q_{z}^{j}$ ) can be formulated as follows:

$q_{z}^{j}=\exp \left(D_{z}^{j}\right) /\left(\exp \left(D_{A 0}^{j}\right)+\exp \left(D_{A 1}^{j}\right)+\exp \left(D_{B 0}^{j}\right)+\exp \left(D_{B 1}^{j}\right)\right)$

Section 3.2.4 addresses the surplus of losses and gains in each alternative, which form the deterministic part of the utility of choosing that alternative. Referring to Equation 3.1, the probability of a choice is 1 if it is the only option.

In each of the four options ( $\mathrm{A} 0, \mathrm{~A} 1, \mathrm{~B} 0$ and $\mathrm{B} 1)$, the deterministic component of the consumer utility $\left(D_{z}^{j}\right)$ is obtained by identifying the consumer's gains and costs associated from choosing that alternative. Consumer gains can be earned through the value a consumer gets from acquiring/consuming the product of firm $i\left(v_{i}>0\right)$, or from any rewards earned while purchasing the product. Consumer costs are associated with the cost of purchasing the product (price), or the lost value of loyalty rewards due to redemption. When a consumer pays a certain amount in cash to purchase from Firm $i$, his cost is equal to the price paid for that product (i.e., $p_{i}$ ). However, when a customer redeemed (earns) reward points that have a certain cash value $x$, we consider that 
the consumer's cost (gain) is different from $x$. The next section describes the value function used by consumers to value reward gains and losses in our model and explains the rationale for our modeling approach.

\subsubsection{The rewards value function}

According to the mental accounting theory (Thaler, 1985), customers value cash and rewards differently. To model this mentality, we assume that a reward that costs $x$ dollars is evaluated as $\alpha_{v} x$ dollars by consumers, where $\alpha_{v}$ is a positive parameter. We also assume $\alpha_{v}$ to be less than 1 to give rewards a lower value than cash, since otherwise customers would never redeem their rewards to save on cash. Parameter $\alpha_{v}$ is denoted as reward value coefficient in the rest of this thesis. This parameter represents customers' valuation/sensitivity regarding the amount of rewards.

To model the goal-gradient theory in the consumer utility functions (e.g., Kivetz et al., 2006; Besanko \& Winston, 1990), we consider that customers' valuation of rewards is negatively affected by the time distance to the redemption, i.e., the number of purchasing occasions they have left until they can redeem their points. In particular, a reward that can be redeemed sooner has more value than the one can be redeemed later. Furthermore, the value of a reward increases as the customer gets closer to the redemption time. Assuming that purchasing occasions are units of time, and using the discounting formula (Crosson \& Needles, 2008), one can formulate the value of $x$ dollars of rewards that is $t$ purchasing periods left before the redemption, $V(x, t)$, as follows:

$V(x, t)=\alpha_{v} x /\left(1+\alpha_{d}\right)^{t}$.

where $\alpha_{d}$ is the time value coefficient, and varies in the range of $(0,1)$. It means that 1 dollar after $t$ periods is evaluated as $1 /\left(1+\alpha_{d}\right)^{t}$ dollars by customers at the present time. Parameter $\alpha_{d}$ 
represents the customers' valuation/sensitivity regarding the timing of rewards redemption (consumer discount rate).

Equation (3.2) follows the goal-gradient theory (Kivetz et al., 2006) since the value of a point increases as the customer gets closer to the redemption time.

\subsubsection{Deterministic components of customer's utilities}

Denoting $n_{i}^{j}$ as the number of customer $j$ 's purchases from Firm $i \in\{a, b\}$ after the last redemption at that firm and until the time of being eligible to receive a free product, one can say that customer $j$ is $\left(N_{i}-n_{i}^{j}\right)$ periods away from qualifying to receive the reward of Firm $i$, which is a free product valued at $p_{i}$.

Recall that Firm $a$ offers LP in Scenario S1 and S2. In alternative A0, customer $j$ 's surplus of purchasing from Firm $a$ and not redeeming $\left(D_{A 0}^{j}\right)$ consists of the value of the product $\left(v_{a}^{j}\right)$ diminished by its price $\left(p_{a}\right)$, added to the value of the reward earned in Scenarios S1 and S2. Therefore:

$D_{A 0}^{j}=\left\{\begin{array}{lrr}v_{a}^{j}-p_{a} & \text { if } & n_{a}^{j}=N_{a}, \text { in Scenario } S 1 \& S 2 \\ v_{a}^{j}-p_{a}+V\left(p_{a}, N_{a}-n_{a}^{j}\right) & \text { if } & n_{a}^{j}<N_{a}, \text { in Scenario } S 1 \& S 2 \\ v_{a}^{j}-p_{a} & \text { if } & \text { in Scenario } S 3\end{array}\right.$

In alternative A1, customer $j$ 's surplus of purchasing from Firm $a$ and redeeming $\left(D_{A 1}^{j}\right)$ also consists in the value of purchasing the product $\left(v_{a}^{j}\right)$ diminished by the value of the redeemed reward $\left(V\left(p_{a}, 0\right)\right)$. In $\mathrm{A} 1$, rewards can only be redeemed if the consumer completed all required purchasing periods (i.e., $n_{a}^{j}=N_{a}$ ) and has a value of rewards in cash equal to the price of the product of Firm a. If Firm $a$ 's customer has not completed the required number of purchases to 
receive a reward $\left(n_{a}^{j} \neq N_{a}\right.$ in Scenario S1 \& S2), or if Firm $a$ does not offer LP (in Scenario S3), the customer has no option of redemption. Therefore:

$D_{A 1}^{j}=v_{a}^{j}-V\left(p_{a}, 0\right) \quad$ for $\quad n_{a}^{j}=N_{a}$, in Scenario $S 1 \& S 2$

Similarly to A0 and A1, in alternatives B0 and B1, customer $j$ 's surplus of purchasing from Firm $b$ and not redeeming $\left(D_{B 0}^{j}\right)$ and redeeming $\left(D_{B 1}^{j}\right)$ are obtained as shown in Equations (3.5) and (3.6), considering that Firm $b$ offers LP only under Scenario S1.

$$
\begin{aligned}
& D_{B 0}^{j}=\left\{\begin{array}{llr}
v_{b}^{j}-p_{b} & \text { if } & n_{b}^{j}=N_{b}, \text { in Scenario } S 1 \\
v_{b}^{j}-p_{b}+V\left(p_{b}, N_{b}-n_{b}^{j}\right) & \text { if } & n_{b}^{j}<N_{b}, \text { in Scenario } S 1 \\
v_{b}^{j}-p_{b} & \text { if } & \text { in Scenario } S 2 \& S 3
\end{array}\right. \\
& D_{B 1}^{j}=v_{b}^{j}-V\left(p_{b}, 0\right) \text { for } \\
& n_{b}^{j}=N_{b}, \text { in Scenario } S 1
\end{aligned}
$$

Given that we consider one particular product, it is assumed that customer $j$ 's valuation of the product is constant regardless of where he/she purchases it from. This fact results in equal valuations $\left(v_{a}^{j}=v_{b}^{j}\right)$.

\subsubsection{The Firms' profit functions}

Each firm's expected profit is equal to its expected revenues minus its expected costs. The next paragraphs describe how the number of consumers purchasing from each firm is obtained. By determining the number of customers who redeem their rewards and the amount of redeemed rewards, we can later calculate the firms' revenues, costs and profits.

Referring to Equations (3.1-3.6), given a certain decision variable set of $\left\{N_{a(b)}, p_{a(b)}\right\}$, and behavioural parameters of $\left\{\alpha_{v}, \alpha_{d}\right\}$, the probability of choosing alternative $z$ by customer $j$ 
in Scenarios S1 and S2 is a function of the number of his/her previous purchases from the firm(s) that offer LP $\left(\left(n_{a}^{j}, n_{b}^{j}\right)\right.$ in Scenario S1 and $n_{a}^{j}$ in Scenario S2). This allows us to categorize customers based on their purchasing history. Let $Q_{z}^{S 1}\left(n_{a}, n_{b}\right)$ be the probability of choosing alternative $z$ by a customer who has purchased $n_{a}$ and $n_{b}$ times from Firm $a$ and Firm $b$ respectively in Scenario S1. In other words,

$Q_{z}^{S 1}\left(n_{a}, n_{b}\right)=q_{z}^{j}, \quad \forall z \in\{A 0, A 1, B 0, B 1\}, \forall z \mid n_{a}^{j}=n_{a}, n_{b}^{j}=n_{b}$,

where variables $n_{a}$ and $n_{b}$ are non-negative integers in the ranges of $\left[0, N_{a}\right]$ and $\left[0, N_{b}\right]$, respectively.

The above definition indicates that the probability of a choice in Scenario S1 is equal for all customers who are characterized by $\left(n_{a}, n_{b}\right)$. Denoting $M^{S 1}\left(n_{a}, n_{b}\right)$ as the set of such customers in Scenario S1 at the stationary demand condition, where the number of customers does not change during subsequent purchasing periods, one can derive a flow chart of two subsequent periods of Scenario S1 at the stationary demand condition. Figure 3.1 presents this flow chart.

Similar to Scenario S1, it can easily be shown that the probability of choosing alternative $z \in\{A 0, A 1, B 0, B 1\}$ by a customer in Scenario $\mathrm{S} 2$ is a function of $n_{a}$, which means that the probability of a choice in Scenario S2 is equal for all customers who have purchased $n_{a}$ times from Firm $a$ after their last redemption and until the time of being eligible for reward. Denoting the set of these customers and the probability of choosing alternative $z$ by them as $M^{S 2}\left(n_{a}\right)$ and $Q_{z}^{S 2}\left(n_{a}\right)$, respectively, one can derive a flow chart of two subsequent purchasing periods in Scenario S2, as shown in Figure 3.2. 


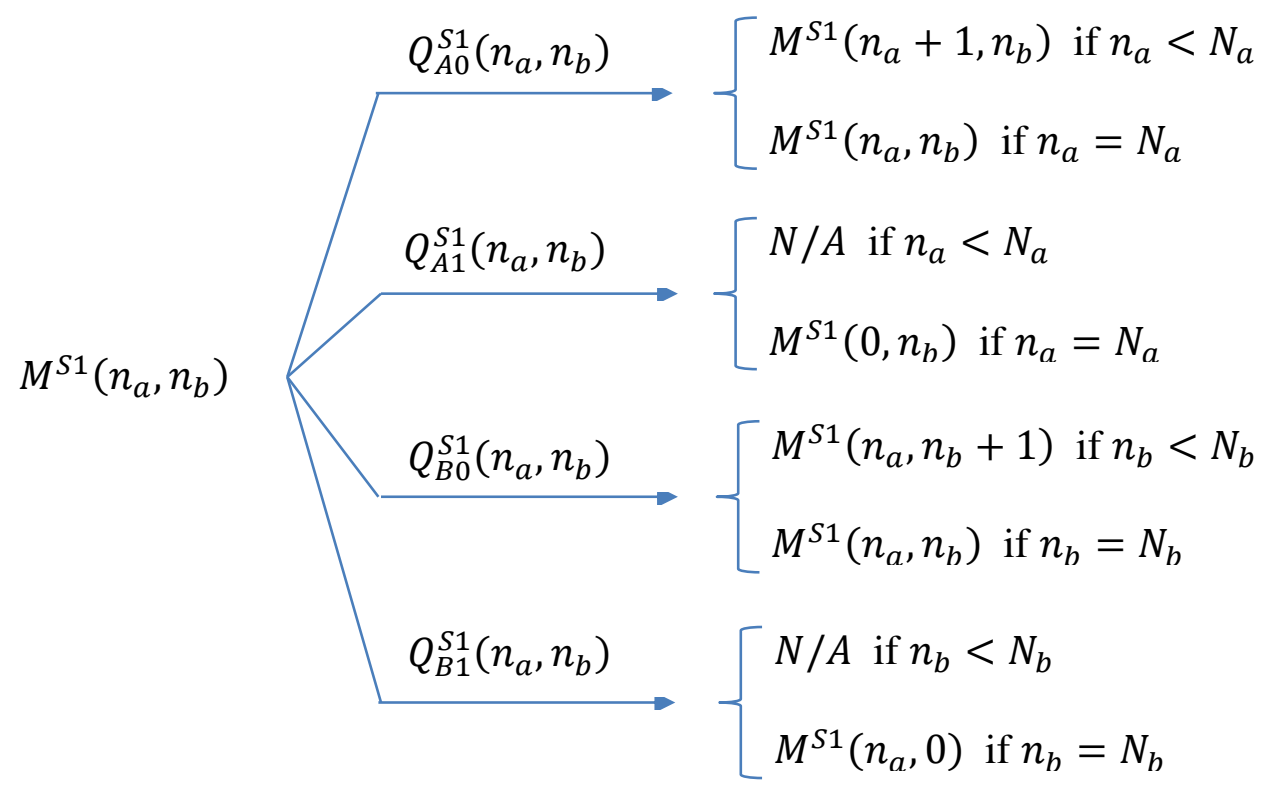

Figure 3.1: Flow chart of two subsequent purchasing periods in Scenario S1 of the game between LP and No-LP

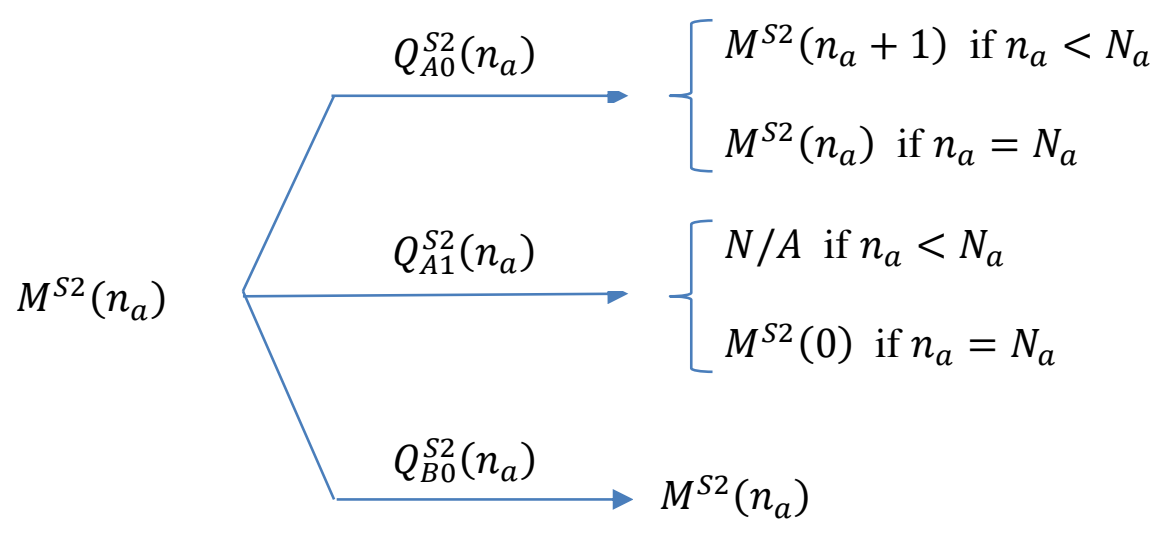

Figure 3.2: Flow chart of two subsequent purchasing periods in Scenario S2 of the game between LP and No-LP

Based on the flow charts in Figure 3.1 and Figure 3.2, and denoting $\Pi^{S 1}\left(n_{a}, n_{b}\right)$ and $\Pi^{S 2}\left(n_{a}\right)$ as the number of customers in the sets of $M^{S 1}\left(n_{a}, n_{b}\right)$ and $M^{S 2}\left(n_{a}\right)$, respectively, one can derive $\left(N_{a}+1\right) *\left(N_{b}+1\right)$ independent equations for all values of $n_{a}$ and $n_{b}$ in Scenario S1, and $\left(N_{a}+1\right)$ independent equations for all values of $n_{a}$ in Scenario S2. Solving these equations 
simultaneously, we are able to obtain $\Pi^{S 1}\left(n_{a}, n_{b}\right)$ and $\Pi^{S 2}\left(n_{a}\right)$ for all values of $n_{a}$ and $n_{b}$. It should be noticed that the firms' decision variables (price and reward timing) affect the probabilities of choosing different alternatives by customers (see equations 3.1-3.6) and therefore the number of different groups of customers.

In Scenario S3, none of the firms offers LP. Consequently, all customers can be treated as one single set, which decides between purchasing from Firm $a$ and from Firm $b$. The deterministic part of utility in purchasing from Firm $a$ and Firm $b$ is $\left(v_{a}-p_{a}\right)$ and $\left(v_{b}-p_{b}\right)$ respectively. Assuming $v_{a}=v_{b}$, and referring to Equation (3.1), the probability of purchasing from Firm $a$ in Scenario S3 (denoted by $Q_{A 0}^{S 3}$ ) and purchasing from Firm $b$ in Scenario S3 (denoted by $Q_{B 0}^{S 3}$ ) can then be calculated as follows:

$$
\begin{aligned}
Q_{A 0}^{S 3} & =\exp \left(-p_{a}\right) /\left(\exp \left(-p_{a}\right)+\exp \left(-p_{b}\right)\right), \\
Q_{B 0}^{S 3} & =\exp \left(-p_{b}\right) /\left(\exp \left(-p_{a}\right)+\exp \left(-p_{b}\right)\right) .
\end{aligned}
$$

Based on the number of customers in the stationary demand condition, one can calculate Firm $i$ 's profits in this condition (denoted by $I_{i}$ ) for all scenarios as follows:

$$
\begin{array}{r}
I_{a}= \begin{cases}p_{a}\left[\sum_{n_{a}=0}^{N_{a}} \sum_{n_{b}=0}^{N_{b}} \Pi^{S 1}\left(n_{a}, n_{b}\right) Q_{A 0}^{S 1}\left(n_{a}, n_{b}\right)\right] & \text { in Scenario } S 1 \\
p_{a}\left[\sum_{n_{a}=0}^{N_{a}} \Pi^{S 2}\left(n_{a}\right) Q_{A 0}^{S 2}\left(n_{a}\right)\right] & \text { in Scenario } S 2 \\
p_{a} Q_{A 0}^{S 3} & \text { in Scenario } S 3\end{cases} \\
I_{b}= \begin{cases}p_{b}\left[\sum_{n_{a}=0}^{N_{a}} \sum_{n_{b}=0}^{N_{b}} \Pi^{S 1}\left(n_{a}, n_{b}\right) Q_{B 0}^{S 1}\left(n_{a}, n_{b}\right)\right] & \text { in Scenario } S 1 \\
p_{b}\left[\sum_{n_{a}=0}^{N_{a}} \Pi^{S 2}\left(n_{a}\right) Q_{B 0}^{S 2}\left(n_{a}\right)\right] & \text { in Scenario } S 2 \\
p_{b} Q_{B 0}^{S 3} & \text { in Scenario } S 3\end{cases}
\end{array}
$$

It should be noticed that the total revenue of the firms that offer LP results from all purchases both with and without reward redemption. However, the firms' costs consist in the 
rewards they pay to the customers who redeem their rewards, which is equal to their revenues from those customers. Consequently, the firms' revenues and costs arising from purchases by those customers who redeem are removed from the firms' profit functions in Equations 3.9 and 3.10. For example, Firm $a$ 's profit in Scenario S1 is as follows:

$I_{a}=p_{a}\left[\sum_{n_{a}=0}^{N_{a}} \sum_{n_{b}=0}^{N_{b}} \Pi^{S 1}\left(n_{a}, n_{b}\right)\left(Q_{A 0}^{S 1}\left(n_{a}, n_{b}\right)+Q_{A 1}^{S 1}\left(n_{a}, n_{b}\right)\right)-\Pi^{S 1}\left(n_{a}, n_{b}\right) Q_{A 1}^{S 1}\left(n_{a}, n_{b}\right)\right]$

\subsection{Solving the model}

Solving the firms' problems in each scenario (S1, S2, and S3), we obtain the needed information to solve the general game where each firm decides whether to offer LP or not given the competitor's choice. In each of the three scenarios, each firm (player) chooses the optimal decision variables that maximize its profit under imperfect information, meaning that each player at the time of making its decision is unaware of the competitor's decision, but knows the latter's possible strategies and actions.

In the first Scenario S1, both firms offer LPs, and decide the timing of the reward (variables $N_{a}$ for Firm $a$ and $N_{b}$ for Firm $b$ ) and the prices $\left(p_{a}\right.$ for Firm $a$ and $p_{b}$ for Firm $b$ ). In the second Scenario S2, only Firm $a$ applies LP and decides about its reward timing $\left(N_{a}\right)$ and price $\left(p_{a}\right)$, while Firm $b$ does not offer LP and decides only of its price $\left(p_{b}\right)$. In the third Scenario S3, none of the firms offers LP, and they each decide only of the price ( $p_{a}$ for Firm $a$ and $p_{b}$ for Firm $b$ ). Table 3.1 summarizes the firms' decision variables in the different scenarios. 
Table 3.1: Scenario definitions and firms' decision variables

\begin{tabular}{cccc}
\hline Scenario & Definition & $\begin{array}{c}\text { Firm } a \text { 's decision } \\
\text { variables }\end{array}$ & $\begin{array}{c}\text { Firm } b \text { 's decision } \\
\text { variables }\end{array}$ \\
\hline S1 & Both firms offer LP & $N_{a}$ and $p_{a}$ & $N_{b}$ and $p_{b}$ \\
S2 & One firm offers LP & $N_{a}$ and $p_{a}$ & $p_{b}$ \\
S3 & Neither firm offers LP & $p_{a}$ & $p_{b}$ \\
\hline
\end{tabular}

Based on equations (3.1-3.10), the firms' profits are functions of: (1) the decision variables $\left(N_{a}, p_{a}, N_{b}, p_{b}\right)$; and, (2) the behavioural parameters $\left(\alpha_{v}, \alpha_{d}\right)$. In each scenario, we find the firms' optimal decision variables by simultaneously maximizing the firms' profits, each one in terms of its own decision variables. Table 3.2 shows that the two optimization problems are solved simultaneously in each scenario.

Table 3.2: Optimization problems in each scenario

\begin{tabular}{lll}
\hline \multicolumn{3}{c}{ Optimization problems } \\
\hline \multirow{2}{*}{ Scenario S1 } & (I) $\max _{N_{a}, p_{a}} I_{a}$ & (II) $\max _{N_{b}, p_{b}} I_{b}$ \\
& s.t. $N_{a}$ is integer, $p_{a}>0$ & s.t. $N_{b}$ is integer, $p_{b}>0$ \\
\hline \multirow{2}{*}{ Scenario S2 } & (I) $\max _{N_{a}, p_{a}} I_{a}$ & (II) $\max _{p_{b}} I_{b}$ \\
& s.t. $N_{a}$ is integer, $p_{a}>0$ & s.t. $p_{b}>0$ \\
\hline \multirow{2}{*}{ Scenario S3 } & (I) $\max _{p_{a}} I_{a}$ & (II) $\max _{p_{b}} I_{b}$ \\
& s.t. $p_{a}>0$ & s.t. $p_{b}>0$ \\
\hline
\end{tabular}

Since the profit equations (3.9-3.10) are highly nonlinear, an analytical solution to find the optimal decision variables, if available, is difficult to derive. Consequently, we apply an iterative numerical algorithm as explained in Table 3.3. This algorithm is based on the firms' optimal responses, which are the optimal decision variables that maximize the profit. In Table 3.3, Firm 
$i$ 's optimal response in iteration $r$ is denoted as $O_{i}^{r}$. Based on these scenarios, and as discussed above, a firm's optimal response might be a set of optimal required numbers to receive a reward and optimal price, or only an optimal price.

Table 3.3: Equilibrium finder algorithm

\begin{tabular}{ll}
\hline & Task \\
\hline 1 & Find Firm $a$ 's optimal response $O_{a}^{1}$ to a Firm $b$ 's initial strategy $O_{b}^{1}$ \\
2 & Find Firm $b$ 's optimal response $O_{b}^{2}$ to the strategy of $O_{a}^{1}$ \\
3 & Find Firm $a$ 's optimal response $O_{a}^{2}$ to the strategy of $O_{b}^{2}$ \\
4 & $x=a b s\left(\left[O_{a}^{2}, O_{b}^{2}\right]-\left[O_{a}^{1}, O_{b}^{1}\right]\right)$ \\
5 & While $x \geq$ converge threshold, do \\
6 & Set $O_{b}^{1}=O_{b}^{2}$ \\
7 & Repeat step $1-$ step 4 \\
8 & End while \\
\hline
\end{tabular}

The algorithm in Table 3.3 seeks the Nash equilibrium, where neither firm can increase its profit by unilaterally deviating to any other possible one (Nash, 1950, 1951). Applying this algorithm, we find the closest condition to the equilibrium with an error of (0.001). Not converging in this algorithm is interpreted as either having more than one equilibrium or no equilibrium. It should also be noted that the initial strategy and the choice of the firm from which we start the algorithm in Table 3.3 do not affect the results.

To be more realistic, we limit reward timing for the firms that apply a restricted redemption policy LP (variables $N_{a}$ and $N_{b}$ in Scenario S1, and variable $N_{a}$ in Scenario S2) to be equal or less than 10, similar to the loyalty programs in place at McDonald's, Starbucks and Second Cup. We do not consider a maximum limit for the prices, and optimal values of $p_{i}$ in the range of $(0, \infty)$ is found which maximizes Firm i's profit. Employing Matlab's fmincon function, we apply an 
interior-point algorithm based on Byrd et al. (2000) to reach the optimal price with the accuracy of 32 decimal digits.

In our framework, parameters $\alpha_{v}$ and $\alpha_{d}$ are bounded in the $(0,1)$ interval. To manage the results, we consider the step size of 0.1 in the range of [0.1, 0.9] for parameters $\alpha_{v}$ and $\alpha_{d}$, which results in 81 different combinations of these parameters. We solve three sub-games and the general game in which the firms decide whether or not to offer LP for all 81 combinations of parameters $\alpha_{v}$ and $\alpha_{d}$.

\subsection{Results and discussion}

As discussed in Section 3.2, we formulate Firm $a$ 's and Firm $b$ 's profits (Equation 3.9 and 3.10) as functions of their decision variables and behavioural parameters of $\alpha_{v}$ (reward valuation coefficient) and $\alpha_{d}$ (time valuation coefficient) for the three scenarios of S1, S2, and S3. Then, applying a numerical method (explained in Table 3.3), we obtain the equilibrium solutions for each scenario. Comparing the results for these scenarios, we solve the general game between Firm $a$ and $b$ in which each player decides about offering or not offering LP. The following sections describe these steps.

\subsubsection{Scenario $S 1$}

This scenario is a game between Firm $a$ and $b$, where both firms offer a free product to their loyal customers who have purchased a certain number of times. Firms decide on the required number of purchases a customer needs to be rewarded $\left(N_{i}\right.$ for Firm $i$ ) and the price of the product ( $p_{i}$ for Firm i) to maximize their profits. Using the algorithm explained in Table 3.3, we seek a Nash equilibrium for each combination of parameters $\alpha_{v}$ and $\alpha_{d}$ in Scenario S1. 
Since Scenario S1 is symmetric, both firms reach the same strategy (decision variables) in the equilibrium condition. Table 3.4 shows the optimal variable $N_{i}$ (number of required purchases to get reward), for different combinations of $\alpha_{v}$ and $\alpha_{d}$. As mentioned before, the maximum value considered for $N_{i}$ is 10 in this thesis. So all values greater than 10 are indicated as 10.

Table 3.4: Optimal reward timing (required number of purchases before redemption) in Scenario S1 of the game between LP and No-LP for combinations of mental parameters

\begin{tabular}{l|ccccccccc}
\hline$\alpha_{v}$ & 0.1 & 0.2 & 0.3 & 0.4 & 0.5 & 0.6 & 0.7 & 0.8 & 0.9 \\
\hline 0.1 & 10 & 10 & 10 & 10 & 10 & 10 & 10 & 10 & 10 \\
0.2 & 9 & 7 & 8 & 10 & 10 & 10 & 10 & 10 & 10 \\
0.3 & 6 & 5 & 5 & 5 & 5 & 7 & 10 & 10 & 10 \\
0.4 & 5 & 4 & 4 & 4 & 4 & 4 & 4 & 5 & 10 \\
0.5 & 5 & 4 & 3 & 3 & 3 & 3 & 3 & 3 & 3 \\
0.6 & 5 & 4 & 3 & 3 & 3 & 3 & 3 & 3 & 3 \\
0.7 & 5 & 4 & 3 & 3 & 3 & 3 & 3 & 3 & 3 \\
0.8 & 6 & 4 & 4 & 3 & 3 & 3 & 3 & 3 & 3 \\
0.9 & 7 & 5 & 4 & 3 & 3 & 3 & 3 & 3 & 3 \\
\hline
\end{tabular}

As can be seen in Table 3.4, under very low values of parameter $\alpha_{v}$ (when customers do not highly value reward) the optimal number of required purchases is equal or higher than the maximum level, which means that we cannot be sure about the real optimal values for this variable. Except under the condition of low values of parameter $\alpha_{v}$, Table 3.4 shows that the optimal number of required purchases to receive a reward increases with lower values of the customers' time valuation (parameter $\alpha_{d}$ ), meaning that the firms can delay their reward when customers do not highly value time. Under low values of $\alpha_{d}$, Table 3.4 shows that there is a trade-off area for $\alpha_{v}$ 
under which the required number of purchases for rewarding reaches its minimum. It is also observed that results are more sensitive to $\alpha_{v}$ than $\alpha_{d}$.

Table 3.5, on the other hand, shows the firms' optimal price in Scenario S1 for different combinations of parameters $\alpha_{v}$ and $\alpha_{d}$. This table reveals that the optimal price decreases for higher values of parameter $\alpha_{d}$ and lower values of parameter $\alpha_{v}$. It should be noticed that as the price increases the value of reward also increases, since the reward is a free product. Comparing the results in tables 3.4 and 3.5, one can conclude that when customers highly value reward, the firms should offer earlier and higher reward except when customers have low valuation for time. Under the latter condition, the firms can delay the reward but they still should offer a high value of reward.

Table 3.5: Optimal price in Scenario S1 of the game between LP and No-LP for combinations of mental parameters

\begin{tabular}{|c|c|c|c|c|c|c|c|c|c|}
\hline$\alpha$ & 0.1 & 0.2 & 0.3 & 0.4 & 0.5 & 0.6 & 0.7 & 0.8 & 0.9 \\
\hline 0.1 & 2.127 & 2.083 & 2.059 & 2.044 & 2.035 & 2.029 & 2.024 & 2.021 & 2.018 \\
\hline 0.2 & 2.287 & 2.219 & 2.146 & 2.090 & 2.071 & 2.059 & 2.050 & 2.043 & 2.038 \\
\hline 0.3 & 2.547 & 2.419 & 2.319 & 2.253 & 2.207 & 2.127 & 2.073 & 2.063 & 2.056 \\
\hline 0.4 & 2.847 & 2.661 & 2.509 & 2.407 & 2.336 & 2.284 & 2.244 & 2.172 & 2.072 \\
\hline 0.5 & 3.140 & 2.865 & 2.765 & 2.624 & 2.522 & 2.445 & 2.387 & 2.340 & 2.303 \\
\hline 0.6 & 3.399 & 3.043 & 2.905 & 2.737 & 2.616 & 2.525 & 2.455 & 2.400 & 2.355 \\
\hline 0.7 & 3.483 & 3.125 & 2.959 & 2.796 & 2.672 & 2.576 & 2.501 & 2.442 & 2.394 \\
\hline 0.8 & 3.368 & 3.063 & 2.864 & 2.776 & 2.672 & 2.587 & 2.517 & 2.459 & 2.412 \\
\hline 0.9 & 3.184 & 2.928 & 2.781 & 2.683 & 2.615 & 2.551 & 2.495 & 2.447 & 2.405 \\
\hline
\end{tabular}


Table 3.6 shows the firms' profit under the decision variables of tables 3.4 and 3.5. Table 3.6 reveals that under most conditions, optimal profit decreases for higher values of parameter $\alpha_{d}$ and lower values of parameter $\alpha_{v}$.

Table 3.6: Optimal profit in Scenario S1 of the game between LP and No-LP for combinations of mental parameters

\begin{tabular}{c|ccccccccc}
\hline$\alpha_{v} \alpha_{d}$ & 0.1 & 0.2 & 0.3 & 0.4 & 0.5 & 0.6 & 0.7 & 0.8 & 0.9 \\
\hline 0.1 & 0.968 & 0.948 & 0.937 & 0.931 & 0.926 & 0.923 & 0.921 & 0.920 & 0.919 \\
0.2 & 1.031 & 0.974 & 0.956 & 0.952 & 0.943 & 0.937 & 0.933 & 0.930 & 0.928 \\
0.3 & 1.096 & 1.014 & 0.972 & 0.945 & 0.926 & 0.934 & 0.944 & 0.940 & 0.936 \\
0.4 & 1.193 & 1.075 & 1.014 & 0.974 & 0.945 & 0.925 & 0.909 & 0.913 & 0.944 \\
0.5 & 1.317 & 1.159 & 1.057 & 1.005 & 0.966 & 0.938 & 0.916 & 0.899 & 0.885 \\
0.6 & 1.428 & 1.234 & 1.116 & 1.053 & 1.007 & 0.973 & 0.947 & 0.926 & 0.909 \\
0.7 & 1.468 & 1.273 & 1.144 & 1.083 & 1.036 & 0.999 & 0.971 & 0.949 & 0.930 \\
0.8 & 1.460 & 1.255 & 1.175 & 1.084 & 1.045 & 1.012 & 0.985 & 0.963 & 0.945 \\
0.9 & 1.410 & 1.247 & 1.149 & 1.060 & 1.033 & 1.008 & 0.986 & 0.968 & 0.951 \\
\hline
\end{tabular}

\subsubsection{Scenario S2}

In Scenario S2, only one firm (Firm $a$ ) offers LP. In this scenario, Firm $a$ decides about its price and the required number of purchases to receive the reward (which is an integer in the range of $[1,10])$, and Firm $b$ only decides about its price. Based on the method explained in Table 3.3, we seek a Nash equilibrium for the game between Firm $a$ and $b$, where the optimal decision for each firm is the best response to the other firm's strategy. Tables 3.7 and 3.8 show Firm $a$ 's optimal decision variables $\left(N_{a}\right.$ and $\left.p_{a}\right)$, respectively. All values of $N_{a}$ greater than 10 are indicated as 10 . 
Table 3.7: Firm a's optimal reward timing (number of required purchases before redemption) in Scenario S2 of the game between LP and No-LP for combinations of mental parameters

\begin{tabular}{c|ccccccccc}
\hline$\alpha_{v}$ & 0.1 & 0.2 & 0.3 & 0.4 & 0.5 & 0.6 & 0.7 & 0.8 & 0.9 \\
\hline 0.1 & 10 & 10 & 10 & 10 & 10 & 10 & 10 & 10 & 10 \\
0.2 & 9 & 8 & 8 & 10 & 10 & 10 & 10 & 10 & 10 \\
0.3 & 6 & 5 & 5 & 5 & 6 & 7 & 10 & 10 & 10 \\
0.4 & 5 & 4 & 4 & 4 & 4 & 4 & 4 & 5 & 10 \\
0.5 & 5 & 4 & 3 & 3 & 3 & 3 & 3 & 3 & 4 \\
0.6 & 5 & 4 & 3 & 3 & 3 & 3 & 3 & 3 & 3 \\
0.7 & 6 & 4 & 3 & 3 & 3 & 3 & 3 & 3 & 3 \\
0.8 & 6 & 4 & 4 & 3 & 3 & 3 & 3 & 3 & 3 \\
0.9 & 7 & 5 & 4 & 4 & 3 & 3 & 3 & 3 & 3 \\
\hline
\end{tabular}

Table 3.8: Firm a's optimal price in Scenario S2 of the game between LP and No-LP for combinations of mental parameters

\begin{tabular}{c|ccccccccc}
\hline$\alpha_{v}$ & 0.1 & 0.2 & 0.3 & 0.4 & 0.5 & 0.6 & 0.7 & 0.8 & 0.9 \\
\hline 0.1 & 2.161 & 2.116 & 2.092 & 2.078 & 2.068 & 2.062 & 2.057 & 2.053 & 2.051 \\
0.2 & 2.327 & 2.246 & 2.190 & 2.126 & 2.106 & 2.093 & 2.083 & 2.076 & 2.071 \\
0.3 & 2.606 & 2.489 & 2.389 & 2.322 & 2.235 & 2.177 & 2.109 & 2.098 & 2.090 \\
0.4 & 2.916 & 2.748 & 2.596 & 2.494 & 2.423 & 2.370 & 2.329 & 2.242 & 2.108 \\
0.5 & 3.209 & 2.954 & 2.879 & 2.737 & 2.635 & 2.557 & 2.498 & 2.450 & 2.319 \\
0.6 & 3.480 & 3.139 & 3.026 & 2.856 & 2.732 & 2.639 & 2.568 & 2.512 & 2.466 \\
0.7 & 3.557 & 3.245 & 3.096 & 2.926 & 2.796 & 2.696 & 2.618 & 2.557 & 2.507 \\
0.8 & 3.531 & 3.219 & 2.994 & 2.922 & 2.808 & 2.715 & 2.639 & 2.578 & 2.527 \\
0.9 & 3.382 & 3.093 & 2.936 & 2.798 & 2.764 & 2.689 & 2.624 & 2.570 & 2.524 \\
\hline
\end{tabular}

Tables 3.7 and 3.8 show a similar pattern for Firm $a$ 's optimal decision variables in Scenario S1 and S2. However, comparing Table 3.5 and Table 3.8, one can conclude that a firm 
that offers LP should increase the price if its competitor decides to not offer LP rather than the condition under which both firms offer LP.

Table 3.9 shows Firm $a$ 's optimal profit in Scenario S2. This table reveals that Firm $a$ 's optimal profits in Scenario S2 are higher with higher levels $\alpha_{v}$ and lower values of $\alpha_{d}$. Comparing tables 3.6 and 3.9, we conclude that a firm that offers LP gains more profit if its competitor does not offer LP rather than the condition under which both firms offer LP.

Table 3.9: Firm a's optimal profit in Scenario S2 of the game between LP and No-LP for combinations of mental parameters

\begin{tabular}{c|ccccccccc}
\hline$\alpha_{v} \alpha_{d}$ & 0.1 & 0.2 & 0.3 & 0.4 & 0.5 & 0.6 & 0.7 & 0.8 & 0.9 \\
\hline 0.1 & 0.999 & 0.979 & 0.968 & 0.961 & 0.957 & 0.954 & 0.952 & 0.950 & 0.949 \\
0.2 & 1.066 & 1.020 & 0.995 & 0.984 & 0.975 & 0.969 & 0.964 & 0.961 & 0.959 \\
0.3 & 1.146 & 1.072 & 1.030 & 1.003 & 0.987 & 0.978 & 0.977 & 0.972 & 0.968 \\
0.4 & 1.250 & 1.144 & 1.084 & 1.043 & 1.015 & 0.993 & 0.977 & 0.971 & 0.977 \\
0.5 & 1.374 & 1.229 & 1.142 & 1.090 & 1.051 & 1.022 & 1.000 & 0.982 & 0.976 \\
0.6 & 1.495 & 1.311 & 1.206 & 1.142 & 1.095 & 1.060 & 1.033 & 1.011 & 0.994 \\
0.7 & 1.584 & 1.370 & 1.249 & 1.181 & 1.130 & 1.091 & 1.061 & 1.037 & 1.017 \\
0.8 & 1.614 & 1.389 & 1.283 & 1.201 & 1.151 & 1.112 & 1.081 & 1.056 & 1.035 \\
0.9 & 1.614 & 1.4 & 1.285 & 1.216 & 1.156 & 1.121 & 1.092 & 1.068 & 1.047 \\
\hline
\end{tabular}

Firm $b$ under Scenario S2 does not offer LP. Tables 3.10 and 3.11 show Firm $b$ 's optimal prices and profits under Scenario S2 for different combinations of $\alpha_{v}$ and $\alpha_{d}$. These results show that Firm b's optimal price and profit are higher under higher customers' rewards valuation. Comparing tables 3.9 and 3.11 also reveals that in the asymmetric scenario, the firm that offers LP can offer a higher price and gain more profit under most conditions. 
Table 3.10: Firm b's optimal price in Scenario S2 of the game between LP and No-LP for combinations of mental parameters

\begin{tabular}{|c|c|c|c|c|c|c|c|c|c|}
\hline$\alpha_{v}$ & 0.1 & 0.2 & 0.3 & 0.4 & 0.5 & 0.6 & 0.7 & 0.8 & 0.9 \\
\hline 0.1 & 1.969 & 1.968 & 1.968 & 1.968 & 1.968 & 1.968 & 1.968 & 1.968 & 1.968 \\
\hline 0.2 & 1.967 & 1.962 & 1.961 & 1.968 & 1.967 & 1.967 & 1.967 & 1.968 & 1.968 \\
\hline 0.3 & 1.957 & 1.946 & 1.944 & 1.942 & 1.950 & 1.955 & 1.967 & 1.967 & 1.967 \\
\hline 0.4 & 1.955 & 1.940 & 1.936 & 1.933 & 1.932 & 1.930 & 1.930 & 1.940 & 1.967 \\
\hline 0.5 & 1.959 & 1.943 & 1.926 & 1.922 & 1.919 & 1.917 & 1.915 & 1.914 & 1.929 \\
\hline 0.6 & 1.955 & 1.942 & 1.926 & 1.922 & 1.919 & 1.917 & 1.916 & 1.915 & 1.914 \\
\hline 0.7 & 1.940 & 1.928 & 1.915 & 1.916 & 1.915 & 1.915 & 1.914 & 1.914 & 1.914 \\
\hline 0.8 & 1.896 & 1.898 & 1.913 & 1.900 & 1.905 & 1.908 & 1.909 & 1.910 & 1.911 \\
\hline 0.9 & 1.857 & 1.881 & 1.886 & 1.902 & 1.888 & 1.895 & 1.900 & 1.903 & 1.906 \\
\hline
\end{tabular}

Table 3.11: Firm b's optimal profit in Scenario S2 of the game between LP and No-LP for combinations of mental parameters

\begin{tabular}{|c|c|c|c|c|c|c|c|c|c|}
\hline$\alpha_{v}$ & 0.1 & 0.2 & 0.3 & 0.4 & 0.5 & 0.6 & 0.7 & 0.8 & 0.9 \\
\hline 0.1 & 0.969 & 0.968 & 0.968 & 0.968 & 0.968 & 0.968 & 0.968 & 0.968 & 0.968 \\
\hline 0.2 & 0.967 & 0.962 & 0.961 & 0.968 & 0.967 & 0.967 & 0.967 & 0.968 & 0.968 \\
\hline 0.3 & 0.957 & 0.946 & 0.944 & 0.942 & 0.950 & 0.955 & 0.967 & 0.967 & 0.967 \\
\hline 0.4 & 0.955 & 0.940 & 0.936 & 0.933 & 0.932 & 0.930 & 0.930 & 0.940 & 0.967 \\
\hline 0.5 & 0.959 & 0.943 & 0.926 & 0.922 & 0.919 & 0.917 & 0.915 & 0.914 & 0.929 \\
\hline 0.6 & 0.955 & 0.942 & 0.926 & 0.922 & 0.919 & 0.917 & 0.916 & 0.915 & 0.914 \\
\hline 0.7 & 0.940 & 0.928 & 0.915 & 0.916 & 0.915 & 0.915 & 0.914 & 0.914 & 0.914 \\
\hline 0.8 & 0.896 & 0.898 & 0.913 & 0.900 & 0.905 & 0.908 & 0.909 & 0.910 & 0.911 \\
\hline 0.9 & 0.857 & 0.881 & 0.886 & 0.902 & 0.888 & 0.895 & 0.900 & 0.903 & 0.906 \\
\hline
\end{tabular}




\subsubsection{Scenario S3}

In Scenario S3, none of the firms offers LP. Therefore, each firm only decides of its price. Similar to Scenario S1, Scenario S3 is a symmetric game, and as expected, the optimal prices are equal for both firms. Based on Equations (3.10-3.11), the profits in Scenario S3 are not functions of parameters $\alpha_{v}$ and $\alpha_{d}$. Applying the numerical method explained in Table 3.3, we obtain the firms' optimal price, which is equal to $2\left(p_{i}=2\right)$, and the firms' optimal profit, which is equal to $1\left(I_{i}^{S 3}=\right.$ 1) in Scenario S3, for any $\alpha_{v}$ and $\alpha_{d}$.

\subsubsection{The main game}

Having found the optimal profit in Scenario S3, and in the two other scenarios (tables 3.6, 3.9, and 3.11), one can solve the general game in which the two firms $(a, b)$ decide whether to offer LP or not. Considering the strategy of offering and not offering LP by each firm, the payoff matrix of this game for each combination of $\alpha_{v}$ and $\alpha_{d}$ can be derived as follows.

\begin{tabular}{l|cc}
\hline Firm $a$ & Firm $b$ & No-LP \\
\cline { 1 - 2 } LP & $\left(I_{a}^{S 1}, I_{b}^{S 1}\right)$ & $\left(I_{a}^{S 2}, I_{b}^{S 2}\right)$ \\
No-LP & $\left(I_{b}^{S 2}, I_{a}^{S 2}\right)$ & $\left(I_{a}^{S 3}, I_{b}^{S 3}\right)$ \\
\hline
\end{tabular}

Since firms are symmetric in all aspects except their LP policy, an asymmetric game where Firm $a$ offers LP while Firm $b$ does not will provide the same output for Firm $a$ 's profit as Firm b's profit in S2 and the same output for Firm $b$ 's profit as Firm $a$ 's profit in S2. This is why the lower left side quadrant of the above payoff matrix indicates a profit of $I_{b}^{S 2}$ for Firm $a$ and of $I_{a}^{S 2}$ for Firm $b$. Table B.1, in Appendix B, scales the amounts for these profits for each combination of parameters $\alpha_{v}$ and $\alpha_{d}$. Studying the payoff matrices of all 81 combinations of parameters $\alpha_{v}$ 
and $\alpha_{d}$, one can categorize these combinations into three different regions as shown in Table 3.12. In the dark shaded area of this table, where customers highly value reward but not time, offering LP is a dominant Nash equilibrium. In the moderately dark shaded region, the firms face a prisoner dilemma, meaning that they both offer LP at the equilibrium while not offering LP results at a higher profit for both firms. In the remaining regions, where customers highly value time but not reward, not offering LP is the equilibrium. However, it should be noted that in the white area, we obtain the optimal number of required purchases to get reward equal to the maximum value. Therefore, we cannot be sure whether the reward policy we get is optimal.

Table 3.12: Different regions of the game between LP and No-LP policies for combinations of mental parameters

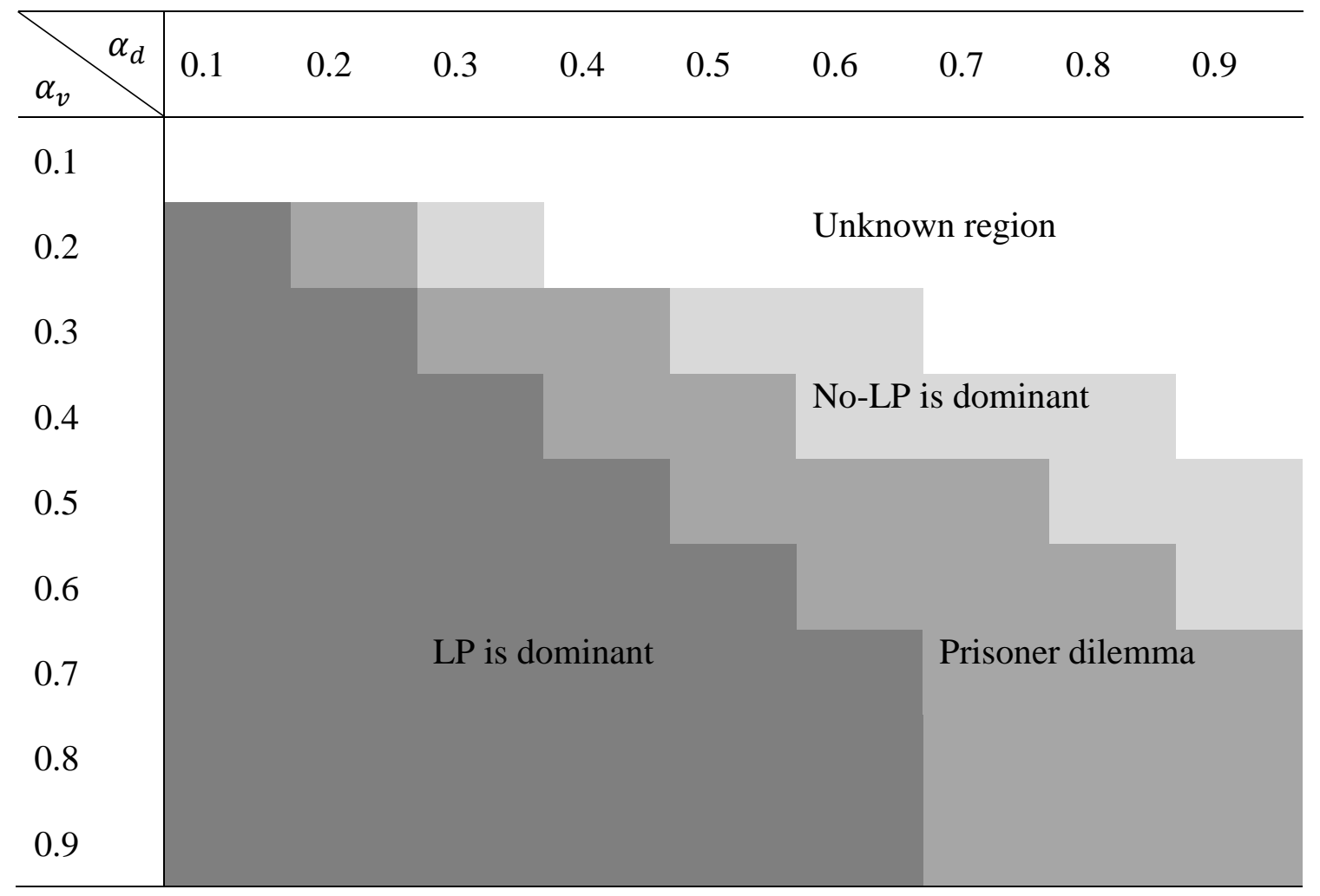




\subsection{Extended model}

In the model explained in section 3.2, and following other studies (e.g., Singh et al., 2008; Gandomi \& Zolfaghari, 2013; Caminal \& Matutes, 1990; Kim et al., 2001), we assume that customers' valuation for the product is sufficiently high that it exceeds the product price, and therefore, that customers buy one unit of the product in each period of purchasing from either Firm $a$ or Firm $b$.

We now extend this model by allowing customers to leave the market, i.e., not buying any of the products offered by Firms $a$ and $b$. While previous studies assumed that the portion of customers who leave the market (light users) is exogenous to the model, we endogenously determine the number of such customers. In our extended model, the fraction of leaving customers is affected by the firms' decision variables. To account for this, we consider that customers can leave the market if they choose a product that is offered outside the market at the price of $p_{c}$. This is known as "outside goods" in the literature (Kim, 1987; Salop, 1979). Making this assumption, we let the customers purchase from outside of the market based on their utilities. And since the customers' utility is affected by the firms' decision variables, the number of customers who leave the market is a function of the firms' decisions.

Based on the above definitions, we add the alternative of purchasing from outside of the market, denoted by $\mathrm{C}$, into the possible alternatives z. In other words, in the extended model, customer $j$ chooses the alternative $z \in\{\mathrm{A} 0, \mathrm{~A} 1, \mathrm{~B} 0, \mathrm{~B} 1, \mathrm{C}\}$ if his/her utility of this alternative $\left(U_{z}^{j}\right)$ is greater than his/her utility in all other alternatives. Consequently, Equation (3.1) can be rewritten as follows:

$q_{z}^{j}=\exp \left(D_{z}^{j}\right) /\left(\exp \left(D_{A 0}^{j}\right)+\exp \left(D_{A 1}^{j}\right)+\exp \left(D_{B 0}^{j}\right)+\exp \left(D_{B 1}^{j}\right)+\exp \left(D_{C}^{j}\right)\right)$ 
In all scenarios, customer $j$ has the option of purchasing from neither Firm $a$ nor Firm $b$. The surplus of this decision $\left(D_{c}^{j}\right)$ includes customer $j$ 's valuation for the product $\left(v_{c}^{j}\right)$ diminished by the price $\left(p_{c}\right)$. It is given by:

$D_{c}^{j}=v_{c}^{j}-p_{c}$

Incorporating the alternative $\mathrm{C}$, the flow charts for scenarios S1 and S2 in Figures 3.1 and 3.2 must be changed to those shown in Figure 3.3 and 3.4, respectively, where $M^{S}\left(n_{a}, n_{b}\right)$ is the set of customers who have purchased $n_{a(b)}$ times from Firm $a(b)$ in scenario $S$. Furthermore, assuming $v_{a}^{j}=v_{b}^{j}=v_{c}^{j}$, the probabilities of purchasing from Firm $a$ and $b$ in Scenario S3 $\left(q_{A 0}^{S 3}\right.$ and $q_{B 0}^{S 3}$ ) can be obtained as follows:

$$
\begin{gathered}
q_{A 0}^{S 3}=\exp \left(-p_{a}\right) /\left(\exp \left(-p_{a}\right)+\exp \left(-p_{b}\right)+\exp \left(-p_{c}\right)\right) \\
q_{B 0}^{S 3}=\exp \left(-p_{b}\right) /\left(\exp \left(-p_{a}\right)+\exp \left(-p_{b}\right)+\exp \left(-p_{c}\right)\right)
\end{gathered}
$$

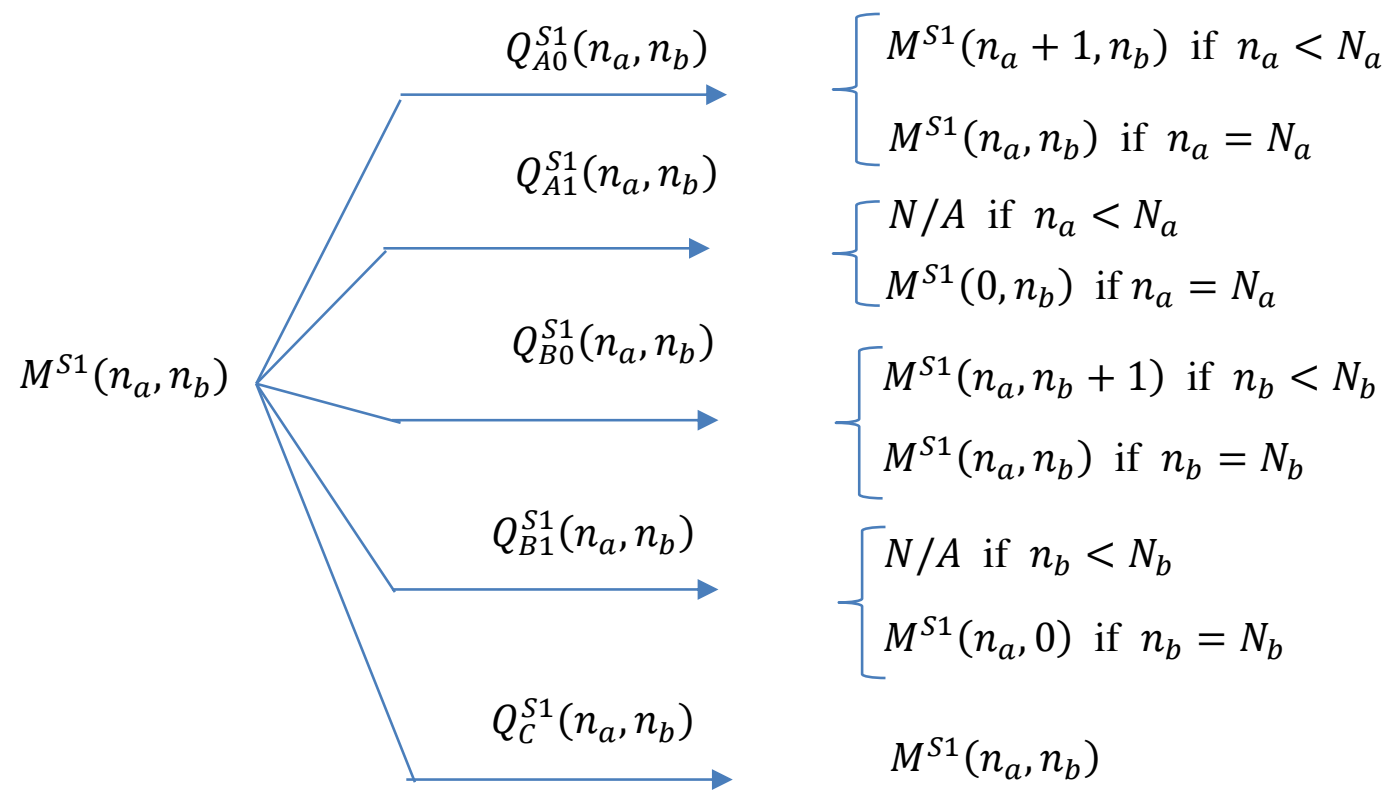

Figure 3.3: Flow chart between two subsequent periods in Scenario S1 of the game between LP and No-LP with outside goods 


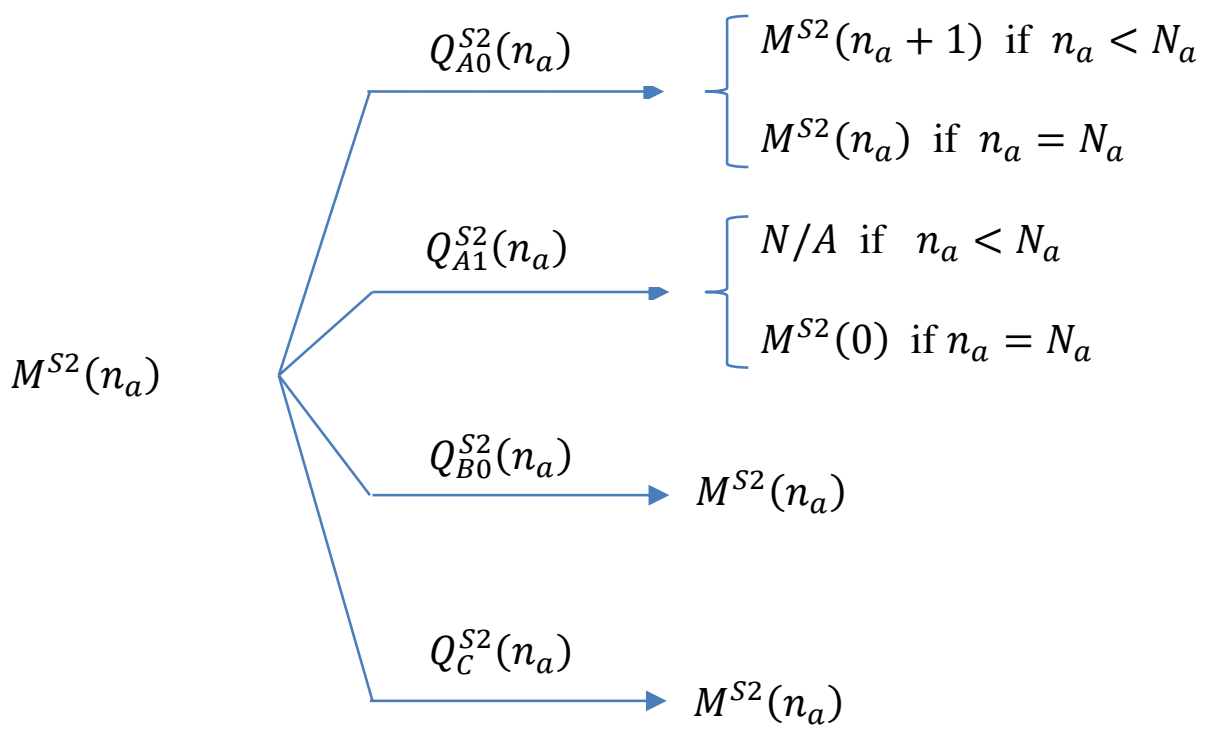

Figure 3.4: Flow chart between two subsequent periods in Scenario S2 of the game between LP and No-LP with outside goods

Normalizing the outside price $\left(p_{c}\right)$ to $1\left(p_{c}=1\right)$, we obtain the firms' optimal decision variables and profits in scenarios S1, S2, and S3 for all 81 combinations of $\alpha_{v}$ and $\alpha_{d}$. Tables A.1A.8 in Appendix A deal with these results. As can be derived from these tables, the optimal decisions and profits under the condition of having outside goods follow similar pattern as those under the condition of having no outside good. However, comparing the corresponding tables in Section 3.4 and Appendix A, one can conclude that the existence of an outside good reduces the competition between Firm $a$ and Firm $b$ since they can offer lower prices and delay their rewards; however, as expected, an outside good causes the firms to gain less profits.

The different regions of the game between Firm $a$ and Firm $b$ under the condition of having an outside good is shown in Table 3.13. The scaling format of the payoff matrix is reported in Table B.2 in Appendix B. In the dark shaded area of Table 3.13, where customers highly value reward but not time, offering LP is a dominant Nash equilibrium. In the light shaded area, the firms face a prisoner dilemma, meaning that they both offer LP at the equilibrium while not offering LP results in a higher profit for each firm. In the rest of the conditions, where customers do not highly 
value reward, the payoff matrix shows the policy of not offering LP by both firms as the equilibrium; however, we cannot be sure about this since in this region the obtained optimal number of required purchases to receive a reward is equal to the maximum value. Comparing tables 3.13 and 3.12, one can conclude that the existence of an outside good increases the chance of the LP being a profitable policy.

Table 3.13: Different regions of the game between LP and No-LP considering an outside good for combinations of mental parameters

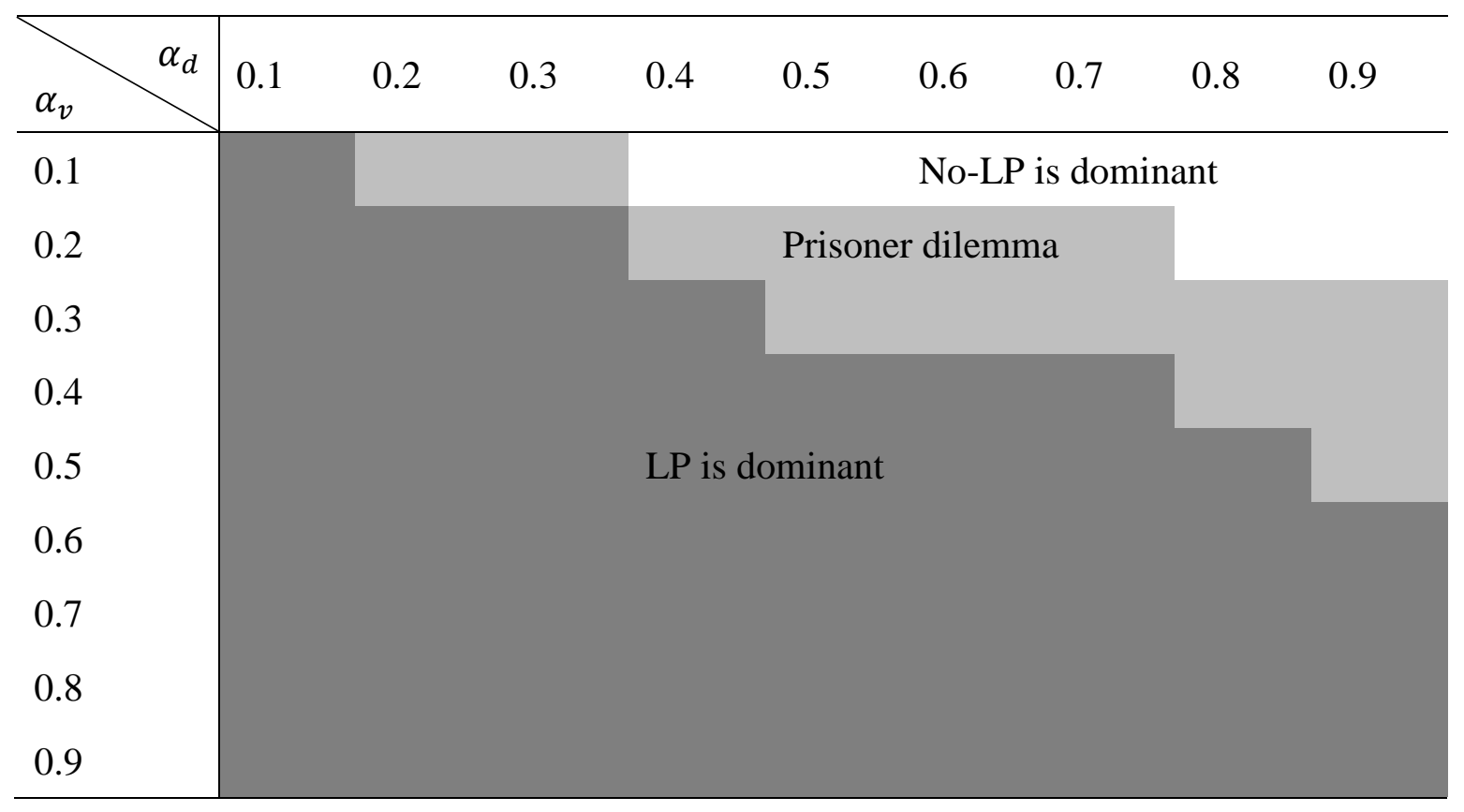

\subsection{Conclusion}

Despite the ubiquity of LPs, the literature reports contrary results regarding their profitability. Although some researchers believe in the positive effects of LPs, others claim that LPs might lose their competitive advantage in an environment in which all companies offer LPs since this condition may equalize the first situation and only increase marketing costs (Shugan, 2005; Singh et al., 2008). This chapter investigated the profitability of offering LP in the restaurant and 
entertainment industries, where firms do not change their prices, and consequently rely upon other managerial tools such as LPs to increase their profit. The main goal of this chapter has been to specify the conditions under which LPs are profitable, and to account for conflicting results in the literature. To address this research problem, we applied a game theoretic approach to study the profitability of LPs in a competitive environment.

Using a numerical analysis, we obtained Nash equilibrium solutions for three games: two symmetric games, (1) where both firms offer LP, and (2) where neither firm offers LP; and (3) one asymmetric game where only one firm offers LP. In each of these three games, the firm that offers LP determines the price and the timing of the reward, while the firm that does not offer LP determines the price. Comparing optimal profits across scenarios, an equilibrium solution was found for the main game in which each firm decides whether or not to offer LP for different combinations of customers' behavioural parameters of reward and time valuation.

Our main findings indicated that in the asymmetric game, the firm that offers LP earns higher profit under all conditions; however, when the market serves customers who highly value time but not reward, not offering LP by both firms results in maximum profit for both firms. We specified the conditions under which there is a prisoner dilemma, and the equilibrium of the game is offering LP by two firms. We also observed that when customers highly value reward but not time, offering LP by both firms is a dominant strategy of competition. We showed that the existence of an outside good increases the conditions under which offering LP policy is a dominant strategy. Furthermore, our results revealed that under most conditions, optimal profits decreases for higher values of parameter $\alpha_{d}$ and lower values of parameter $\alpha_{v}$. The firm with LP should offer a higher price if its competitor decides to not offer LP rather than the condition under which both firms offer LP. 


\section{Profitability of restricted redemption in loyalty programs}

\subsection{Introduction}

In order to reap the benefits that LPs offer, firms implement different designs of LPs. The design of LP is multifaceted, involving several elements, such as reward magnitude, reward type (monetary versus non-monetary), and redemption policies. In particular, some firms commonly impose a predefined number of purchases before consumers can redeem their rewards. Typical examples of such restrictive loyalty programs include coffee shops' reward cards (e.g., "buy 10, get one free"), and some hotel promotional offers (e.g., "stay 10 nights and earn one night free"). Such practices have been used by large companies such as Second Cup in Canada and Marriott across North America. While these restrictions are common, many firms in the same industry do not impose such restrictions on the redemption of their points. For example, Waves Coffee, a franchised coffee chain in Western Canada, offers its customers loyalty rewards that can be redeemed at any time.

The empirical literature indicates that LPs that withhold rewards can have both positive and negative consequences. They can be perceived negatively by customers (Dickinson, 1989), may result in lowering customer satisfaction (Stauss et al., 2005), and therefore can be detrimental to profits (Dowling \& Uncles, 1997; Noble et al., 2014). However, the point pressure mechanism of withholding rewards can also stimulate customer purchases (Kopalle \& Neslin, 2003; Drèze \& Nunes, 2009). For example, Kivetz et al. (2006) found that for a coffee shop using a "buy 10, get one free" LP, the customers' likelihood to buy a product increases as they approach the reward redemption period. The discrepancy in these empirical results calls for an analytical study that 
evaluates the implications of such restrictions on redemption policies and identifies conditions under which such restrictions could benefit the firms offering the rewards. To our knowledge, such a study has not yet been done despite the widespread use of both restricted and unrestricted LPs in practice. This chapter aims to fill this knowledge gap and to investigate for the first time the profitability of restricting the time of redemption of loyalty rewards. This chapter focuses on restricting the starting time of redemption, while the next chapter studies the profitability of adding an end time for redemption (expiry) in LPs.

To address this research problem, this chapter evaluates the effectiveness of loyalty programs with and without restrictive redemption policies on the profits of two competing firms. We aim to answer the following research questions: For two competing firms offering loyalty programs, which is a more profitable redemption policy: a restricted or unrestricted one? Under what market conditions?

In our approach, we develop a comprehensive analytical model based on consumers' valuation of loyalty programs, incorporating both the mental accounting and goal-gradient theories. In our set-up, two competing firms offer loyalty programs. When the LP is restricted, a specific number of purchases is required before the consumer can redeem the accumulated points to earn a free product. In the unrestricted LP, the reward is a price reduction that the consumer can redeem at any subsequent purchase. We solve a stochastic Nash game in three scenarios (games). In the first and third games, both firms choose the same reward redemption policy (both either restrict or do not restrict the redemption), but in the second game the firms' policies are asymmetric (only one firm restricts the redemption while the other does not). Comparison of equilibrium outputs across games provides insights into the effects of restricting redemption on the firms' profits. 
The remainder of this chapter is organized as follows. Section 4.2 explains the model formulation, Section 4.3 describes the methodology used to solve the model, Section 4.4 presents and discusses the results, and Section 4.5 summarizes and concludes.

\subsection{Model}

\subsubsection{Assumptions and definitions}

In the model presented in this chapter, the market has a fixed size normalized to 1 , and is served by two firms named $a$ and $b$ selling substitutable but similar products. To study the effects of restricting redemption, we consider that each firm offers a loyalty program and has the possibility of imposing restrictions on the redemption of rewards earned by its customers. Firm $a$ and $b$ sell their products at price $p_{a}$ and $p_{b}$, respectively. It is assumed that both firms' prices are constant and do not change during the periods of purchasing. This is a reasonable assumption for many businesses using restricted and unrestricted LPs such as coffee shops and golf courses. This assumption also helps us to focus on understanding the effects of restricting redemption on consumers' product choice and therefore firms' demands and profits in isolation of pricing effects. We also assume that the firms play a Nash game, i.e., they set their decision variables simultaneously at the beginning of the selling season, without knowing each other's decisions.

Since each firm can choose to either restrict or not restrict redemption of its rewards, this results in three scenarios (games). In the first scenario (S1), both firms choose a restricted redemption policy. In the second scenario (S2), only Firm a restricts redemption. Finally, in scenario 3 (S3), both firms apply an unrestricted redemption policy (denoted by S3). 
A firm imposes a restriction on redemption if it only allows its customers to redeem their rewards after a pre-specified number of purchases, $N_{i}$, with $N_{i}$ an integer higher than 1 and $i \in$ $\{a, b\}$. As is usually the case for a restricted LP offered as "Buy $n$ times, get one product free," we consider that customers of a firm offering a restricted LP can receive a reward "in kind," i.e., a free product after completing the required number of purchases imposed by the company.

In the unrestricted LP, on the other hand, customers are offered a reward in each purchasing period, which can be redeemed as early as the next purchase. In order to focus on the effects of reward redemption policies, and exclude those of reward magnitude, we assume that customers at Firm $i \in\{a, b\}$, which offers an unrestricted LP, are also able to accumulate rewards valued at one product price, after $N_{i}$ purchases. This is equivalent to offering a fraction of price $\left(p_{i} / N_{i}\right)$ as a reward point in each purchasing period.

In summary, Firm $i \in\{a, b\}$ offers a free product (valued at $p_{i}$ ) as reward after $N_{i}$ purchases under a restricted redemption policy, and offers $\left(p_{i} / N_{i}\right)$ reward points in each purchasing period under an unrestricted redemption policy ${ }^{2}$. In other words, regardless of redemption policy, $N_{i}$ is the required number of purchases from Firm $i \in\{a, b\}$ to achieve a reward valued at the product price.

To track the customers' purchasing history, we denote $n_{i}^{j}$ as customer $j$ 's number of purchases from Firm $i \in\{a, b\}$, after the last redemption and until the time of being eligible to receive a free product as reward. Consequently, one can say customer $j$ has to buy $\left(N_{i}-n_{i}^{j}\right)$ more times from Firm $i$ before he/she can redeem the reward of a free product if Firm $i$ restricts the redemption, while this customer possesses redeemable $\left(n_{i}^{j} p_{i} / N_{i}\right)$ points at the current period.

\footnotetext{
${ }^{2}$ The policy of offering No-LP is a special case of the unrestricted policy, where $N_{i}=\infty, i=\{a, b\}$.
} 
For simplicity, we also assume that with a restrictive LP, customers are not offered a new reward if they are eligible to receive a free product. With the unrestricted LP, customers are not given a new point reward if they have accumulated enough points to get a free product but have not redeemed their points. In other words, $0 \leq n_{i}^{j} \leq N_{i}$.

\subsubsection{Customers' choices}

Following other studies (e.g., Singh et al., 2008; Gandomi \& Zolfaghari, 2013; Caminal \& Matutes, 1990; Kim et al., 2001), we assume that customers' valuation for the product is sufficiently high that it exceeds the product price, and therefore that customers buy one unit of the product in each period of purchasing from either Firm $a$ or Firm $b$. Customers are also allowed to switch between firms without penalty or extra cost. Consequently, at each period of purchasing, a customer should decide among a maximum of four options: purchasing from Firm $a$ and not redeem (denoted by A0); purchasing from Firm $a$ and redeem (denoted by A1); purchasing from Firm $b$ and not redeem (denoted by B0); and purchasing from Firm $b$ and redeem (denoted by B1). As mentioned before, redemption in a restricted LP is not permitted before a certain number of purchases.

As in Chapter 3, customers are assumed to be rational and forward looking when making their purchasing and redemption decisions, so customer $j$ will choose the alternative $z \in\{\mathrm{A} 0, \mathrm{~A} 1$, B0, B1 \} if his/her utility of this alternative (denoted by $U_{z}^{j}$ ) is greater than the other choice utilities. As explained in Section 3.2.2, to represent random effects that can influence consumer utility, we consider customer $j$ 's utility of choosing alternative $z\left(U_{z}^{j}\right)$ as a summation of a deterministic part

$\left(D_{z}^{j}\right)$ and a random part $\left(\varepsilon_{z}^{j}\right)$ so that $\left(U_{z}^{j}=D_{z}^{j}+\varepsilon_{z}^{j}\right)$. In line with the multinomial logit model (MNL), the random parts are considered independently and identically Gumbel distributed (the 
type-1 extreme value), and the probability of choosing alternative $z$ by customer $j\left(q_{z}^{j}\right)$ is obtained via Equation (3.1).

\subsubsection{The rewards value function}

The valuation function used in this chapter is similar to the one presented in Chapter 3 (Equation 3.2). Referring to Section 3.2.3, the value function $V(x, t)$ representing consumers' valuation of $x$ units of reward that can be redeemed after $t$ periods is $\alpha_{v} x /\left(1+\alpha_{d}\right)^{t}$, where $\alpha_{v}$ and $\alpha_{d}$ are behavioural/mental parameters of reward valuation and time valuation, respectively.

As mentioned before, this valuation function aligns with the mental accounting theory (Thaler, 1985), which indicates that customers value cash and rewards differently. To model this mentality, it is assumed that $x$ amounts of reward are evaluated at $\alpha_{v} x$. Considering $\alpha_{v}$ a positive parameter lower than 1 , we ensure that points are evaluated less than cash.

Moreover, the valuation function aligns with the goal-gradient theory (e.g., Kivetz et al., 2006; Besanko \& Winston, 1990) such that the value of a point increases as the customer gets closer to the redemption time.

\subsubsection{Deterministic components of customer's utilities}

To derive consumer $j$ 's surplus in each alternative $z \in\{\mathrm{A} 0, \mathrm{~A} 1, \mathrm{~B} 0, \mathrm{~B} 1\}, D_{z}^{j}$, we must consider scenarios where each firm restricts redemption of its rewards. Three different scenarios are under study: both firms restrict redemption (Scenario S1); only Firm A restricts redemptions (Scenario S2); and both firms do not restrict redemption (Scenario S3). Consequently, Firm a restricts redemption in Scenario S1 and Scenario S2, while Firm $b$ restricts redemption in only S1.

Therefore, customer $j$ 's surplus of purchasing from Firm $a$ and not redeeming $\left(D_{A 0}^{j}\right)$ consists of the value of purchasing the product $\left(v_{a}^{j}\right)$ diminished by the price $\left(p_{a}\right)$ in addition to the 
value of any accumulated points, which depends on whether the firm restricts rewards (Scenario S1 and S2) or not (Scenario S3). It is given by:

$$
D_{A 0}^{j}=\left\{\begin{array}{lr}
v_{a}^{j}-p_{a} & \text { if } n_{a}^{j}=N_{a} \\
v_{a}^{j}-p_{a}+V\left(p_{a}, N_{a}-n_{a}^{j}\right) & \text { if } n_{a}^{j}<N_{a}, \text { in Scenario } S 1 \& S 2 \\
v_{a}^{j}-p_{a}+V\left(p_{a} / N_{a}, 1\right) & \text { if } n_{a}^{j}<N_{a}, \text { in Scenario } S 3
\end{array}\right.
$$

Customer $j$ 's surplus of purchasing from Firm $a$ and redeeming $\left(D_{A 1}^{j}\right)$ consists in the value of purchasing the product diminished by the price $\left(v_{a}^{j}-p_{a}\right)$ diminished by the value of the redeemed rewards, which depends on whether the firm restricts rewards (Scenario S1 and Scenario S2) or not (Scenario S3). If Firm $a$ 's customer has not completed the required number of purchases to receive a reward and has no points to redeem, He/she has no option of redemption. Therefore:

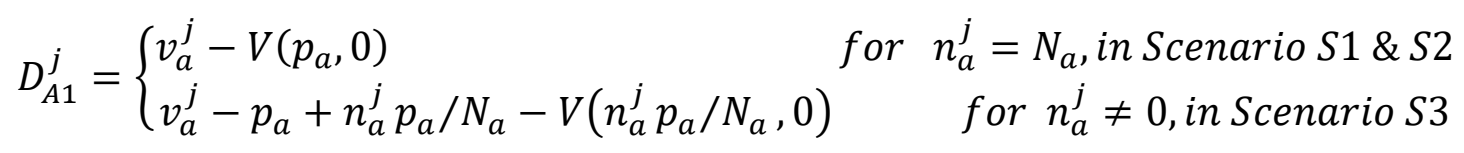

Similarly, $n_{b}^{j}$ denotes the number of customer $j$ 's purchases from Firm $b$ after the last redemption, $\left(p_{b} / N_{b}\right)$ is the reward earned by purchasing (without redemption) from Firm $b$ under an unrestricted redemption policy (in Scenario S2 and Scenario S3), and $N_{b}$ is the required number of purchases before earning a free product when Firm $b$ restricts redemption (in Scenario S1). Customer $j$ 's surplus when purchasing from Firm $b$ and not redeeming $\left(D_{B 0}^{j}\right)$ consists of the value of purchasing the product $\left(v_{b}^{j}\right)$ diminished by the price $\left(p_{b}\right)$ in addition to the value of any accumulated points, which depends on whether the firm restricts rewards (Scenario S1) or not (Scenario S2 and Scenario S3). It is given by:

$$
D_{B 0}^{j}=\left\{\begin{array}{lr}
v_{b}^{j}-p_{b} & \text { if } n_{b}^{j}=N_{b} \\
v_{b}^{j}-p_{b}+V\left(p_{b} / N_{b}, 1\right) & \text { if } n_{b}^{j}<N_{b}, \text { in Scenario S2 \& S3 } \\
v_{b}^{j}-p_{b}+V\left(p_{b}, N_{b}-n_{b}^{j}\right) & \text { if } n_{b}^{j}<N_{b}, \text { in Scenario S1 }
\end{array}\right.
$$


Finally, customers $j$ 's surplus when purchasing from Firm $b$ and redeeming $\left(D_{B 1}^{j}\right)$ consists of the value of purchasing the product diminished by the price $\left(v_{b}^{j}-p_{b}\right)$ diminished by the value of the redeemed points. The latter depends on whether the firm restricts rewards (Scenario S1) or not (Scenario S2 and Scenario S3). If Firm b's customer has not completed the required number of purchases to receive a reward and has no points to redeem, He/she has no option of redemption. This leads to the following formulation:

$D_{B 1}^{j}=\left\{\begin{array}{lr}v_{b}^{j}-p_{b}+n_{b}^{j} p_{b} / N_{b}-V\left(n_{b}^{j} p_{b} / N_{b}, 0\right) & \text { for } n_{b}^{j} \neq 0, \text { in Scenario S2 \& S3 } \\ v_{b}^{j}-V\left(p_{b}, 0\right) & \text { for } n_{b}^{j}=N_{b}, \text { in Scenario S1 }\end{array}\right.$

It is easy to show that a customer would receive a higher surplus from redeeming all his/her stockpiled points rather than a part of them. This can be proved based on Equation (4.4) since, for any $x>0, V(x, 0)$ is monotonously increasing in $x$. Therefore, a customer of a firm that does not restrict redemption chooses between redeeming all his/her points or none of them. Further, to simplify the analysis, and given that both firms sell similar products, we assume customers similarly evaluate products of Firm $a$ and $b$, which leads to equal valuations $\left(v_{b}^{j}=v_{a}^{j}\right.$ for any $\left.j\right)$.

\subsubsection{The Firms' demand functions}

Referring to Equations (4.1-4.4), the probability of choosing alternative $z$ by customer $j\left(q_{z}^{j}\right)$ is a function of the number of his/her previous purchases from Firm $a\left(n_{a}^{j}\right)$ and from Firm $b\left(n_{b}^{j}\right)$. Let $Q_{z}\left(n_{a}, n_{b}\right)$ be the probability of choosing alternative $z$ by any customer who has purchased $n_{a}$ and $n_{b}$ times from Firm $a$ and Firm $b$, respectively. In other words,

$Q_{z}\left(n_{a}, n_{b}\right)=q_{z}^{j}, \quad \forall z \in\{A 0, A 1, B 0, B 1\}, \forall z \mid n_{a}^{j}=n_{a}, n_{b}^{j}=n_{b}$

Therefore, the probability of a choice is equal for all customers who are characterized by $\left(n_{a}, n_{b}\right)$. Denoting $M\left(n_{a}, n_{b}\right)$ as the set of such customers at the stationary demand condition, 
where the number of customers does not change during the purchasing periods, one can derive the flow chart of two subsequent periods at the stationary demand condition. Figures 4.1 presents the flow chart under all scenarios. Based on this flow chart, where $\Pi\left(n_{a}, n_{b}\right)$ is the number of customers in the set of $M\left(n_{a}, n_{b}\right)$, one can derive $\left(N_{a}+1\right) *\left(N_{b}+1\right)$ independent equations for all values of $n_{a}$ and $n_{b}$. Solving these equations simultaneously, we are able to obtain $\Pi\left(n_{a}, n_{b}\right)$ for all values of $n_{a}$ and $n_{b}$.

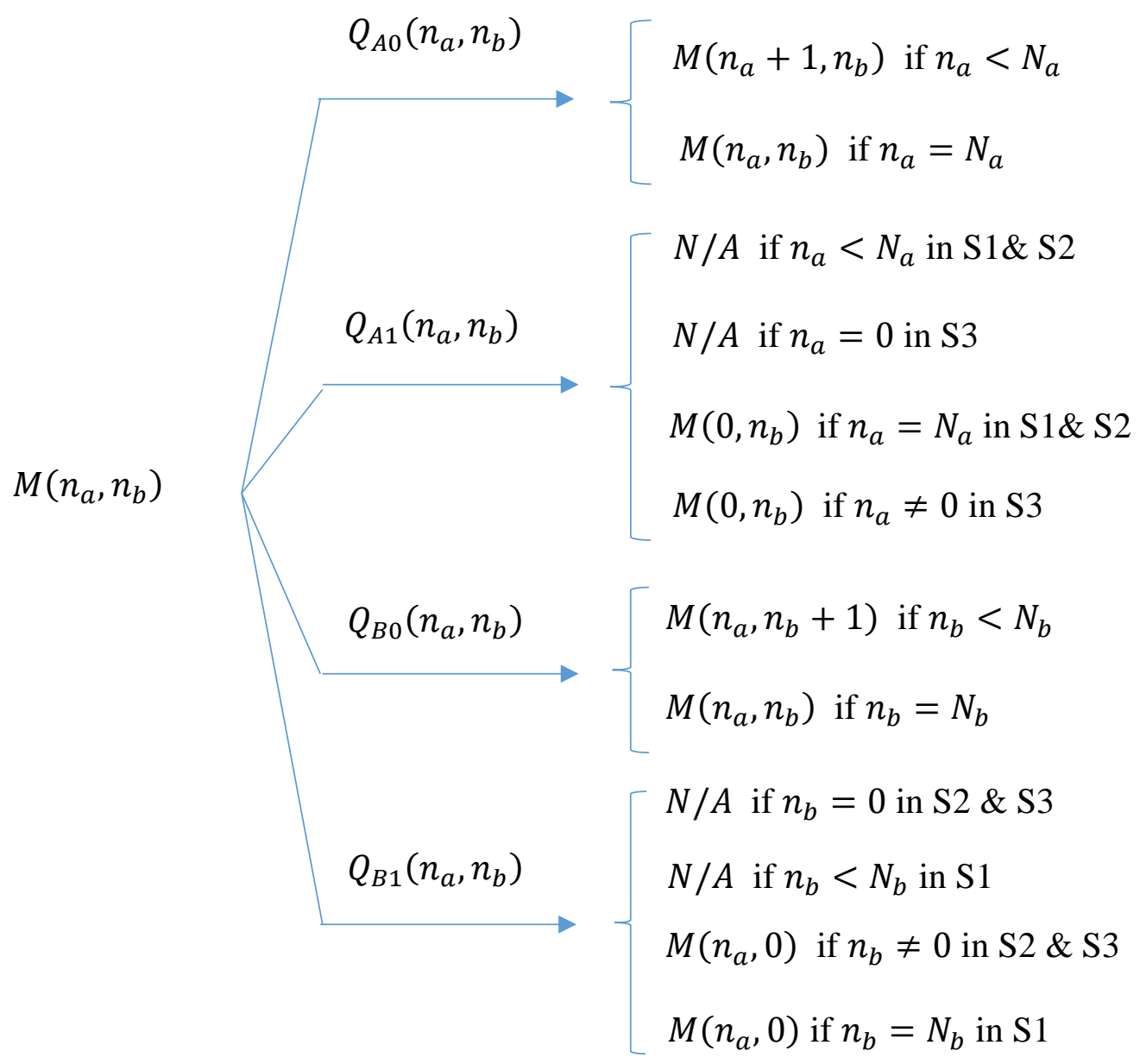

Figure 4.1: Flow chart between two subsequent purchasing periods in a market including restricted and unrestricted redemption policies 


\subsubsection{The Firms' profit functions}

Each firm's profit is given by its expected revenue from selling the product minus its expected cost of rewards redemption. Therefore, the expected profits of Firm $i \in\{a, b\}$ in scenario $S \in$ $(S 1, S 2, S 3)$ at the stationary demand is denoted by $\left(I_{i}^{S}\right)$, and given by:

$$
\begin{aligned}
& I_{a}^{S 1, S 2}=p_{a} \sum_{n_{a}=0}^{N_{a}} \sum_{n_{b}=0}^{N_{b}} \Pi\left(n_{a}, n_{b}\right) Q_{A 0}\left(n_{a}, n_{b}\right), \\
& I_{a}^{S 3}=p_{a} \sum_{n_{a}=0}^{N_{a}} \sum_{n_{b}=0}^{N_{b}} \Pi\left(n_{a}, n_{b}\right)\left(Q_{A 0}\left(n_{a}, n_{b}\right)+Q_{A 1}\left(n_{a}, n_{b}\right)\right)- \\
& \sum_{n_{a}=0}^{N_{a}} \sum_{n_{b}=0}^{N_{b}} \Pi\left(n_{a}, n_{b}\right) Q_{A 1}\left(n_{a}, n_{b}\right) n_{a} p_{a} / N_{a}, \\
& I_{b}^{S 2, S 3}=p_{b} \sum_{n_{a}=0}^{N_{a}} \sum_{n_{b}=0}^{N_{b}} \Pi\left(n_{a}, n_{b}\right)\left(Q_{B 0}\left(n_{a}, n_{b}\right)+Q_{B 1}\left(n_{a}, n_{b}\right)\right)- \\
& \sum_{n_{a}=0}^{N_{a}} \sum_{n_{b}=0}^{N_{b}} \Pi\left(n_{a}, n_{b}\right) Q_{B 1}\left(n_{a}, n_{b}\right) n_{b} p_{b} / N_{b}, \\
& I_{b}^{S 1}=p_{b} \sum_{n_{a}=0}^{N_{a}} \sum_{n_{b}=0}^{N_{b}} \Pi\left(n_{a}, n_{b}\right) Q_{B 0}\left(n_{a}, n_{b}\right) .
\end{aligned}
$$

\subsection{Solving the model}

Each scenario (S1, S2 and S3), Firms $a$ and $b$ play a stochastic Nash game, i.e., each firm sets its decision variables that maximize its profits and both firms make their decisions simultaneously without knowing each other's decisions. Comparison of the firms' profits in each scenario (subgame) will then lead to identifying the equilibrium solution for the game played by Firm $a$ and Firm $b$. In each scenario, each firm decides its price $\left(p_{i}\right)$ and reward variable $\left(N_{i}\right)$.

As can be derived from Equations (4.1-4.8), the firms' profits are functions of their decision variables $\left(N_{a}, p_{a}, N_{b}, p_{b}\right)$ and of the behavioural parameters $\left(\alpha_{v}, \alpha_{d}\right)$. In each scenario $S \in$ 
$(S 1, S 2, S 3)$, we obtain the firms' optimal decisions and profits by solving the two enclosed optimization problems simultaneously.
(I) $\left\{\begin{array}{l}\max _{N_{a}, p_{a}} I_{a}^{S} \\ \text { s.t } N_{a} \text { is an integer, } p_{a}>0 .\end{array}\right.$
(II) $\left\{\begin{array}{l}\max _{N_{b}, p_{b}} I_{b}^{S} \\ \text { s.t } N_{b} \text { is an integer, } p_{b}>0 .\end{array}\right.$

An analytical solution of these problems, if available, is difficult to derive because of the high nonlinearity of the profit functions (Equations (4.5-4.8)). Therefore, we use the iterative algorithm explained in Table 3.3 to find the optimal solutions. In each scenario, this algorithm numerically seeks the Nash equilibrium, where neither firm can increase its profit by unilaterally deviating to any other possible solution, and finds the closest condition to the equilibrium with an error of (0.001). Based on the scenarios, and as discussed above in Section 4.2, Firm $i$ 's optimal response might be a set of optimal required numbers to receive a reward and optimal price. In Table 3.3, Firm $i$ 's optimal response in iteration $r$, denoted by $O_{i}^{r}$, is $\left[N_{i}{ }^{r}, p_{i}{ }^{r}\right]$. Not converging in this algorithm is interpreted as either having more than one equilibrium or no equilibrium. It should also be noted that the initial strategy and the choice of firm from which we start the algorithm in Table 3.3 do not affect the results of the algorithm.

Next, we set the range of numerical values for the model's variables and parameters. In restricted LPs of the type "Buy $n$ times, get one free," the $n$ is usually limited to no more than 10 purchases (e.g., McDonald's, Starbucks and Second Cup loyalty cards). Therefore, we vary the positive integer variables $N_{i}$ between 1 and 10 if Firm $i$ restricts the redemption. In unrestricted LPs, customers of Firm $i$ receive a reward equal to $\left(p_{i} / N_{i}\right)$. We vary the positive integer variables $N_{i}$ between 1 and 100 if Firm $i$ does not restrict the redemption. Finally, we do not set a maximum limit for the pricing variables, i.e., for each combination of $\left(N_{a}, N_{b}, p_{b(a)}\right)$, an optimal positive 
price $\left(p_{a(b)}\right)$ is found which maximizes Firm $a(b)$ 's profit. Employing Matlab's fmincon function, we apply an interior-point algorithm based on Byrd et al. (2000) to reach the optimal price with the accuracy of 32 decimal digits.

In our framework, parameters $\alpha_{v}$ and $\alpha_{d}$ are bounded in the $(0,1)$ interval. We consider the range of [0.1,0.9] with a step size of 0.1 for parameter $\alpha_{v}$ and a smaller range of $[0.1,0.5]$ with the same step size for parameter $\alpha_{d}$. Note that $\alpha_{d}=0.5$ means that a reward loses half of its value after one single unit of time, a higher depreciation of the reward would not be a realistic assumption. This results in 45 different combinations of the behavioural parameters. Next, we solve for the optimal solutions in the three scenarios. Then, we identify the Nash equilibrium for the general game in which the firms decide whether or not to restrict the redemption policy.

\subsection{Results and discussion}

Applying the numerical method explained in the previous section, we obtain each firm's optimal decision variables and profits for all 45 combinations of $\alpha_{v}$ (reward valuation coefficient) and $\alpha_{d}$ (time valuation coefficient) in each scenario. This section presents the solutions obtained in each scenario (S1, S2, and S3), then compares these results.

\subsubsection{Scenario S1}

In S1, both firms restrict redemption. They decide on the required number of purchases a customer needs to make before being rewarded with a free product, as well as on the price of the product to maximize their profits when the market reaches a stationary demand condition. Using the algorithm explained in Table 3.3, we obtain a Nash equilibrium $\left(N_{i}\right.$ and $\left.p_{i}, i=a, b\right)$ for each combination of $\alpha_{v}$ and $\alpha_{d}$. As expected, the firms' optimal decision variables, and therefore 
optimal profits, are equal in Scenario S1. The firms' optimal decision variables $\left(N_{i}, p_{i}\right)$ and optimal profits in Scenario S1 are shown in Table 4.1 and Table 4.2, respectively, for different combinations of $\alpha_{v}$ and $\alpha_{d}$. All values of $N_{i}$ greater than 10 are indicated as 10 in Table 4.1.

Table 4.1: Firms' optimal decision variables in Scenario S1 of the game between restricted and unrestricted redemption policies for combinations of mental parameters

\begin{tabular}{c|cc|cc|cc|cc|cc}
\hline$\alpha_{d}$ & \multicolumn{2}{|c|}{0.1} & \multicolumn{2}{|c|}{0.2} & \multicolumn{2}{|c|}{0.3} & \multicolumn{2}{|c|}{0.4} & \multicolumn{2}{|c}{0.5} \\
\hline$\alpha_{v}$ & $N_{i}$ & $p_{i}$ & $N_{i}$ & $p_{i}$ & $N_{i}$ & $p_{i}$ & $N_{i}$ & $p_{i}$ & $N_{i}$ & $p_{i}$ \\
\hline 0.1 & 10 & 2.127 & 10 & 2.083 & 10 & 2.059 & 10 & 2.044 & 10 & 2.035 \\
0.2 & 9 & 2.287 & 7 & 2.219 & 8 & 2.146 & 10 & 2.090 & 10 & 2.071 \\
0.3 & 6 & 2.547 & 5 & 2.419 & 5 & 2.319 & 5 & 2.253 & 5 & 2.207 \\
0.4 & 5 & 2.847 & 4 & 2.661 & 4 & 2.509 & 4 & 2.407 & 4 & 2.336 \\
0.5 & 5 & 3.140 & 4 & 2.865 & 3 & 2.765 & 3 & 2.624 & 3 & 2.522 \\
0.6 & 5 & 3.399 & 4 & 3.043 & 3 & 2.905 & 3 & 2.737 & 3 & 2.616 \\
0.7 & 5 & 3.483 & 4 & 3.125 & 3 & 2.959 & 3 & 2.796 & 3 & 2.672 \\
0.8 & 6 & 3.368 & 4 & 3.063 & 4 & 2.864 & 3 & 2.776 & 3 & 2.672 \\
0.9 & 7 & 3.184 & 5 & 2.928 & 4 & 2.781 & 3 & 2.683 & 3 & 2.615 \\
\hline
\end{tabular}

As can be seen in Table 4.1, apart from the very low customers' reward valuation (parameter $\alpha_{v}$ ), the optimal number of required purchases to receive a reward increases for lower customers' time valuation (parameter $\alpha_{d}$ ). This table also reveals that when customers do not highly evaluate time (low values of $\alpha_{d}$ ), there is a trade-off area for $\alpha_{v}$ under which the required number of purchases for rewarding is at the minimum. On the other hand, when customers highly value time, the required number of purchases for rewarding increases for higher values of customers' reward valuation (parameter $\alpha_{v}$ ).

Table 4.1 shows that the optimal price also increases for higher customers' time valuation. In other words, the firms should offer a higher price and an earlier reward when their customers 
highly value time. Furthermore, we observe that for each $\alpha_{d}$, there is a trade-off $\alpha_{v}$ under which the optimal price reaches its maximum level.

Table 4.2: Firms' optimal profit in Scenario S1 of the game between restricted and unrestricted redemption policies for combinations of mental parameters

\begin{tabular}{c|ccccc}
\hline$\alpha_{d}$ & 0.1 & 0.2 & 0.3 & 0.4 & 0.5 \\
\hline$\alpha_{v}$ & & & & & \\
\hline 0.1 & 0.968 & 0.948 & 0.937 & 0.931 & 0.926 \\
0.2 & 1.031 & 0.974 & 0.956 & 0.952 & 0.943 \\
0.3 & 1.096 & 1.014 & 0.972 & 0.945 & 0.926 \\
0.4 & 1.193 & 1.075 & 1.014 & 0.974 & 0.945 \\
0.5 & 1.317 & 1.159 & 1.057 & 1.005 & 0.966 \\
0.6 & 1.428 & 1.234 & 1.116 & 1.053 & 1.007 \\
0.7 & 1.468 & 1.273 & 1.144 & 1.083 & 1.036 \\
0.8 & 1.460 & 1.255 & 1.175 & 1.084 & 1.045 \\
0.9 & 1.410 & 1.247 & 1.149 & 1.060 & 1.033 \\
\hline
\end{tabular}

Table 4.2 addresses the firms' optimal profits in Scenario S1, where firms follow the optimal decision variables in Table 4.1. Table 4.2 shows a similar pattern for optimal profits as optimal prices in terms of parameters $\alpha_{d}$ and $\alpha_{v}$, so that optimal profits increase for lower customers' time valuation (parameter $\alpha_{d}$ ), and for each $\alpha_{d}$, there is a threshold value $\alpha_{v}$ below which the optimal profit reaches its maximum value.

\subsubsection{Scenario S2}

In Scenario S2, each Firm $i \in\{a, b\}$ chooses its decision variables $\left(N_{i}, p_{i}\right)$; however, only Firm $a$ restricts redemption. This means Firm $a$ 's customers can redeem their rewards of $\left(p_{i}\right)$ after $\left(N_{a}\right)$ purchases, while Firm $b$ 's customers are given $\left(p_{b} / N_{b}\right)$ rewards for each purchase, which can be stockpiled and redeemed in each period. Using the numerical algorithm presented in Table 3.3, we 
get the Nash equilibrium for the game between Firm $a$ and $b$, where the optimal decision of each firm is the best response to the other firm's strategy. Tables 4.3 and 4.4 show Firm $a$ 's optimal decision variables $\left(N_{a}, p_{a}\right)$ and optimal profits, respectively, in Scenario S2 for different combinations of $\alpha_{v}$ and $\alpha_{d}$. In Table 4.3, similar to previous chapter, all values of $N_{a}$ greater than 10 are indicated as 10.

Table 4.3: Firm $a$ 's optimal decision variables in Scenario $\mathrm{S} 2$ of the game between restricted and unrestricted redemption policies for combinations of mental parameters

\begin{tabular}{c|cc|cc|cc|cc|cc}
\hline$\alpha_{d}$ & \multicolumn{2}{|c|}{0.1} & \multicolumn{2}{|c|}{0.2} & \multicolumn{2}{|c|}{0.3} & \multicolumn{2}{|c|}{0.4} & \multicolumn{2}{|c}{0.5} \\
\hline$\alpha_{v}$ & $N_{a}$ & $p_{a}$ & $N_{a}$ & $p_{a}$ & $N_{a}$ & $p_{a}$ & $N_{a}$ & $p_{a}$ & $N_{a}$ & $p_{a}$ \\
\hline 0.1 & 10 & 2.022 & 10 & 1.980 & 10 & 1.958 & 10 & 1.944 & 10 & 1.935 \\
0.2 & 8 & 2.195 & 7 & 2.123 & 8 & 2.049 & 9 & 2.002 & 10 & 1.972 \\
0.3 & 6 & 2.437 & 5 & 2.327 & 5 & 2.233 & 5 & 2.171 & 5 & 2.128 \\
0.4 & 5 & 2.726 & 4 & 2.567 & 4 & 2.425 & 4 & 2.331 & 4 & 2.264 \\
0.5 & 5 & 2.998 & 4 & 2.759 & 3 & 2.686 & 3 & 2.554 & 3 & 2.459 \\
0.6 & 5 & 3.252 & 4 & 2.932 & 3 & 2.822 & 3 & 2.665 & 3 & 2.550 \\
0.7 & 5 & 3.380 & 4 & 3.034 & 3 & 2.891 & 3 & 2.732 & 3 & 2.611 \\
0.8 & 6 & 3.320 & 4 & 3.019 & 4 & 2.803 & 3 & 2.734 & 3 & 2.625 \\
0.9 & 7 & 3.186 & 5 & 2.908 & 4 & 2.756 & 3 & 2.671 & 3 & 2.589 \\
\hline
\end{tabular}

Table 4.3 shows almost similar patterns for the optimal decision variables of the firm that restricts redemption in Scenario S2 as those in Scenario S1. Firm a's optimal number of required purchases to receive a reward decreases with $\alpha_{d}$ for high enough values of the reward valuation parameter $\left(\alpha_{v}\right)$. Furthermore, when customers do not highly value time (low values of parameter $\alpha_{d}$ ), there is a trade-off area for $\alpha_{v}$ under which the required number of purchases for rewarding is at minimum and optimal price is at maximum. 
Table 4.4: Firm $a$ 's optimal profits in Scenario S2 of the game between restricted and unrestricted redemption policies for combinations of mental parameters

\begin{tabular}{c|ccccc}
\hline$\alpha_{d}$ & 0.1 & 0.2 & 0.3 & 0.4 & 0.5 \\
$\alpha_{v}$ & & & & & \\
\hline 0.1 & 0.873 & 0.855 & 0.845 & 0.840 & 0.836 \\
0.2 & 0.930 & 0.889 & 0.869 & 0.858 & 0.852 \\
0.3 & 1.001 & 0.937 & 0.900 & 0.876 & 0.859 \\
0.4 & 1.092 & 0.999 & 0.947 & 0.912 & 0.887 \\
0.5 & 1.200 & 1.074 & 0.998 & 0.952 & 0.919 \\
0.6 & 1.306 & 1.145 & 1.053 & 0.998 & 0.957 \\
0.7 & 1.378 & 1.198 & 1.092 & 1.033 & 0.988 \\
0.8 & 1.415 & 1.217 & 1.123 & 1.051 & 1.007 \\
0.9 & 1.412 & 1.228 & 1.127 & 1.050 & 1.013 \\
\hline
\end{tabular}

Based on Table 4.4, Firm $a$ 's optimal profit shows an increasing trend for higher customers' reward valuations (higher $\alpha_{v}$ ) and lower customers' time valuations (lower $\alpha_{d}$ ).

In Scenario S2, Firm $b$ offers the fraction $\left(1 / N_{b}\right)$ of the price as reward for each purchase. This fraction can be presented as reward percentage (i.e., $R(\%)=1 / N_{b}$ ). Tables 4.5 and 4.6 concern Firm b's optimal decision variables (reward percentage, price) and optimal profits, respectively, in Scenario S2, and for different combinations of $\alpha_{v}$ and $\alpha_{d}$. Since the maximum value of $N_{b}$ is assumed to be 100 , the minimum reward percentage is $1 \%$. All values less than this amount are indicated as $1 \%$ in Table 4.5 .

Tables 4.5 and 4.6 reveal that, apart from the condition of serving customers who value time very low, Firm $b$ 's optimal price and profit increase for higher customers' reward valuations. Table 4.5 also shows an optimal value equal to the minimum amount (1\%) for Firm $b$ 's reward percentage for most conditions. This means that we cannot be sure of the real optimal value of this 
variable in these conditions since it could be any number less than $1 \%$ that our numerical method does not catch.

Table 4.5: Firm $b$ 's optimal decision variables in Scenario $\mathrm{S} 2$ of the game between restricted and unrestricted redemption policies for combinations of mental parameters

\begin{tabular}{c|cc|cc|cc|cc|cc}
\hline$\alpha_{d}$ & \multicolumn{2}{|c|}{0.1} & \multicolumn{2}{|c|}{0.2} & \multicolumn{2}{|c|}{0.3} & \multicolumn{2}{|c|}{0.4} & \multicolumn{2}{|c}{0.5} \\
\hline$\alpha_{v}$ & $R(\%)$ & $p_{b}$ & $R(\%)$ & $p_{b}$ & $R(\%)$ & $p_{b}$ & $R(\%)$ & $p_{b}$ & $R(\%)$ & $p_{b}$ \\
\hline 0.1 & $1 \%$ & 2.117 & $1 \%$ & 2.116 & $1 \%$ & 2.116 & $1 \%$ & 2.115 & $1 \%$ & 2.115 \\
0.2 & $1 \%$ & 2.112 & $1 \%$ & 2.105 & $1 \%$ & 2.109 & $1 \%$ & 2.113 & $1 \%$ & 2.116 \\
0.3 & $1 \%$ & 2.105 & $1 \%$ & 2.092 & $1 \%$ & 2.090 & $1 \%$ & 2.088 & $1 \%$ & 2.087 \\
0.4 & $1 \%$ & 2.103 & $1 \%$ & 2.086 & $1 \%$ & 2.081 & $1 \%$ & 2.078 & $1 \%$ & 2.076 \\
0.5 & $1 \%$ & 2.108 & $1 \%$ & 2.090 & $1 \%$ & 2.070 & $1 \%$ & 2.065 & $1 \%$ & 2.062 \\
0.6 & $1 \%$ & 2.105 & $1 \%$ & 2.089 & $1 \%$ & 2.071 & $1 \%$ & 2.066 & $1 \%$ & 2.063 \\
0.7 & $1 \%$ & 2.080 & $1 \%$ & 2.076 & $1 \%$ & 2.060 & $1 \%$ & 2.060 & $1 \%$ & 2.059 \\
0.8 & $4 \%$ & 2.095 & $1 \%$ & 2.046 & $1 \%$ & 2.060 & $1 \%$ & 2.045 & $1 \%$ & 2.049 \\
0.9 & $20 \%$ & 2.304 & $1 \%$ & 2.030 & $1 \%$ & 2.034 & $1 \%$ & 2.021 & $1 \%$ & 2.032 \\
\hline
\end{tabular}

Table 4.6: Firm $b$ 's optimal profits in Scenario S2 of the game between restricted and unrestricted redemption policies for combinations of mental parameters

\begin{tabular}{c|ccccc}
\hline$\alpha_{d}$ & 0.1 & 0.2 & 0.3 & 0.4 & 0.5 \\
\hline 0.1 & 1.106 & 1.105 & 1.105 & 1.105 & 1.104 \\
0.2 & 1.100 & 1.093 & 1.098 & 1.101 & 1.105 \\
0.3 & 1.093 & 1.081 & 1.078 & 1.077 & 1.076 \\
0.4 & 1.091 & 1.074 & 1.070 & 1.067 & 1.065 \\
0.5 & 1.095 & 1.078 & 1.058 & 1.054 & 1.050 \\
0.6 & 1.092 & 1.077 & 1.058 & 1.054 & 1.051 \\
0.7 & 1.067 & 1.063 & 1.047 & 1.048 & 1.047 \\
0.8 & 1.034 & 1.033 & 1.047 & 1.032 & 1.037 \\
0.9 & 0.997 & 1.016 & 1.021 & 1.009 & 1.020 \\
\hline
\end{tabular}


Table 4.7 compares the profits shown in tables 4.4 and 4.6. Even considering the mentioned uncertainty about the optimal reward percentage, one can say that in the hatched area of Table 4.7, the firm that does not restrict redemption gains higher profits than the firm that restricts redemption. As for the other areas, one can say that the restricted redemption policy is more profitable than the unrestricted one if the percentage rewarded is equal or greater than $1 \%$ of the price.

Table 4.7: Comparison of firms' profits in Scenario S2 of the game between restricted and unrestricted redemption policies for combinations of mental parameters

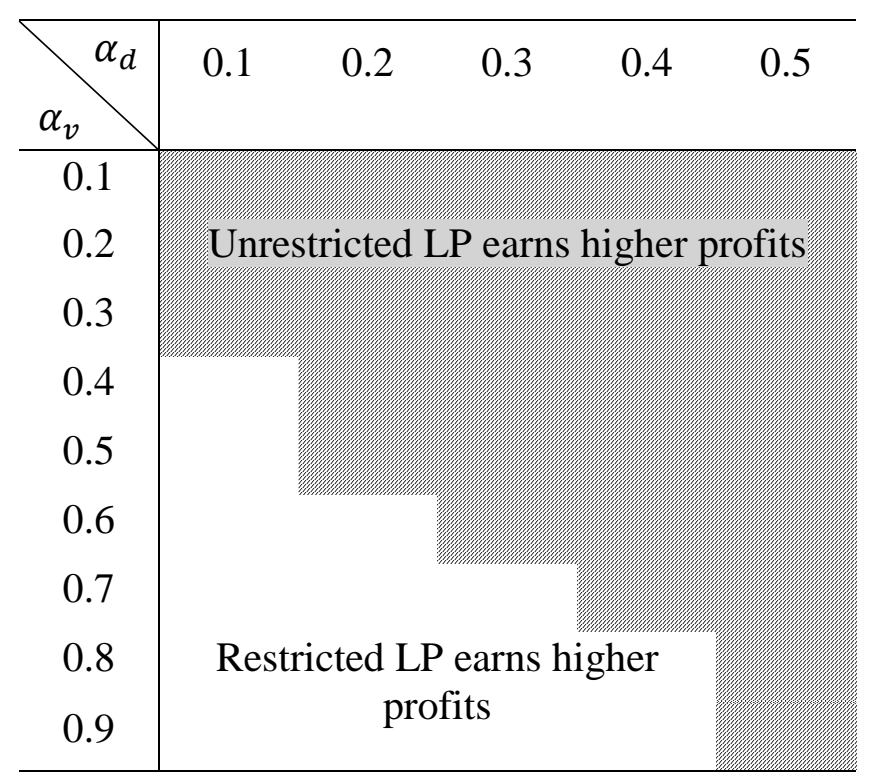

\subsubsection{Scenario S3}

In Scenario S3, neither firm restricts redemption, and both decide about price and reward. Since Scenario S3 is a symmetric condition, the optimal decision variables are equal for both firms, as expected.

Tables 4.8 and 4.9 show the optimal decision variables, including the reward percentage $\left(R(\%)=1 / N_{i}\right)$ and price, and optimal profits, respectively, under Scenario S3, for different 
combinations of $\alpha_{v}$ and $\alpha_{d}$. In table 4.8, similar to Table 4.5, the values of reward percentage less than 0.01 are indicated as 0.01 .

Table 4.8: Firms' optimal decision variables in Scenario S3 of the game between restricted and unrestricted redemption policies for combinations of mental parameters

\begin{tabular}{c|cc|cc|cc|cc|cc}
\hline$\alpha_{d}$ & \multicolumn{2}{|c|}{0.1} & \multicolumn{2}{|c|}{0.2} & \multicolumn{2}{|c|}{0.3} & \multicolumn{2}{|c|}{0.4} & \multicolumn{2}{c}{0.5} \\
\hline$\alpha_{v}$ & $R(\%)$ & $p_{i}$ & $R(\%)$ & $p_{i}$ & $R(\%)$ & $p_{i}$ & $R(\%)$ & $p_{i}$ & $R(\%)$ & $p_{i}$ \\
\hline 0.1 & $1 \%$ & 2.006 & $1 \%$ & 2.006 & $1 \%$ & 2.006 & $1 \%$ & 2.006 & $1 \%$ & 2.006 \\
0.2 & $1 \%$ & 2.007 & $1 \%$ & 2.007 & $1 \%$ & 2.007 & $1 \%$ & 2.006 & $1 \%$ & 2.006 \\
0.3 & $1 \%$ & 2.008 & $1 \%$ & 2.008 & $1 \%$ & 2.007 & $1 \%$ & 2.007 & $1 \%$ & 2.007 \\
0.4 & $1 \%$ & 2.009 & $1 \%$ & 2.008 & $1 \%$ & 2.008 & $1 \%$ & 2.008 & $1 \%$ & 2.007 \\
0.5 & $1 \%$ & 2.010 & $1 \%$ & 2.009 & $1 \%$ & 2.009 & $1 \%$ & 2.008 & $1 \%$ & 2.008 \\
0.6 & $1 \%$ & 2.011 & $1 \%$ & 2.010 & $1 \%$ & 2.009 & $1 \%$ & 2.009 & $1 \%$ & 2.008 \\
0.7 & $1 \%$ & 2.011 & $1 \%$ & 2.011 & $1 \%$ & 2.010 & $1 \%$ & 2.009 & $1 \%$ & 2.009 \\
0.8 & $5 \%$ & 2.062 & $1 \%$ & 2.011 & $1 \%$ & 2.010 & $1 \%$ & 2.010 & $1 \%$ & 2.009 \\
0.9 & $20 \%$ & 2.304 & $1 \%$ & 2.012 & $1 \%$ & 2.011 & $1 \%$ & 2.010 & $1 \%$ & 2.010 \\
\hline
\end{tabular}

Table 4.9: Firms' optimal profits in Scenario S3 of the game between restricted and unrestricted redemption policies for combinations of mental parameters

\begin{tabular}{c|ccccc}
\hline$\alpha_{d}$ & 0.1 & 0.2 & 0.3 & 0.4 & 0.5 \\
\hline$\alpha_{v}$ & & & & & \\
\hline 0.1 & 0.996 & 0.996 & 0.996 & 0.996 & 0.996 \\
0.2 & 0.997 & 0.997 & 0.997 & 0.997 & 0.996 \\
0.3 & 0.997 & 0.997 & 0.997 & 0.997 & 0.997 \\
0.4 & 0.998 & 0.997 & 0.997 & 0.997 & 0.997 \\
0.5 & 0.998 & 0.998 & 0.998 & 0.997 & 0.997 \\
0.6 & 0.999 & 0.998 & 0.998 & 0.998 & 0.997 \\
0.7 & 0.999 & 0.999 & 0.998 & 0.998 & 0.998 \\
0.8 & 0.999 & 0.999 & 0.999 & 0.998 & 0.998 \\
0.9 & 0.997 & 0.999 & 0.999 & 0.998 & 0.998 \\
\hline
\end{tabular}


As one can see in tables 4.8 and 4.9, the firms in Scenario S3 should increase their prices for lower customers' time valuations and higher customers' reward valuations. This trend is observed for the firms' optimal profit, except when customers very highly value reward but not time. This is the only condition under which both firms should offer a high reward percentage.

\subsubsection{Main game}

To find the optimal strategy for each firm given different LP choices by its competitor, we now compare the solutions obtained under the three scenarios S1, S2, and S3. We start by comparing the optimal prices and find that optimal prices in Scenario S3 are lower than those of Firm $b$ in Scenario S2. This means that a firm that does not restrict redemption should offer a higher price if its competitor restricts redemption in comparison with the condition where its competitor does not restrict redemption. A similar comparison between optimal prices in Scenario S1 and those of Firm $a$ in Scenario $\mathrm{S} 2$ shows that a firm that applies a restricted redemption policy should offer a higher price if its competitor also applies a restricted redemption policy.

Knowing the firms' profits in each of the scenarios, we can also solve the general game in which two firms $(a, b)$ decide about setting or not setting an expiry date. For each firm, considering two strategies of restricting redemption and restricting for each firm, the firms' payoff matrix for this game for each combination of $\alpha_{v}$ and $\alpha_{d}$ can be derived as follows.

\begin{tabular}{l|ll}
\hline Firm $a$ & Restricting & Unrestricting \\
\hline Restricting & $\left(I_{a}^{S 1}, I_{b}^{S 1}\right)$ & $\left(I_{a}^{S 2}, I_{b}^{S 2}\right)$ \\
Unrestricting & $\left(I_{b}^{S 2}, I_{a}^{S 2}\right)$ & $\left(I_{a}^{S 3}, I_{b}^{S 3}\right)$ \\
\hline
\end{tabular}


Comparing the obtained profits in scenarios S1, S2 and S3 (tables 4.2, 4.4, 4.6 and 4.9), for each of the 45 combinations of parameters $\alpha_{v}$ and $\alpha_{d}$, one can categorize the results in three different regions as shown in Table 4.10 (see Table B.3 in Appendix B for a scaled version of Table 4.10). In the dark shaded area of this table, characterized by low customers' reward valuation $\left(\alpha_{v}\right)$ and high customers' time valuation $\left(\alpha_{d}\right)$, not restricting redemption is the dominant Nash equilibrium. In this region, both firms are better off not restricting redemption, meaning that customers are allowed to redeem their earned rewards at the next purchasing occasion. Although the price (and therefore the revenue) at equilibrium is higher in Scenario S1 than in S3, both firms earn a higher profit in S3. This is due to two reasons. First, each firm earns a higher profit with an unrestricted reward policy in the asymmetric game. Second, both firms earn higher profits when they both do not restrict redemption than when they both do (i.e., in Scenario S1). Comparisons of optimal strategies across scenarios S1 and S3 show that although firms charge higher prices in S3 than in S1, they also pay lower rewards to consumers. Overall, the lower cost of rewards results in higher profits in S3 than in S1.

The second region of interest in Table 4.10 is shown in the light shaded area. In this region, firms face a prisoner dilemma, which ends up not restricting the redemption by both firms at the equilibrium. This is despite the fact that both firms would earn higher profits when they both restrict redemption. The Prisoner dilemma situation arises because each firm earns a higher profit by unilaterally restricting redemption while the competitor does not. In this region of the parameters, the Nash equilibrium in S3 generates lower revenue and reward costs than in S1 with a restricted redemption by both firms, leading to overall lower profits than in S1.

Finally, in the unshaded area in Table 4.10 , restricting redemption by both firms is the dominant Nash equilibrium of the game. In this area, the optimal profit in Scenario S1 is higher 
than in S3, mainly because they both earn higher revenue levels in S1 and the gains in revenue exceed the additional incurred cost of rewards for both firms. Further, in the asymmetric games, each firm can increase its profit by restricting redemption while the competitor does not.

Table 4.10: Different regions of the game between restricted and unrestricted policies for combinations of mental parameters

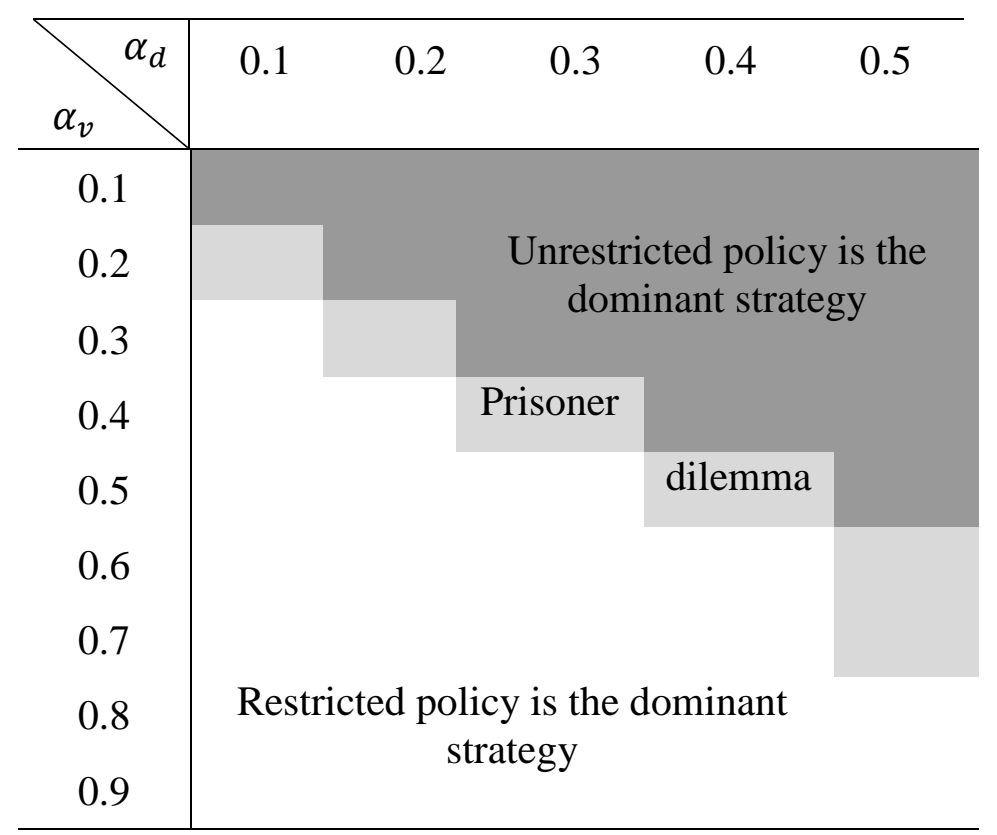

\subsection{Conclusion}

This chapter investigated whether it is profitable for competing firms to restrict redemption of their loyalty rewards. Restricted redemption was studied in the form of the "Buy $n$ times, get one free" form of loyalty program (LP). This kind of LP is commonly used in industries characterized by uniform pricing (e.g., coffee shops), where LPs can increase the possibility of repeat customer purchases (Henderson et al., 2011; Kumar \& Shah, 2004; Nunes \& Dréze, 2006). The motivation for this research is the lack of clear guidance in the literature about the impact of such restrictions, and the observation in practice of different restricted and unrestricted LP programs. 
A game theoretic approach was applied to explain why and when releasing constraints of redemption can be beneficial to competing firms given different customers' mentalities about time and reward valuations. To the best of our knowledge, this is the first attempt to study the strategic impact of restricting or not restricting the redemption policies of loyalty programs in a competitive environment. To address this new research problem, we developed and solved a game theoretic model of a market served by two firms.

Using a numerical analysis, we obtain Nash equilibrium solutions for three scenarios (games): two symmetric games, (1) where both firms restrict redemption, and (2) where neither firm restricts redemption; and (3) one asymmetric game where only one firm restricts redemption. In each of these three games, the firm that restricts redemption determines its price and the required number of purchases to receive a free product as reward. The firm that applies the unrestricted redemption policy determines the reward as a percentage of its price. Comparing optimal profits across scenarios, an equilibrium solution is found for the main game in which each firm decides whether or not to restrict redemption, given the competitor's reaction.

Our main findings indicate that each firm's optimal strategies are significantly affected by whether the competitor decides to restrict or not to restrict redemption. For example, a firm that restricts reward redemption should offer a higher price if its competitor also restricts redemption.

Further, the dominant strategy of the game depends on customers' valuations of time and rewards. In particular, both firms should not restrict their reward redemption, i.e., should allow their customers to redeem their earned rewards at the next purchasing occasion when customers do not highly value rewards and are willing to wait to redeem their earned rewards (i.e., have low time valuation). Under such conditions, the competing firms gain a lower revenue but pay lower 
rewards to consumers with unrestricted reward policy than with a restricted one, which ultimately results in higher profits when reward redemption restrictions are lifted.

We also find that unrestricted redemption is still the Nash equilibrium when customer valuation of time and rewards are slightly higher. However, in this case, the competing firms face a Prisoner dilemma situation with each firm earning a higher profit by restricting redemption while the competitor does not. This is because when both firms restrict redemption, they earn lower revenue levels and incur lower reward costs than when they both restrict redemption, leading to overall lower profits. Finally, when customers highly value both reward and time, both firms should restrict redemption at equilibrium, mainly because they both earn higher revenue levels and the gains in revenue exceed the additional incurred cost of rewards. 


\section{Profitability of reward expiration in loyalty programs}

\section{$5.1 \quad$ Introduction}

As discussed earlier, loyalty programs can differ with regards to the structure, quantity and type of reward offered, and to the restrictions set by the firm on the time of reward redemption. The literature offers several insights into consumer reactions to reward types (Jones et al., 2006; Noble et al., 2014; Pauler \& Dick, 2006), linear versus non-linear rewarding structures (Wagner et al., 2009), and into the effects of varying reward offers (Pauler \& Dick, 2006). However, the effectiveness of the restrictions set by the firm on the time of reward redemption has thus far received minimal research attention, especially with regards to the effects of reward expiry (Breugelmans et al., 2015; Noble et al., 2014; Bijmolt et al., 2012). Redemption can be restricted by setting a starting time of redemption and/or setting a finishing time of redemption (expiry date). The previous chapter investigated the impact of restricting the starting time of redemption. In this chapter, we turn to the profitability of adding an expiry as another restriction on LPs.

In practice, we can observe in different industries that some firms choose to set an expiry date on their rewards while others do not. For example, in the airline industry, JetBlue has recently changed its loyalty program so that travelers' points do not expire, matching the policy of its main competitor Delta (Yahoo news, 2013). Other airlines, such as United, Alaska Airlines and Air France have maintained the expiry of their rewards. We observe the same differences for fuel retailers. For instance, in the US, points earned through the BP Driver reward card program expire after one year and Shell Fuel rewards expire after one month, while Esso points do not expire. It is unclear how competing firms decide whether to incorporate reward expiry into their loyalty 
programs and whether such decisions are based on analytical insight or on industry practice. Changing reward policies and expiry rules are more common in the food and entertainment industries since in these businesses firms do not often change their price, and consequently LPs are considered a powerful managerial tools. For example, Starbucks has recently made changes to reward timing and its expiration policies, while other companies such as McDonald's do not apply expiry on their rewards.

The management science and operation research literature contains a few analytical studies that investigate the implications of loyalty programs on firms' revenues (e.g., Gandomi \& Zolfaghari, 2011 and 2013; Chun et al., 2015; Caminal \& Matutes, 1990; Klemperer, 1995; Kim et al., 2001; Singh et al., 2008). In each of these studies, the authors ignore the possibility of imposing reward expiry.

The purpose of this chapter is to provide a better understanding of the implications of reward expiry. Specifically, we investigate how setting a reward expiry can affect competing firms' profits and revenues as well as consumers' redemptions. Such an analysis will provide managers with insight into whether reward expiry can be profitable and, if so, under which conditions. As in the previous chapters, this chapter focuses on the case of firms offering constant prices during the periods of purchasing.

To address this research problem, we develop a game-theoretic model representing a market served by two competing firms. We solve three games. In two of these games (games 1 and 3), both firms choose the same reward redemption policy (both either setting or not setting reward expiry), but in the second game, the firms' policies are asymmetric (one chooses reward expiry and the other does not). Comparison of equilibrium outputs across games provides insights 
into the effects of setting reward expiry on the firms' revenues and profits and on consumers' redemptions.

The remainder of this chapter is arranged as follows: Section 5.2 presents the model, Section 5.3 explains the method used to solve the three games, Section 5.4 presents and discusses results, Section 5.5 develops an extended model, and Section 5.6 summarizes and concludes.

\subsection{Model}

\subsubsection{Assumptions and definitions}

We consider that the market is served by two competing firms named $a$ and $b$ that are assumed to be rational decision makers, to have complete information about the market, and to make their decisions simultaneously. Both firms offer loyalty programs such that consumers are eligible to receive a free product after a certain number of purchases.

We assume that the competing firms offer undifferentiated products with a constant price during the purchasing periods in order to focus on mature industries characterized by dominant firms with similar market shares. Firms in such environments use marketing strategies aimed at increasing customers' loyalty and are therefore concerned about issues related to the effective design of their loyalty programs. Finally, following the model presented in the previous chapters, the market size is normalized to 1 unit and kept constant in order to exclude the impact of market expansion.

The firms' decision variables are represented by the price, the loyalty reward offered by each firm, and the reward expiry period. The price offered by Firm $i \in\{a, b\}$ is denoted by $p_{i}$. Both firms are assumed to set an LP by offering a free product after a certain number of purchases (denoted by $N_{i}$ for Firm $i$ ). This is a common LP used by coffee shop chains such as Starbucks 
and Second Cup, and retailers such as 7-Eleven. Each firm can set an expiration on its customers' earned rewards by restricting the number of purchasing periods in which those rewards can be redeemed (denoted by $T_{i}$ for Firm $i$ ) to avoid expiry.

Both symmetric and asymmetric expiry conditions are considered in this paper by studying three different scenarios (games). In the first scenario (S1), neither firm sets an expiration on their LPs $\left(T_{a}=T_{b}=\infty\right)$. In the second scenario (S2), only one firm sets an expiry date $\left(T_{a}\right.$ or $\left.T_{b}=\infty\right)$. In the third scenario (S3), both firms set an expiry date $\left(T_{a}, T_{b} \neq \infty\right)$. Consequently, each firm has two decision variables (price, time of reward) in Scenario S1; one firm has two decision variables (price, time of reward) and the other has three (price, time of reward, expiry length) in Scenario S2; and each firm has three decision variables (price, time of reward, expiry length) in Scenario S3. Assuming Firm $b$ is the firm that sets expiry in the asymmetric scenario, the firms' decision variables are shown in Table 5.1.

Following Singh et al. (2008) and Gandomi \& Zolfaghari (2013), it is assumed that customers buy one unit of the product in each period of purchasing from either Firm $a$ or Firm $b$. Also following these and other studies (e.g., Caminal \& Matutes, 1990; Kim et al., 2001), we assume that the customers purchase in each period. In other words, it is assumed that customers' valuation for the product is sufficiently high that it exceeds the product price, and that customers select the firm from which they purchase and decide either to redeem or not to redeem their rewards (if they have any). In our model, customers are allowed to switch between firms in all periods of purchasing, meaning that a customer with a history of purchasing from one firm can purchase from the other. 
Table 5.1: Scenario definitions and firms' decision variables for the reward expiry problem

\begin{tabular}{cccc}
\hline Scenario & Definition & $\begin{array}{c}\text { Firm } a \text { 's decision } \\
\text { variables }\end{array}$ & $\begin{array}{c}\text { Firm } b \text { 's decision } \\
\text { variables }\end{array}$ \\
\hline S1 & Neither firm sets expiry & $N_{a}$ and $p_{a}$ & $N_{b}$ and $p_{b}$ \\
S2 & One firm sets expiry & $N_{a}$ and $p_{a}$ & $N_{b}, p_{b}$ and $T_{b}$ \\
S3 & Both firms set expiry & $N_{a}, p_{a}$ and $T_{a}$ & $N_{b}, p_{b}$ and $T_{b}$ \\
& & & \\
\hline
\end{tabular}

\subsubsection{The rewards value function}

As mentioned in Section 3.2.3, under the psychological theory of mental accounting (Thaler, 1985), customers value cash and rewards differently. We apply a reward valuation parameter $\alpha_{v}$ to model this mentality so that $x$ value of reward are evaluated as $\alpha_{v} x$, where $\alpha_{v}$ varies in the range of $(0,1)$.

Furthermore, following common practice in the literature (e.g., Besanko \& Winston, 1990) and to model the aspect of timing on the customers' utility, it is assumed that customers evaluate $x$ value of an asset as $x /\left(1+\alpha_{d}\right)^{t}$ after $t$ periods, where $\alpha_{d}$ is the interest rate for one period, and is therefore between 0 and 1.

Based on the above definitions, consumers' valuation of $x$ units of reward that can be redeemed after $t$ periods (denoted by $V(x, t))$ is $\alpha_{v} x /\left(1+\alpha_{d}\right)^{t}$. Without loss of generality, denoting $\left(W\left(x, t_{1}, t_{2}\right)\right)$ as the value of $x$ units of rewards that should be redeemed after period $t_{1}$ and will be expired after period $t_{2}$, one can say that:

$W\left(x, t_{1}, t_{2}\right) / W(x, 0, \infty)=\int_{t_{1}}^{t_{2}} V(x, t) d t / \int_{0}^{\infty} V(x, t) d t$ 
Considering the value of $x$ units of rewards that can be redeemed at the current period and never be expired $(W(x, 0, \infty))$ to be equal to $\alpha_{v} x$, one can formulate the value of $x$ units of rewards that should be redeemed after period $t_{1}$ and will be expired after period $t_{2}$ as follows:

$W\left(x, t_{1}, t_{2}\right)=\alpha_{v} x\left(\left(1+\alpha_{d}\right)^{-t_{1}}-\left(1+\alpha_{d}\right)^{-t_{2}}\right)$.

\subsubsection{Customers' choices}

As in Chapter 4, the customer has a maximum of four alternative choices when he or she has purchased enough times from both firms to receive their rewards: purchasing from Firm $a$ and not redeem (denoted by A0), purchasing from Firm $a$ and redeem (denoted by A1), purchasing from Firm $b$ and not redeem (denoted by B0), and purchasing from Firm $b$ and redeem (denoted by B1). A customer who does not have Firm $a(b)$ 's reward cannot choose A1(B1).

As in previous chapters, the multinomial logit model is used, which indicates that customers choose the option that results in the maximum utility. The logit model is related to the revenue management models developed by Talluri and van Ryzin (2004) and widely used in the literature (e.g., Liu \& van Ryzin, 2008; van Ryzin \& Vulcano, 2008; Hongmin \& Woonghee Tim, 2011; Meissner \& Strauss, 2012; Meissner et al., 2012; Topaloglu, 2013; Rusmevichientong et al., 2014).

As explained in Section 4.2.2, the utility that consumer $j$ obtains from alternative $z \in\{\mathrm{A} 0$, $\mathrm{A} 1, \mathrm{~B} 0, \mathrm{~B} 1\}, U_{z}^{j}$, includes a deterministic part $\left(D_{z}^{j}\right)$ and a random part $\left(\varepsilon_{z}^{j}\right)$ so that $\left(U_{z, j}=D_{z}^{j}+\right.$

$\varepsilon_{z}^{j}$ ). Considering $\varepsilon_{z}^{j}$ as an independently and identically distributed extreme value (also called a Gumbel and type I extreme value) for all alternative $z \in\{\mathrm{A} 0, \mathrm{~A} 1, \mathrm{~B} 0, \mathrm{~B} 1\}$, the probability of choosing alternative $z$ by decision maker $j\left(q_{z}^{j}\right)$ can be obtained via Equation (3.1). 
Denoting $n_{i}^{j}$ as customer $j$ 's number of purchases from Firm $i$ since the last redemption and until the time of being qualified to receive the reward $\left(n_{i}^{j} \leq N_{i}\right)$, one can say that customer $j$ is $\left(N_{i}-n_{i}^{j}\right)$ periods away from qualifying for Firm $i$ 's reward. Consequently, the value of an additional purchase increases when the customer gets closer to the reward. In this regard, our model aligns with the goal gradient theory (Kivetz et al., 2006), which specifies that the closer a customer is to a reward the more likely a new purchase is. After achieving the required number of purchases to receive the reward $\left(n_{i}^{j}=N_{i}\right)$, each purchase moves the customer one period closer to the expiry, which causes pressure to redeem. In order to model this fact, we define parameter $\tau_{i}^{j}$, which denotes customer $j$ 's distance to the Firm $i$ 's reward expiry if he/she has the reward. These variables are positive integers lower than or equal to Firm $i$ 's expiry length (denoted by $T_{i}$ ) for customers who have a reward, and zero for those who do not have a reward. As a result, customer $j$ possesses $p_{i}$ in reward value after $N_{i}$ purchases which can be redeemed at the current period and will be expired after $T_{i}$ periods. Based on these definitions, a customer's situation can be specified by the four parameters $\left(n_{a}^{j}, n_{b}^{j}, \tau_{a}^{j}, \tau_{b}^{j}\right)$. The next sections show how to calculate the probability of choosing alternative $z \in\{\mathrm{A} 0, \mathrm{~A} 1, \mathrm{~B} 0, \mathrm{~B} 1\}$ by customer $j$ based on the utilities earned in these different alternatives.

\subsubsection{Deterministic components of customer's utilities}

As mentioned above, we consider a customer's utility in choosing alternative $\mathrm{z}$ as the surplus of the value gained by choosing alternative $z$ subtracted by the value paid for it. Besides modeling a customer's gain and loss of cash and of rewards associated with purchasing, our model also takes into account the loss of getting closer to the expiry. Considering this loss, we model the pressure a customer feels when his/her reward gets closer to expiry. To do so, we define the function $Y(x, t)$ 
to represent the customer loss of $x$ value of rewards what will be expired after $t$ periods, when the customer gets one unit of time closer to the expiry. Referring to Equation (5.1), one can conclude:

$Y(x, t)=W(x, 0, t)-W(x, 0, t-1)=\alpha_{v} x\left(\left(1+\alpha_{d}\right)^{-t+1}-\left(1+\alpha_{d}\right)^{-t}\right)$.

Based on the above definitions, and after formulating the value functions for the gain and loss of cash and rewards, $D_{z}^{j}$ — the deterministic part of customer $j$ 's utility in choosing alternative $z \in\{\mathrm{A} 0, \mathrm{~A} 1, \mathrm{~B} 0, \mathrm{~B} 1\}$ - represents customer $j$ 's surplus and is equal to the value gained by choosing alternative $z$ subtracted by the value paid for it. Therefore, $D_{z}^{j}$ is formulated as follows in equations (5.3-5.6).

$$
\begin{aligned}
& D_{A 0}^{j}=\left\{\begin{array}{lr}
v_{a}^{j}-p_{a}-Y\left(p_{a}, \tau_{a}^{j}\right)-Y\left(p_{b}, \tau_{b}^{j}\right) & \text { if } n_{a}^{j}=N_{a} \& n_{b}^{j}=N_{b} \\
v_{a}^{j}-p_{a}+W\left(p_{a}, N_{a}-n_{a}^{j}, N_{a}-n_{a}^{j}+T_{a}\right)-Y\left(p_{b}, \tau_{b}^{j}\right) & \text { if } n_{a}^{j}<N_{a} \& n_{b}^{j}=N_{b} \\
v_{a}^{j}-p_{a}-Y\left(p_{a}, \tau_{a}^{j}\right) & \text { if } n_{a}^{j}=N_{a} \& n_{b}^{j}<N_{b} \\
v_{a}^{j}-p_{a}+W\left(p_{a}, N_{a}-n_{a}^{j}, N_{a}-n_{a}^{j}+T_{a}\right) & \text { if } n_{a}^{j}<N_{a} \& n_{b}^{j}<N_{b}
\end{array}\right. \\
& D_{A 1}^{j}=\left\{\begin{array}{lr}
v_{a}^{j}-W\left(p_{a}, 0, \tau_{a}^{j}\right)-Y\left(p_{b}, \tau_{b}^{j}\right) & \text { for } \quad n_{a}^{j}=N_{a} \& n_{b}^{j}=N_{b} \\
v_{a}^{j}-W\left(p_{a}, 0, \tau_{a}^{j}\right) & \text { for } \quad n_{a}^{j}=N_{a} \& n_{b}^{j}<N_{b}
\end{array}\right. \\
& D_{B 0}^{j}=\left\{\begin{array}{lll}
v_{b}^{j}-p_{b}-Y\left(p_{b}, \tau_{b}^{j}\right)-Y\left(p_{a}, \tau_{a}^{j}\right) & \text { if } n_{b}^{j}=N_{b} \& n_{a}^{j}=N_{a} \\
v_{b}^{j}-p_{b}+W\left(p_{b}, N_{b}-n_{b}^{j}, N_{b}-n_{b}^{j}+T_{b}\right)-Y\left(p_{a}, \tau_{a}^{j}\right) & \text { if } n_{b}^{j}<N_{b} \& n_{a}^{j}=N_{a} \\
v_{b}^{j}-p_{b}-Y\left(p_{b}, \tau_{b}^{j}\right) & \text { if } n_{b}^{j}=N_{b} \& n_{a}^{j}<N_{a} \\
v_{b}^{j}-p_{b}+W\left(p_{b}, N_{b}-n_{b}^{j}, N_{b}-n_{b}^{j}+T_{b}\right) & \text { if } n_{b}^{j}<N_{b} \& n_{a}^{j}<N_{a}
\end{array}\right. \\
& D_{B 1}^{j}= \begin{cases}v_{b}^{j}-W\left(p_{b}, 0, \tau_{b}^{j}\right)-Y\left(p_{a}, \tau_{a}^{j}\right) & \text { for } n_{b}^{j}=N_{b} \& n_{a}^{j}=N_{a} \\
v_{b}^{j}-W\left(p_{b}, 0, \tau_{b}^{j}\right) & \text { for } n_{b}^{j}=N_{b} \& n_{a}^{j}<N_{a}\end{cases}
\end{aligned}
$$

where $v_{i}^{j}$ is customer $j$ 's valuation for Firm $i \in\{a, b\}$. 
In Equations (5.3) and (5.5), customer $j$ 's surplus in purchasing from Firm $i$ includes the value of the product $\left(v_{a(b)}^{j}\right)$, the loss of cash as price $\left(-p_{a(b)}\right)$, the value of getting closer to the reward $\left(W\left(p_{a(b)}, N_{a(b)}-n_{a(b)}^{j}, N_{a(b)}-n_{a(b)}^{j}+T_{a(b)}\right)\right)$ if the customer has not completed the required number of purchases to get reward $\left(n_{a(b)}^{j}<N_{a(b)}\right)$, the pressure of getting closer to the expiry of the firm's reward $\left(-Y\left(p_{a(b)}, \tau_{a(b)}^{j}\right)\right)$ if the customer has completed the required number of purchases to get the reward $\left(n_{a(b)}^{j}=N_{a(b)}\right)$, and the pressure of getting closer to the expiry of the other firm's reward $\left(-Y\left(p_{b(a)}, \tau_{b(a)}^{j}\right)\right)$ if the customer is qualified to receive that reward $\left(n_{b(a)}^{j}=N_{b(a)}\right)$

In Equations (5.4) and (5.6), customer $j$ 's surplus in redeeming the reward of Firm $a(b)$ includes the value of the product $\left(v_{a(b)}^{j}\right)$, the loss of the reward $\left(-W\left(p_{a(b)}, 0, \tau_{a(b)}^{j}\right)\right)$, the pressure of getting closer to the other firm's reward expiry $\left(-Y\left(p_{b(a)}, \tau_{b(a)}^{j}\right)\right)$ if the customer is qualified to receive that reward $\left(n_{b(a)}^{j}=N_{b(a)}\right)$. When the customer has no reward from Firm $a(b)$ $\left(n_{a(b)}^{j}<N_{a(b)}\right)$, redemption (decision A1 (B1)) is not an option. To show this fact, a negative infinity value has been assigned for $D_{A 1}^{j}\left(D_{B 1}^{j}\right)$ under this condition.

Based on Equations (5.1-5.6), the probability of customer $j$ choosing alternative $z \in\{\mathrm{A} 0$, $\mathrm{A} 1, \mathrm{~B} 0, \mathrm{~B} 1\}$ can be calculated. We assume that $v_{a}^{j}=v_{b}^{j}$ since both firms sell the same product/service. It should also be mentioned that Equations (5.3-5.6) are derived for Scenario S3, where both firms set an expiry date. In the condition of not setting an expiry date in Scenario S2 and $\mathrm{S} 1, T_{a}$ and $T_{b}$ are set to infinity, and the terms $\left(N_{a(b)}-n_{a(b)}^{j}+T_{a(b)}\right)$ also turn to infinity. 
As mentioned before, customer $j$ is specified by four parameters of $\left(n_{a}^{j}, n_{b}^{j}, \tau_{a}^{j}, \tau_{b}^{j}\right)$. So, in purchasing period $i$, all customers who have the same $\left(n_{a}^{j}, n_{b}^{j}, \tau_{a}^{j}, \tau_{b}^{j}\right)$ have an equal probability of choosing alternative $z$ and can therefore be grouped. Denoting this group as $M_{i}\left(n_{a}, n_{b}, \tau_{a}, \tau_{b}\right)$ and the probability of this group choosing $z$ as $Q_{z, i}\left(n_{a}, n_{b}, \tau_{a}, \tau_{b}\right)$, we get:

$$
\left\{\begin{array}{l}
M_{i}\left(n_{a}, n_{b}, \tau_{a}, \tau_{b}\right)=\left\{\forall \text { customer } j \text { in period } i \mid n_{a}^{j}=n_{a}, n_{b}^{j}=n_{b}, \tau_{a}^{j}=\tau_{a}, \tau_{b}^{j}=\tau_{b}\right\}, \\
Q_{z, i}\left(n_{a}, n_{b}, \tau_{a}, \tau_{b}\right)=q_{z}^{j}, \forall z \in\{A 0, A 1, B 0, B 1\}, \quad \forall z \mid n_{a}^{j}=n_{a}, n_{b}^{j}=n_{b}, \tau_{a}^{j}=\tau_{a}, \tau_{b}^{j}=\tau_{b}
\end{array}\right.
$$

Based on the above explanations, the flow chart of customers between two sequent periods can be derived as shown in Figure 5.1. Referring to this flow chart, one can define that the customers set of $M_{i}\left(n_{a}, n_{b}, \tau_{a}, \tau_{b}\right)$ turns to which set of customers and with which probability. Consequently, and denoting $\Pi_{i}\left(n_{a}, n_{b}, \tau_{a}, \tau_{b}\right)$ as the number of customers in group $M_{i}\left(n_{a}, n_{b}, \tau_{a}, \tau_{b}\right)$, one can derive all possible equations between $\Pi_{i}\left(n_{a}, n_{b}, \tau_{a}, \tau_{b}\right)$ and $\Pi_{i+1}\left(n_{a}, n_{b}, \tau_{a}, \tau_{b}\right)$. For instance, one can say:

$\Pi_{i+1}(2,3,0,0)=\Pi_{i}(1,3,0,0) * Q_{A 0, i}(1,3,0,0)+\Pi_{i}(2,2,0,0) * Q_{B 0, i}(2,2,0,0)$

In our model, the firms' variables do not change during the periods. Consequently, a stationary demand condition can be assumed in which all market parameters are constant during two subsequent purchasing periods. Thus in this condition, $\Pi_{i}\left(n_{a}, n_{b}, \tau_{a}, \tau_{b}\right)=$ $\Pi_{i+1}\left(n_{a}, n_{b}, \tau_{a}, \tau_{b}\right)=\Pi\left(n_{a}, n_{b}, \tau_{a}, \tau_{b}\right)$. This assumption allows us to derive a number of independent equations corresponding to all possible values of $\Pi\left(n_{a}, n_{b}, \tau_{a}, \tau_{b}\right)$ corresponding to all possible combinations of $\left(n_{a}, n_{b}, \tau_{a}, \tau_{b}\right)$. By solving these equations simultaneously, we obtain different values of $\Pi\left(n_{a}, n_{b}, \tau_{a}, \tau_{b}\right)$, which can then be used to calculate the firms' profits (denoted by $I_{a}$ and $I_{b}$ ) in the stationary demand condition as shown in Equation (5.7). 
$\left\{\begin{array}{l}I_{a}=p_{a} \sum_{n_{a}} \sum_{n_{b}} \sum_{\tau_{a}} \sum_{\tau_{b}} \Pi\left(n_{a}, n_{b}, \tau_{a}, \tau_{b}\right) Q_{A 0}\left(n_{a}, n_{b}, \tau_{a}, \tau_{b}\right) \\ I_{b}=p_{b} \sum_{n_{a}} \sum_{n_{b}} \sum_{\tau_{a}} \sum_{\tau_{b}} \Pi\left(n_{a}, n_{b}, \tau_{a}, \tau_{b}\right) Q_{B 0}\left(n_{a}, n_{b}, \tau_{a}, \tau_{b}\right)\end{array}\right.$,

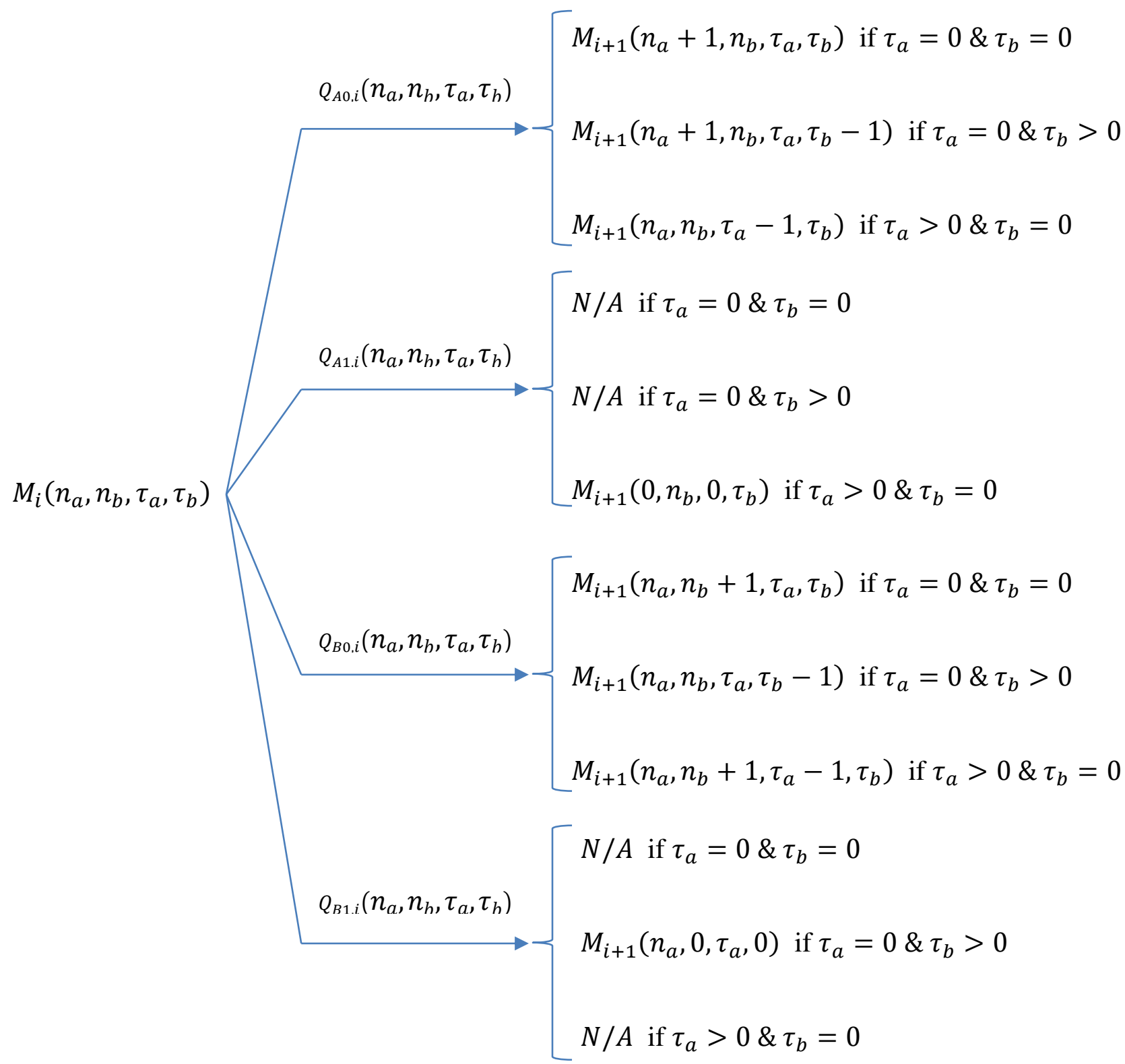

Figure 5.1: Flow chart between two subsequent purchasing periods for the game between expiry and no expiry policies

Based on Equations (5.1-5.7), the firms' profits in the stationary demand condition can be obtained. It should be noted that although in Equation (5.7) parameters $n_{i}$ and $\tau_{i}$ change in the ranges of $\left[0, N_{i}\right]$ and $\left[0, T_{i}\right]$ respectively, some special combinations of $\left(n_{a}, n_{b}, \tau_{a}, \tau_{b}\right)$ are not 
logically possible. For example, $\left(N_{a}, N_{b}, T_{a}, T_{b}\right)$ is not possible. The reason is that when a customer becomes eligible to receive the reward of Firm $a(b)$ for the first time, $n_{i}=N_{i}$ and $\tau_{i}=T_{i}$. We assume that customers purchase from either firm in each period (not from both of them), and therefore a customer cannot become eligible for Firm $a$ 's and Firm $b$ 's reward for the first time in the same period. Using similar logic, one can argue that $T_{b}-\tau_{b} \neq T_{a}-\tau_{a}$ when $n_{a}=N_{a}$ and $n_{b}=N_{b}$.

\subsection{Solving the model}

From Equations (5.1-5.7), the firms' profits are functions of: (1) the decision variables of Firm $a$ $\left(N_{a}, p_{a}\right.$, and $\left.T_{a}\right)$ and of Firm $b\left(N_{b}, p_{b}\right.$, and $\left.T_{b}\right)$, and (2) the behavioural parameters $\left(\alpha_{v}, \alpha_{d}\right)$. To study the profitability of setting an expiry date, we solve a Nash game played by Firm $a$ and Firm $b$ where each player can either set or not set an expiry date. To find such an equilibrium, the firms' optimal profits in scenarios S1, S2, and S3 are obtained and then compared. In each scenario, we solve a sub-game in which the optimal values of the firms' decision variables are determined by maximizing simultaneously the firms' profits, each one in terms of its own decision variables. For instance, in Scenario S3 (where both firms set an expiry date), for given values of parameters $\left(\alpha_{v}\right.$, $\alpha_{d}$, we obtain the firms' optimal decisions and profits by solving the two enclosed optimization problems simultaneously.
(I) $\left\{\begin{array}{l}\max _{N_{a}, T_{a}, p_{a}} I_{a}^{S} \\ \text { s.t } N_{a} \text { and } T_{a} \text { are integer, } p_{a}>0 .\end{array}\right.$
(II) $\left\{\begin{array}{l}\max _{N_{b}, T_{b}, p_{b}} I_{b}^{S} \\ \text { s.t } N_{b} \text { and } T_{b} \text { are integer, } p_{b}>0 .\end{array}\right.$

In order to solve these problems together, we employed the iterative algorithm explained in Table 3.3. In this table, Firm $i$ 's optimal response in iteration $r$ is denoted as $O_{i}^{r}$. The algorithm 
is based on the definition of a Nash equilibrium, which is the condition under which neither firm can increase its profit by unilaterally deviating from that condition to any other possible one.

In each iteration of the algorithm from Table 3.3, a firm's best response (optimal decision variables) to its competitor's is found. An analytical solution to find the best response, if available, is difficult to derive because the profit functions are highly nonlinear. Therefore, we resort to numerical analyses by considering reasonable limits for the decision variables. We limit positive integer parameters $N_{i}$ (required number of purchases to receive Firm $i$ 's reward) to be equal or less than $10 . N_{i}=10$ means that Firm $i$ gives a reward after 10 purchases.

Using a numerical method, it is not possible to find the optimal $T_{i}$ (Firm $i$ 's expiry length) if its value is very high. To address this issue, we consider an upper limit for expiry length (denoted by $T_{\max }$ ) so that one can assume that customers do not differentiate between a point that expires after $T_{\max }$ and a point that never expires. Consequently, an optimal expiry length greater than or equal to $T_{\max }$ is interpreted as a "long expiry." According to the value functions discussed in Section 5.2.2 (See Equation (5.1)), as the expiry length of a point increases, its value increases, and the value reaches its maximum amount when the expiry length is infinity. One can find the expiry length at which the value of a point reaches a certain percentage of its maximum, which is a function of the customer's time valuation $\left(\alpha_{d}\right)$. We consider $T_{\max }$ as the expiry length under which one point has 99 percent of its maximum value for the most non-sensitive customers to time (those whose $a_{d}$ is minimum) since the minimum $\alpha_{d}$ results in the maximum $T_{\max }$. Based on this definition, one can conclude:

$T_{\max } \geq\left\lceil\ln (100) / \ln \left(1+\alpha_{d}^{\min }\right)\right\rceil$.

Where $\alpha_{d}^{\min }$ is the smallest value of parameter $\alpha_{d}$, which is 0.1 . 
We do not consider a maximum limit for price, and for each combination of $\left(N_{i}, T_{i}\right)$, an optimal price in the range of $(0, \infty)$ is found which maximizes Firm $i$ 's profit. Employing Matlab's fmincon function, which uses an interior-point algorithm based on Byrd et al. (2000), we are able to reach the optimal price with an accuracy of 32 decimal digits. As a result, we obtain and report the optimal set of $\left(N_{a(b)}, T_{a(b)}, p_{a(b)}\right)$.

It should be noted that using the algorithm described in Table 3.3, we find the closest condition to the equilibrium with an error of (0.001), not the exact equilibrium. However, we are able to check if the algorithm converges or not. If it does not converge, it can be concluded that either there is more than one equilibrium or there is no equilibrium.

In our framework, parameters $\alpha_{v}$ and $\alpha_{d}$ are bounded in the $(0,1)$ interval; however, to make the model more realistic, we consider the ranges of $[0.5,0.9]$ and $[0.1,0.5]$ with step sizes of 0.1 for parameters $a_{v}$ and $a_{d}$, or 25 different combinations of these parameters. Referring to Inequality (10), $T_{\max }$ is assumed to be 50 . In order to give a better sense of these parameters and justify the mentioned limits, we note that $\alpha_{v}=0.5$ means that the customer evaluates a one-dollar reward as 50 cents, and $\alpha_{d}=0.5$ means that a reward loses half of its value after one unit of time.

We solve the general game in which the firms decide whether to set an expiry or not for all 25 combinations of parameters $\alpha_{v}$ and $\alpha_{d}$. For this purpose, we also solve three sub-games as three scenarios of S1 (none of the firms sets reward expiry), S2 (one of the firms sets reward expiry), and S3 (both firms set reward expiry).

\subsection{Results and discussion}

Using Equations (5.1-5.8), and by applying the solution method explained in the previous section, we obtain each firm's optimal decision variables in each scenario, and therefore the optimal profits. 
These outcomes are obtained for different combinations of the reward valuation coefficient $\left(\alpha_{v}\right)$ and time valuation coefficient $\left(\alpha_{d}\right)$. By comparing these outcomes for each firm, and under different scenarios (sub-games), we can analyze the impact of setting a reward expiry. The following sections present scenarios S1, S2, and S3 separately, and then in comparison with each other.

\subsubsection{Scenario S1}

This scenario is a game between Firm $a$ and Firm $b$, where neither sets an expiry date for the rewards they offer to their customers. Firms decide about the required number of purchases a customer needs have made to be rewarded a free product, as well as the price of the product to maximize their profits when the market reaches a stationary demand condition. At the beginning of the selling horizon, firms set their decision variables simultaneously without knowing their competitor's decision. Using the algorithm explained in Table 3.3, we seek a Nash equilibrium for each sub-game where the optimal decision of each firm is the best response to the other firm's strategy for the 25 considered value combinations of parameters $\alpha_{v}$ and $\alpha_{d}$.

As expected, the firms' optimal strategies are equal under Scenario S1 since it is a symmetric condition. Tables 5.2 and 5.3 show the optimal decision variables (number of required purchases, price), and optimal profit, respectively, for different combinations of $\alpha_{v}$ and $\alpha_{d}$. 
Table 5.2: Optimal decision variables in Scenario S1 of the game between expiry and no expiry policies for combinations of mental parameters

\begin{tabular}{c|cc|cc|cc|ccc|c}
\hline$\alpha_{d}$ & \multicolumn{2}{|c|}{0.1} & \multicolumn{2}{|c|}{0.2} & \multicolumn{2}{|c|}{0.3} & \multicolumn{2}{|c|}{0.4} & \multicolumn{2}{|c}{0.5} \\
\hline$\alpha_{v}$ & $N_{i}$ & $p_{i}$ & $N_{i}$ & $p_{i}$ & $N_{i}$ & $p_{i}$ & $N_{i}$ & $p_{i}$ & $N_{i}$ & $p_{i}$ \\
\hline 0.5 & 5 & 3.140 & 4 & 2.865 & 3 & 2.765 & 3 & 2.624 & 3 & 2.522 \\
0.6 & 5 & 3.399 & 4 & 3.043 & 3 & 2.905 & 3 & 2.737 & 3 & 2.616 \\
0.7 & 5 & 3.483 & 4 & 3.125 & 3 & 2.959 & 3 & 2.796 & 3 & 2.672 \\
0.8 & 6 & 3.368 & 4 & 3.063 & 4 & 2.864 & 3 & 2.776 & 3 & 2.672 \\
0.9 & 7 & 3.184 & 5 & 2.928 & 4 & 2.781 & 3 & 2.683 & 3 & 2.615 \\
\hline
\end{tabular}

Table 5.3: Optimal profits in Scenario S1 of the game between expiry and no expiry policies for combinations of mental parameters

\begin{tabular}{c|ccccc}
\hline$\alpha_{v}$ & 0.1 & 0.2 & 0.3 & 0.4 & 0.5 \\
\hline 0.5 & 1.317 & 1.159 & 1.057 & 1.005 & 0.966 \\
0.6 & 1.428 & 1.234 & 1.116 & 1.053 & 1.007 \\
0.7 & 1.468 & 1.273 & 1.144 & 1.083 & 1.036 \\
0.8 & 1.460 & 1.255 & 1.175 & 1.084 & 1.045 \\
0.9 & 1.410 & 1.247 & 1.149 & 1.060 & 1.033 \\
\hline
\end{tabular}

As can be derived from the above tables, the optimal number of required purchases to receive a reward increases for higher values of $\alpha_{v}$ and for lower values of $\alpha_{d}$. In other words, the firms should offer their rewards sooner when their customers value time higher and do not highly value the reward. These tables also reveal that, everything else being the same, optimal prices are lower for higher values of $\alpha_{d}$. This means that when consumers are "impatient", i.e., highly value their time and are not willing to wait (high $\alpha_{d}$ ), firms should incite consumers' purchase by 
charging lower prices in addition to rewarding consumers earlier. Looking at the sensitivity of optimal prices to changes in $\alpha_{v}$, Table 4 shows a non-linear relationship between $p$ and $\alpha_{d}$. In fact, for any given value of $\alpha_{d}$, the firms' optimal price increases with higher values of $\alpha_{v}$ to reach a maximum value at $\alpha_{v}=0.7$. For values of $\alpha_{v}$ exceeding 0.7 , the optimal price decreases for higher values of $\alpha_{v}$. Finally, variations in $\alpha_{v}$ and $\alpha_{d}$ affect the firms' optimal profits in a similar way than prices. Interestingly, this means that no matter consumers' sensitivity to time pressure (or impatience), firms will earn the highest profits when consumers value rewards highly enough but not too much $\left(\alpha_{v}=0.7\right)$.

\subsubsection{Scenario S2}

In Scenario S2, both firms offer rewards, however, only one of them sets an expiry date for the reward. Assuming Firm $b$ is the firm that sets an expiry, Scenario $\mathrm{S} 2$ is a game between the firms where Firm $a$ decides the price and required number of purchases to receive the reward, and Firm $b$ decides the price, required number of purchases to receive the reward, and the expiry length. Using the methods explained in Table 3.3, we seek a Nash equilibrium for the game between Firms $a$ and $b$, where the optimal decision of each firm is the best response to the other firm's strategy. As in the previous scenario, the first step is identifying the firms' optimal decision variables for Scenario S2 under 25 different combinations of parameters $\alpha_{v}$ and $\alpha_{d}$.

Tables 5.4 and 5.5 show Firm $a$ 's optimal decision variables (required number of purchases, price) and optimal profit, respectively, for 25 different combinations of parameters $\alpha_{v}$ and $\alpha_{d}$. These Tables show a similar pattern for the optimal decision variables of the firm that has no expiry in Scenario S2 as in Scenario S1, so that the optimal price and profit decrease for higher customers' time valuations. Also, for $\alpha_{d}=0.1$, the optimal price and profit of Firm $a$ reach their 
maximum values at $\alpha_{v}=0.7$. However, for higher values of $\alpha_{d}$, both Firm $a$ 's price and profit continuously increase with higher values of $\alpha_{v}$.

Table 5.4: Firm $a$ 's optimal decision variables in Scenario S2 of the game between expiry and no expiry policies for combinations of mental parameters

\begin{tabular}{c|cc|cc|cc|cc|cc}
\hline$\alpha_{d}$ & \multicolumn{2}{|c|}{0.1} & \multicolumn{2}{|c|}{0.2} & \multicolumn{2}{|c|}{0.3} & \multicolumn{2}{|c|}{0.4} & \multicolumn{2}{|c}{0.5} \\
\hline$\alpha_{v}$ & $N_{i}$ & $p_{i}$ & $N_{i}$ & $p_{i}$ & $N_{i}$ & $p_{i}$ & $N_{i}$ & $p_{i}$ & $N_{i}$ & $p_{i}$ \\
\hline 0.5 & 5 & 3.141 & 4 & 2.866 & 3 & 2.766 & 3 & 2.625 & 3 & 2.523 \\
0.6 & 5 & 3.401 & 4 & 3.044 & 3 & 2.907 & 3 & 2.739 & 3 & 2.617 \\
0.7 & 6 & 3.444 & 4 & 3.127 & 3 & 2.974 & 3 & 2.811 & 3 & 2.687 \\
0.8 & 6 & 3.386 & 4 & 3.132 & 4 & 2.938 & 3 & 2.849 & 3 & 2.733 \\
0.9 & 7 & 3.284 & 5 & 3.083 & 4 & 2.941 & 4 & 2.778 & 3 & 2.725 \\
\hline
\end{tabular}

Table 5.5: Firm $a$ 's optimal profit in Scenario S2 of the game between expiry and no expiry policies for combinations of mental parameters

\begin{tabular}{|c|c|c|c|c|c|}
\hline$\alpha_{v}$ & 0.1 & 0.2 & 0.3 & 0.4 & 0.5 \\
\hline 0.5 & 1.317 & 1.16 & 1.058 & 1.005 & 0.967 \\
\hline 0.6 & 1.429 & 1.235 & 1.116 & 1.053 & 1.008 \\
\hline 0.7 & 1.482 & 1.274 & 1.150 & 1.088 & 1.041 \\
\hline 0.8 & 1.472 & 1.292 & 1.200 & 1.116 & 1.069 \\
\hline 0.9 & 1.479 & 1.330 & 1.222 & 1.145 & 1.083 \\
\hline
\end{tabular}

The optimal decision variables (required number of purchases, expiry length and price) and profit of Firm $b$ (the firm that sets expiry in scenario S2) are reported in tables 5.6 and 5.7 respectively. First, note that for low time distance parameter values $\left(\alpha_{d}<0.4\right)$, the optimal required number of purchases to receive Firm $b$ 's reward $\left(N_{b}\right)$ decreases with higher values of $\alpha_{d}$. 
However, $N_{b}$ becomes insensitive to changes in $\alpha_{d}$ for $\alpha_{d}>0.3$. Second, $\alpha_{v}$ only impacts $N_{b}$ for $\alpha_{d}=0.1$. Therefore, the firm's reward policy becomes much less sensitive to both behavioral parameters when a reward expiry policy is chosen. Further, notice that the optimal expiry length period $\left(T_{b}\right)$ is found equal to the upper bound value $\left(T_{\max }=50\right)$ for some values of $\alpha_{v}$ and $\alpha_{d}$. This is specifically the case for low values of $\alpha_{v}$ or for low values of both $\alpha_{v}$ and $\alpha_{d}$. Further, Firm $b$ should set a shorter expiry length when customers highly value time and/or reward. Finally, Firm $b$ 's optimal price is higher for higher reward valuation and lower time valuation.

Table 5.6: Firm $b$ 's optimal decision variables in Scenario $\mathrm{S} 2$ of the game between expiry and no expiry policies for combinations of mental parameters

\begin{tabular}{c|ccc|ccc|ccc|ccc|ccc}
\hline$\alpha_{d}$ & \multicolumn{3}{|c|}{0.1} & \multicolumn{3}{|c|}{0.2} & \multicolumn{3}{|c|}{0.3} & & \multicolumn{3}{|c|}{0.4} & \multicolumn{3}{|c}{0.5} \\
\hline$\alpha_{v}$ & $N_{i}$ & $T_{i}$ & $p_{i}$ & $N_{i}$ & $T_{i}$ & $p_{i}$ & $N_{i}$ & $T_{i}$ & $p_{i}$ & $N_{i}$ & $T_{i}$ & $p_{i}$ & $N_{i}$ & $T_{i}$ & $p_{i}$ \\
\hline 0.5 & 5 & 50 & 3.129 & 4 & 50 & 2.867 & 3 & 50 & 2.767 & 3 & 50 & 2.625 & 3 & 50 & 2.523 \\
0.6 & 5 & 50 & 3.391 & 4 & 50 & 3.044 & 3 & 50 & 2.907 & 3 & 50 & 2.739 & 3 & 50 & 2.617 \\
0.7 & 5 & 50 & 3.512 & 4 & 50 & 3.127 & 3 & 19 & 2.979 & 3 & 15 & 2.815 & 3 & 12 & 2.692 \\
0.8 & 6 & 50 & 3.397 & 4 & 19 & 3.177 & 3 & 11 & 3.124 & 3 & 10 & 2.902 & 3 & 8 & 2.779 \\
0.9 & 7 & 33 & 3.373 & 4 & 13 & 3.320 & 3 & 9 & 3.229 & 3 & 8 & 3.031 & 3 & 7 & 2.851 \\
\hline
\end{tabular}

Table 5.7: Firm $b$ 's optimal profit in Scenario S2 of the game between expiry and no expiry policies for combinations of mental parameters

\begin{tabular}{c|ccccc}
\hline$\alpha_{v}$ & 0.1 & 0.2 & 0.3 & 0.4 & 0.5 \\
\hline 0.5 & 1.312 & 1.160 & 1.058 & 1.005 & 0.967 \\
0.6 & 1.424 & 1.235 & 1.116 & 1.053 & 1.008 \\
0.7 & 1.485 & 1.273 & 1.150 & 1.089 & 1.042 \\
0.8 & 1.468 & 1.288 & 1.210 & 1.121 & 1.075 \\
0.9 & 1.464 & 1.335 & 1.240 & 1.178 & 1.100 \\
\hline
\end{tabular}




\subsubsection{Scenario S3}

In Scenario S3, both firms set an expiry date for the reward they offer. Therefore, each firm sets three decision variables: price, required number of purchases to receive a reward, and expiry length. Since Scenario S3 is a symmetric condition, as expected, the optimal decisions variables are equal for both firms.

Tables 5.8 and 5.9 show the optimal decision variables (required number of purchases, expiry length and price) and profit in Scenario S3. As can be derived from these tables, the firms should delay rewarding when customers highly value reward but not time. These tables also reveal that the firms should set a shorter expiry length when customers highly value time and reward. Furthermore, the optimal price and profit in Scenario 3 increase for higher customers' reward valuation and lower customers' time valuation.

Table 5.8: Optimal decision variables in Scenario $S 3$ of the game between expiry and no expiry policies for combinations of mental parameters

\begin{tabular}{c|ccc|ccc|ccc|ccc|ccc}
\hline$\alpha_{d}$ & \multicolumn{3}{|c|}{0.1} & \multicolumn{3}{|c|}{0.2} & \multicolumn{2}{|c|}{0.3} & & \multicolumn{2}{|c|}{0.4} & \multicolumn{3}{|c}{0.5} \\
\hline$\alpha_{v}$ & $N_{i}$ & $T_{i}$ & $p_{i}$ & $N_{i}$ & $T_{i}$ & $p_{i}$ & $N_{i}$ & $T_{i}$ & $p_{i}$ & $N_{i}$ & $T_{i}$ & $p_{i}$ & $N_{i}$ & $T_{i}$ & $p_{i}$ \\
\hline 0.5 & 5 & 50 & 3.129 & 4 & 50 & 2.867 & 3 & 50 & 2.767 & 3 & 50 & 2.625 & 3 & 50 & 2.523 \\
0.6 & 5 & 50 & 3.392 & 4 & 50 & 3.044 & 3 & 50 & 2.907 & 3 & 50 & 2.739 & 3 & 50 & 2.617 \\
0.7 & 5 & 50 & 3.506 & 4 & 50 & 3.127 & 3 & 19 & 2.993 & 3 & 15 & 2.827 & 3 & 12 & 2.705 \\
0.8 & 6 & 50 & 3.416 & 4 & 19 & 3.252 & 3 & 11 & 3.213 & 3 & 9 & 3.007 & 3 & 8 & 2.844 \\
0.9 & 7 & 31 & 3.530 & 4 & 13 & 3.535 & 3 & 9 & 3.463 & 3 & 7 & 3.201 & 3 & 7 & 2.985 \\
\hline
\end{tabular}


Table 5.9: Optimal profit in Scenario S3 of the game between expiry and no expiry policies for combinations of mental parameters

\begin{tabular}{c|ccccc}
\hline$\alpha_{v}$ & 0.1 & 0.2 & 0.3 & 0.4 & 0.5 \\
\hline 0.5 & 1.312 & 1.160 & 1.058 & 1.005 & 0.967 \\
0.6 & 1.425 & 1.235 & 1.116 & 1.053 & 1.008 \\
0.7 & 1.477 & 1.274 & 1.156 & 1.093 & 1.046 \\
0.8 & 1.480 & 1.327 & 1.240 & 1.162 & 1.101 \\
0.9 & 1.558 & 1.440 & 1.335 & 1.235 & 1.157 \\
\hline
\end{tabular}

\subsubsection{Main game}

In the previous sections, three sub-games were discussed and solved as three scenarios $\mathrm{S} 1, \mathrm{~S} 2$, and S3. Comparing optimal prices in Scenario S1 and those of Firm $a$ in Scenario S2, one can conclude that a firm that applies no expiry should offer a higher price if its competitor sets an expiry, as opposed to the condition where its competitor also applies no expiry policy. A similar comparison between optimal prices in Scenario S3 and those of Firm $b$ in Scenario S2 reveal that a firm that applies expiry should offer a higher price if its competitor also sets expiry, as opposed to the condition where its competitor applies no expiry policy.

Knowing the firms' profits in each of the scenarios, we can also solve the general game in which two firms $(a, b)$ decide on setting or not setting an expiry date. Based on tables 5.3, 5.5, 5.7, and 5.9, the payoff matrix of this game for each combination of $\alpha_{v}$ and $\alpha_{d}$ can be derived as shown below, where $I_{i}^{x, y}$ is Firm $i$ 's profit when Firm $a$ and Firm $b$ follow policies $x$ and $y$, respectively. 


\begin{tabular}{c|ll}
\hline Firm $b$ & No Expiry (NE) & Expiry (E) \\
\hline No Expiry (NE) & $\left(I_{a}^{N E, N E}, I_{b}^{N E, N E}\right)$ & $\left(I_{a}^{N E, E}, I_{b}^{N E, E}\right)$ \\
Expiry (E) & $\left(I_{a}^{E, N E}, I_{b}^{E, N E}\right)$ & $\left(I_{a}^{E, E}, I_{b}^{E, E}\right)$ \\
\hline
\end{tabular}

To have (E, E) as Nash equilibrium, the following inequalities must hold true:

$I_{a}^{E, E}>I_{a}^{N E, E}$ and $I_{b}^{E, E}>I_{b}^{E, N E}$

meaning that each firm does not have an incentive, i.e., does not earn higher profit, if it does not set a reward expiry. Moreover, setting an expiry by both firms (S3) is Pareto improving compared to the case where they both do not set reward expiry (S1), i.e., $I_{a}^{E, E}>I_{a}^{N E, N E}$ and $I_{b}^{E, E}>I_{b}^{N E, N E}$.

Comparing the obtained profits in scenarios S1, S2 and S3 (Tables 5.2, 5.4, 5.6 and 5.9), for each of the 25 combinations of parameters $\alpha_{v}$ and $\alpha_{d}$, one can scale the profits as shown in Table B.4 in Appendix B. Based on this table and the payoff matrices of all 25 combinations of parameters $\alpha_{v}$ and $\alpha_{d}$, one can categorize four different regions as shown in Table 5.10. In the light shaded area of this table, where customers highly value time and reward, setting expiry is a dominant equilibrium.

In the white and dark shaded areas, we have an obtained expiry length equal to the upper limit, therefore we cannot be sure about the equilibriums; however, one can say that in the dark solid area, setting an expiry by both firms is Pareto optimal, improving compared to the case where they both do not set reward expiry. In the white area, where customers do not highly value reward and time, not setting an expiry is the dominant Nash equilibrium if we consider "setting short expiry" and "not setting expiry" as the firms" choices. 
Table 5.10: Different regions of the game between expiry and no expiry policies for combinations of mental parameters

\begin{tabular}{|c|c|c|c|c|c|}
\hline$\alpha_{v}$ & 0.1 & 0.2 & 0.3 & 0.4 & 0.5 \\
\hline 0.5 & & & & & \\
\hline 0.6 & $\begin{array}{l}\text { Unknown } \\
\text { region }\end{array}$ & \multicolumn{4}{|c|}{ Setting expiry is Pareto optimal } \\
\hline \multicolumn{3}{|l|}{0.7} & \multirow{3}{*}{\multicolumn{3}{|c|}{$\begin{array}{c}\text { Setting expiry is the dominant Nash } \\
\text { equilibrium }\end{array}$}} \\
\hline 0.8 & & & & & \\
\hline 0.9 & & & & & \\
\hline
\end{tabular}

\section{5 $\quad$ Extended model}

So far in this chapter, we have discussed the competition between two policies: one restricts the start time of the redemption horizon and the other restricts both the start and end time of the redemption horizon. This section models the competition between two policies where one of them does not restrict the redemption and the other restricts start and end time of the redemption horizon. To do so, three enclosed scenarios are assumed.

The first scenario is a symmetric scenario in which neither of the firms restricts the redemption. This scenario is similar to Scenario S3 in Chapter 4, where both firms offer a fraction of price $\left(p_{i} / N_{i}\right)$ as reward point in each purchasing period. Customers can stockpile rewards and redeem in each period of purchasing. In this scenario Firm $i \in\{a, b\}$ decides about price $\left(p_{i}\right)$ and reward $\left(N_{i}\right)$. Tables 4.8 and 4.9 showed the firms' optimal decision variables and profits, respectively, in this scenario and for different combinations of parameters $\alpha_{v}$ and $\alpha_{d}$. 
The next scenario is also a symmetric scenario in which both firms highly restrict the redemption by limiting redemption to be allowed only after $\left(N_{i}\right)$ purchases and during $\left(T_{i}\right)$ periods. This scenario is similar to Scenario S3 discussed in Section 5.2, where both firms offer a free product (valued at $p_{i}$ ) as reward that will expire after $\left(T_{i}\right)$ periods. Firm $i$ in this scenario decides on the price $\left(p_{i}\right)$, reward timing $\left(N_{i}\right)$, and the expiry length $\left(T_{i}\right)$. Tables 5.8 and 5.9 show the firms' optimal decision variables and profits, respectively, in this scenario and for different combinations of parameters $\alpha_{v}$ and $\alpha_{d}$.

In addition to these two symmetric scenarios, we must also consider an asymmetric scenario (denoted by S2e), where one firm (assumed to be Firm $a$ ) does not restrict the redemption, and another firm (Firm $b$ ) highly restricts the redemption by setting an expiry on the reward of a free product offered after a certain number of purchases. Firm $a$ offers its customers $\left(p_{a} / N_{a}\right)$ rewards in each period of purchases if they decide to not redeem their stockpiled rewards, and if their stockpiled rewards are not more than the price, where $N_{a}$ is an integer in the range of $(1,100)$. So customers can receive a Firm $a$ 's free product after $N_{a}$ times purchasing without redemption. On the other hand, Firm $b$ offers a free product (valued at $p_{b}$ ) after $N_{b}$ purchases as reward that will expire after $T_{b}$ periods. As in the previous sections of this chapter, $N_{b}$ and $T_{b}$ are integers in the $[1,10]$ and $[1,50]$ intervals, respectively.

Referring to the above definitions, the deterministic part of alternative $\mathrm{z}$ utility $\left(D_{z}^{j}\right)$ for the asymmetric Scenario S2e is formulated as follows, where $z \in\{\mathrm{A} 0, \mathrm{~A} 1, \mathrm{~B} 0, \mathrm{~B} 1\}$.

$$
D_{A 0}^{j}=\left\{\begin{array}{lr}
v_{a}^{j}-p_{a}-Y\left(p_{b}, \tau_{b}^{j}\right) & \text { if } n_{a}^{j}=N_{a} \& n_{b}^{j}=N_{b} \\
v_{a}^{j}-p_{a}+V\left(\frac{p_{a}}{N_{a}}, 1\right)-Y\left(p_{b}, \tau_{b}^{j}\right) & \text { if } n_{a}^{j}<N_{a} \& n_{b}^{j}=N_{b} \\
v_{a}^{j}-p_{a} & \text { if } n_{a}^{j}=N_{a} \& n_{b}^{j}<N_{b} \\
v_{a}^{j}-p_{a}+V\left(\frac{p_{a}}{N_{a}}, 1\right) & \text { if } n_{a}^{j}<N_{a} \& n_{b}^{j}<N_{b}
\end{array}\right.
$$




$$
\begin{aligned}
& D_{A 1}^{j}= \begin{cases}v_{a}^{j}-p_{a}+n_{a}^{j} p_{a} / N_{a}-V\left(n_{a}^{j} p_{a} / N_{a}, 0\right)-Y\left(p_{b}, \tau_{b}^{j}\right) & \text { for } n_{a}^{j}>0 \& n_{b}^{j}=N_{b} \\
v_{a}^{j}-p_{a}+n_{a}^{j} p_{a} / N_{a}-V\left(n_{a}^{j} p_{a} / N_{a}, 0\right) & \text { for } n_{a}^{j}>0 \& n_{b}^{j}<N_{b}\end{cases} \\
& D_{B 0}^{j}= \begin{cases}v_{b}^{j}-p_{b}-Y\left(p_{b}, \tau_{b}^{j}\right) & \text { if } n_{b}^{j}=N_{b} \\
v_{b}^{j}-p_{b}+W\left(p_{b}, N_{b}-n_{b}^{j}, N_{b}-n_{b}^{j}+T_{b}\right) & \text { if } n_{b}^{j}<N_{b}\end{cases} \\
& D_{B 1}^{j}=v_{b}^{j}-W\left(p_{b}, 0, \tau_{b}^{j}\right) \quad \text { for } n_{b}^{j}=N_{b}
\end{aligned}
$$

Note that the functions $V(x, t), W\left(x, t_{1}, t_{2}\right)$, and $Y(x, t)$ used above, have been defined in Equations (3.2), (5.1), and (5.2), respectively.

Using the method explained in Table 3.3, we solve the asymmetric game of Scenario S2e for different combinations of parameters $\alpha_{v}$ and $\alpha_{d}$. Table 5.11 shows Firm $a$ 's optimal reward percentage $\left(R(\%)=1 / N_{a}\right)$ and optimal price $\left(p_{a}\right)$.

Table 5.11: Firm $a^{\prime}$ optimal decision variables in Scenario S2e for combinations of mental parameters

\begin{tabular}{c|cc|cc|cc|cc|cc|}
\hline$\alpha_{d}$ & \multicolumn{2}{|c|}{0.1} & \multicolumn{2}{|c|}{0.2} & \multicolumn{2}{|c|}{0.3} & \multicolumn{2}{|c|}{0.4} & \multicolumn{2}{|c}{0.5} \\
\hline$\alpha_{v}$ & $R(\%)$ & $p_{i}$ & $R(\%)$ & $p_{i}$ & $R(\%)$ & $p_{i}$ & $R(\%)$ & $p_{i}$ & $R(\%)$ & $p_{i}$ \\
\hline 0.5 & $1 \%$ & 2.109 & $1 \%$ & 2.091 & $1 \%$ & 2.071 & $1 \%$ & 2.066 & $1 \%$ & 2.062 \\
0.6 & $3 \%$ & 2.136 & $1 \%$ & 2.090 & $1 \%$ & 2.071 & $1 \%$ & 2.067 & $1 \%$ & 2.064 \\
0.7 & $20 \%$ & 2.397 & $7 \%$ & 2.166 & $1 \%$ & 2.072 & $1 \%$ & 2.072 & $1 \%$ & 2.072 \\
0.8 & $25 \%$ & 2.495 & $20 \%$ & 2.414 & $11 \%$ & 2.268 & $1 \%$ & 2.105 & $1 \%$ & 2.097 \\
0.9 & $25 \%$ & 2.562 & $20 \%$ & 2.502 & $20 \%$ & 2.493 & $13 \%$ & 2.319 & $3 \%$ & 2.147 \\
\hline
\end{tabular}


Table 5.12: Firm $a^{\prime}$ optimal profits in Scenario S2e for combinations of mental parameters

\begin{tabular}{c|ccccc}
\hline$\alpha_{d}$ & 0.1 & 0.2 & 0.3 & 0.4 & 0.5 \\
\hline$\alpha_{v}$ & & & & & \\
\hline 0.5 & 1.096 & 1.079 & 1.059 & 1.054 & 1.051 \\
0.6 & 1.094 & 1.078 & 1.059 & 1.055 & 1.052 \\
0.7 & 1.080 & 1.065 & 1.054 & 1.054 & 1.054 \\
0.8 & 1.067 & 1.074 & 1.072 & 1.064 & 1.062 \\
0.9 & 1.085 & 1.103 & 1.098 & 1.080 & 1.071 \\
\hline
\end{tabular}

The results in Table 5.11 indicate that Firm $a$ 's optimal reward and price increase for higher customers' reward valuations and lower customers' time valuations. Table 5.12 shows Firm $a$ 's optimal profits, and reveals a similar pattern for profit except when customers do not highly value time.

Tables 5.13 and 5.14 show Firm $b$ 's optimal decision variables $\left(N_{b}, T_{b}, p_{b}\right)$ and optimal profit, respectively, for different combinations of $\alpha_{v}$ and $\alpha_{d}$. As can be derived from Table 5.13, the optimal number of purchases to receive Firm $b$ 's reward increases for higher values of the point valuation parameter $\alpha_{v}$, and for lower values of the time parameter $\alpha_{d}$. This table also reveals that Firm $b$ should set a shorter expiry length when customers more highly value time and reward. Furthermore, according to tables 5.13-5.14, both Firm b's optimal price and profit in Scenario S2e increase for higher customers' reward valuation and lower customers' time valuation. 
Table 5.13: Firm $b$ 's optimal decision variables in Scenario S2e for combinations of mental parameters

\begin{tabular}{|c|c|c|c|c|c|c|c|c|c|c|c|c|c|c|c|}
\hline$\alpha_{d}$ & \multicolumn{3}{|c|}{0.1} & \multicolumn{3}{|c|}{0.2} & \multicolumn{3}{|c|}{0.3} & \multicolumn{3}{|c|}{0.4} & \multicolumn{3}{|c|}{0.5} \\
\hline$\alpha_{v}$ & $N_{i}$ & $T_{i}$ & $p_{i}$ & $N_{i}$ & $T_{i}$ & $p_{i}$ & $N_{i}$ & $T_{i}$ & $p_{i}$ & $N_{i}$ & $T_{i}$ & $p_{i}$ & $N_{i}$ & $T_{i}$ & $p_{i}$ \\
\hline 0.5 & 5 & 50 & 2.987 & 4 & 50 & 2.758 & 3 & 50 & 2.685 & 3 & 50 & 2.554 & 3 & 50 & 2.459 \\
\hline 0.6 & 5 & 50 & 3.243 & 4 & 50 & 2.931 & 3 & 50 & 2.822 & 3 & 50 & 2.664 & 3 & 50 & 2.550 \\
\hline 0.7 & 5 & 50 & 3.385 & 4 & 50 & 3.033 & 3 & 19 & 2.911 & 3 & 15 & 2.750 & 3 & 12 & 2.630 \\
\hline 0.8 & 6 & 50 & 3.350 & 4 & 19 & 3.132 & 3 & 11 & 3.058 & 3 & 10 & 2.861 & 3 & 8 & 2.732 \\
\hline 0.9 & 7 & 33 & 3.388 & 4 & 14 & 3.280 & 3 & 9 & 3.205 & 3 & 8 & 2.985 & 3 & 7 & 2.828 \\
\hline
\end{tabular}

Table 5.14: Firm b's optimal profit in Scenario S2e for combinations of mental parameters

\begin{tabular}{c|ccccc}
\hline$\alpha_{d}$ & 0.1 & 0.2 & 0.3 & 0.4 & 0.5 \\
$\alpha_{v}$ & & & & & \\
\hline 0.5 & 1.195 & 1.073 & 0.997 & 0.952 & 0.918 \\
0.6 & 1.301 & 1.144 & 1.053 & 0.997 & 0.957 \\
0.7 & 1.376 & 1.196 & 1.098 & 1.038 & 0.994 \\
0.8 & 1.423 & 1.249 & 1.158 & 1.088 & 1.037 \\
0.9 & 1.479 & 1.318 & 1.221 & 1.140 & 1.081 \\
\hline
\end{tabular}

Comparing the profits reported in Table 5.12 and Table 5.14, one can find the winner of Scenario S2e game. The hatched region in Table 5.15 refers to the conditions under which the unrestricted policy (Firm $a$ ) wins the competition. 
Table 5.15: Comparison of firms' profits in Scenario S2e for combinations of mental parameters (Firm $a$ earns higher profit than Firm $b$ in the shaded area)

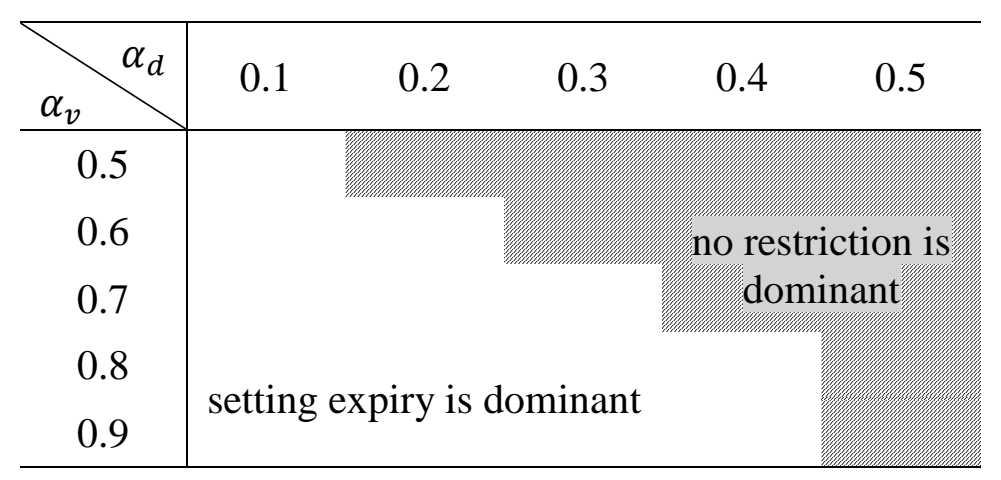

\subsection{Conclusion}

This chapter studied the effectiveness of designing loyalty programs where an expiry is set on rewards offered to customers. The motivation for this research was the lack of clear guidance in the literature about the impact of reward expiry on firms' profitability and customers' redemption of rewards (e.g., Breugelmans et al., 2015). While reward expiry may frustrate customers and lower their satisfaction and motivation, it can also result in increased consumer purchases. We used a game theoretic approach to explain why and when setting reward expiry can be beneficial for competing firms given different customers' preferences and the competing firm's actions and characteristics. To the best of our knowledge, this is the first attempt to study the strategic impact of setting reward expiry on the profitability of loyalty programs for competing firms.

To address this new research problem, we developed and solved a game theoretic model of a market formed by two competing firms. Our comprehensive multinomial logit model has the following unique properties: (1) consumer choice is derived using utility functions that reflect findings about consumer behaviour from two leading theories (the mental accounting and goal gradient theories); (2) the model is stochastic to account for varying consumer valuations; and (3) 
while most studies to date consider a single firm's problem, our model represents a market formed by two competing firms.

Using a numerical analysis, we obtained Nash equilibrium solutions for three games: two symmetric games, (1) where neither firm sets reward expiry, and (2) where both firms set reward expiry; and (3) one asymmetric game where only one firm sets reward expiry. In each of these three games, the firm that sets expiry on rewards determines price, the timing of the reward, and the expiry length, while the firm that sets no expiry determines only price and the timing of the reward. Comparing optimal profits across scenarios, an equilibrium solution is found for the main game in which each firm decides whether or not to set reward expiry.

Our main findings indicate that each firm's price and profit are affected by the loyalty program of the competing firm and by consumers' valuation of rewards and of time distance to rewards. In particular, a firm offering rewards that do not expire should increase its price if the competing firm changes its reward policy from no expiry to expiry, even when the expiry period is quite long. Further, when customers highly value reward and time, reward expiry is a dominant strategy for both firms, i.e., both firms gain the most profits when they both have reward expiry. However, both firms' rewards should not expire if consumers have low valuations of both rewards and time. 


\section{Conclusion, contributions and future research}

\subsection{Conclusion and summary of contributions}

This thesis had two main goals. First, to investigate the profitability of loyalty programs in a competitive market, and second, to examine the effects of restricting the redemption policy on the firms' profitability. These goals were investigated in Chapters 3 to 5 . This section concludes this thesis and provides a summary of its contributions.

In Chapter 3, a model was developed to study the profitability of loyalty programs in a competitive environment. The model presented in Chapter 3 is stochastic to capture unknown parameters of customers' utilities. It addressed a gap in the literature on the impacts of customers' valuation of both value and redemption/expiration time of rewards. The model applied a game theoretic approach with Nash equilibrium solutions. To study the profitability of LPs, three subgames were considered: two symmetric games and an asymmetric one. In the first symmetric game, two firms compete by offering LPs, while in the second game, no LPs are offered. In the asymmetric game, one firm is offering the LP while the other is not. The performance measure of LP was a firm's profit. Different combinations of the values of mental parameters (reward and time value coefficients), which describe a customer's behavior towards a reward and its redemption time, were investigated. The firms' profits in the three scenarios were compared to determine an equilibrium solution for the main game, where each firm decides whether or not it should offer an LP.

The results showed that the firm that offers an LP gains higher profits when the game is asymmetric. However, when customers are highly sensitive to time (have a high discount rate), 
both firms are better off without offering an LP. We also specified the conditions under which the firms face is a prisoner dilemma situation, in which case the equilibrium of the game is to offer LP by both firms, while not offering LP results in a higher profit for both firms. These results could help explain some contradictory findings in the LP literature about their profitability.

The extended model of Chapter 3 considered the common assumption that an exogenous fraction of customers leaves the market. This issue has been insufficiently studied in the literature. To address this gap, the model allows customers to purchase an outside good that is not offered by either of the competing firms. The results showed that the existence of an outside source affects the LP policy less than the No-LP policy. The results also showed that there are better chances of gaining higher profits through LPs.

Chapters 4 and 5 investigated the impact of reward restriction on the profitability of LPs for competing firms. Three levels of restrictions on reward redemption were considered: 1) no restriction on redemption, 2) redemption is not allowed during the first $N$ purchases, and 3) redemption is not allowed during the first $N$ purchases and after $T$ periods from the time of being eligible to redeem. Chapter 4 studied the competition between the first two levels, which we denoted as "unrestricted" and "restricted" redemption policies. Chapter 5 denoted levels 2 and 3 by "without expiry" and "with expiry", respectively. To connect the results in chapters 4 and 5, we denote these three levels of restrictions as unrestricted, low restricted, and high restricted redemption policies, respectively, in the remainder of this thesis.

Chapter 4 compared the unrestricted and the low restricted redemption policies by modeling and solving three sub-games; two symmetric and one asymmetric. In the symmetric games, both firms either restrict or not restrict redemption. In the asymmetric game, one firm restricts and another one does not restrict reward redemption. The results showed that, at 
equilibrium, it is profitable for both firms not to restrict redemption when customers are sensitive to the reward redemption time but not to its value. However, when consumers highly value rewards but not time, applying a low restricted policy is the equilibrium. Furthermore, the conditions under which the firms face a prisoner dilemma were specified. The results showed that the equilibrium occurs when the reward redemption policies are not restricted, while higher profits are gained when the policies are restricted.

Chapter 5 investigated the profitability of exercising a high restriction on redemption for the competing firms' LPs. Three sub-games were studied and solved; two symmetric and one asymmetric. In the first two, both firms either set or do not set an expiry date, while only one firm sets an expiry date in the third game. Different combinations of mental parameters were considered in the three games. The results showed that, at equilibrium, it is profitable for the firms to set an expiry date for their rewards when customers highly value both rewards and time. However, firms react differently when customers have low valuations of rewards and time.

This chapter also studied an asymmetric game where one firm highly restricts redemption of rewards by both setting a required number of purchases and an expiration date. The other firm has an unrestricted redemption policy and allows customers to redeem their rewards as much as and whenever they want without any expiration date. The results showed that the highly restricted policy is more profitable than the unrestricted policy when customers highly value reward but not time.

An additional analysis of the results obtained in Chapters 4 and 5 is included below. A game where the two firms jointly decide of the level of reward redemption restriction is solved. Denoting unrestricted, low restricted, and high restricted policies as UR, L, and H, respectively, the payoff matrix of this game for each combination of parameters $\alpha_{v}$ and $\alpha_{d}$ is as follows. 
The four profits $\left(I_{i}^{U R, U R}, I_{i}^{L, L}, I_{i}^{L, U R}, I_{i}^{U R, L}\right)$ and five profits $\left(I_{i}^{H, H}, I_{i}^{H, L}, I_{i}^{L, H}, I_{i}^{U R, H}, I_{i}^{U R, H}\right)$ are obtained from Chapter 4 and 5, respectively, where $i \in\{a, b\}$ in the final section of Chapter 5. These nine profits are scaled as shown in Table B.5 in Appendix B, for 25 combinations of parameters $\alpha_{v}$ and $\alpha_{d}$.

\begin{tabular}{c|ccc}
\hline Firm $b$ & $\mathrm{UR}$ & $\mathrm{L}$ & $\mathrm{H}$ \\
\hline $\mathrm{UR}$ & $\left(I_{a}^{U R, U R}, I_{b}^{U R, U R}\right)$ & $\left(I_{a}^{U R, L}, I_{b}^{U R, L}\right)$ & $\left(I_{a}^{U R, H}, I_{b}^{U R, H}\right)$ \\
$\mathrm{L}$ & $\left(I_{a}^{L, L}, I_{b}^{L, U R}\right)$ & $\left(I_{a}^{L, L}, I_{b}^{L, L}\right)$ & $\left(I_{a}^{L, H}, I_{b}^{L, H}\right)$ \\
$\mathrm{H}$ & $\left(I_{a}^{H, U R}, I_{b}^{H, U R}\right)$ & $\left(I_{a}^{H, L}, I_{b}^{H, L}\right)$ & $\left(I_{a}^{H, H}, I_{b}^{H, H}\right)$ \\
\hline
\end{tabular}

Based on this table, the combinations of mental parameters can be divided into three regions as shown in Table 6.1.

In almost all the combinations in Table 6.1, both firms follow a highly restricted policy at equilibrium. When customers do not highly value reward and time (the dark shaded area of Table 6.1), a prisoner dilemma occurs, where a low restricted policy results in higher profits for both firms. When customers do not highly value reward but very highly value time (the light shaded area of Table 6.1), a prisoner dilemma also occurs, where an unrestricted policy results in higher profits for both firms. For the remaining conditions, a highly restricted redemption policy is the dominant equilibrium of the system.

As mentioned before, this thesis is an attempt to explain the contradictory findings on the effectiveness of loyalty programs by deriving a comprehensive analytical model. The model contributes to the literature since it is stochastic and competitive, and incorporates two psychological theories (the goal gradient theory and mental accounting theory). Furthermore, this 
thesis presented a comprehensive investigation of the effects of different redemption restriction levels on the profitability of loyalty programs. To the author's knowledge, this thesis is the first to do so. A new numerical method was introduced to solve games between two firms that have nonlinear profit functions.

Table 6.1: Different regions in the game between three levels of restriction redemption policies for combinations of mental parameters

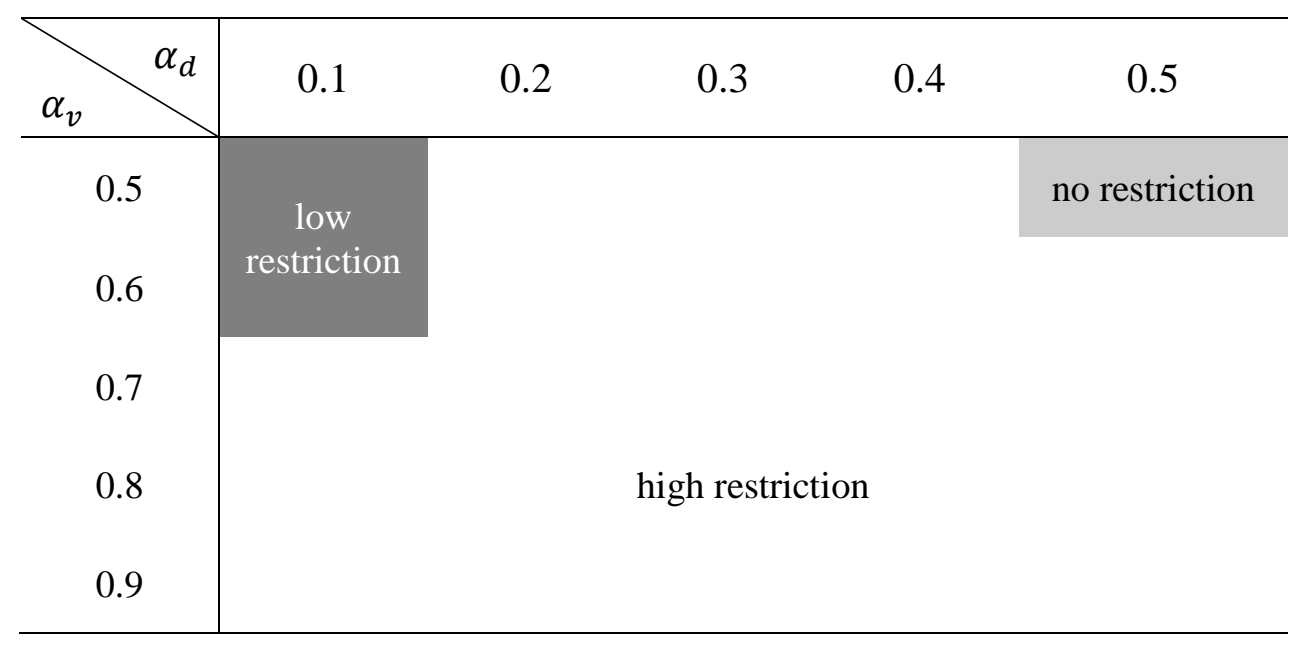

\subsection{Future research}

This thesis provided preliminary insights on the effects of customers' behavioural factors on the design and profitability of loyalty programs. This analysis could be extended in several ways to address issues overlooked in this thesis.

For instance, our model is useful to firms operating in mature industries and facing similar competitors, such as the food and entertainment industries. Firms in such industries are willing to keep their prices constant and use marketing strategies aimed at increasing customers' loyalty (Henderson et al., 2011; Kumar \& Shah, 2004; Nunes \& Drèze, 2006). Therefore, they are highly 
concerned about the effective design of their loyalty programs. One could expand the model by removing this assumption. A dynamic game approach could be used to formulate and optimize the revenue function under the dynamic pricing assumption, making it applicable to other sectors in which prices frequently change (see Haurie \& Zaccour, 2005). For instance, the impact of loyalty programs (e.g., Aeroplan and AIR MILES) and dynamic pricing can be investigated in the airline industry where customers experience dynamic pricing and also dynamic values for the rewards.

Furthermore, we have derived our results for a market offering an undifferentiated product. Future research could adapt our model to study markets where products are differentiated and customers might have significantly different valuations for each firm's product. Under this condition, the value of the products cannot be removed from the equations. Consequently, the probability of purchasing from a particular firm by a customer depends on the customer's valuation of that firm's product as well as the customer's purchasing history. This uncertainty can be addressed by assuming that product valuations follow known random distribution. Besides multiple products, future research can also investigate the conditions under which firms could offer different kinds of LPs or of rewards (e.g., reward points, upgrades or price discounts). For instance, a firm can apply different levels of restriction on redemption policies for different products or different groups of customers. While we considered that the market is homogeneous, i.e., all customers have the same metal parameters, future work can study scenarios where consumers pertain to different segments (groups) with different levels of mental parameters.

Future research can also investigate the impacts of loyalty programs on inventory and production policies. Loyalty programs may increase demand and affect production and inventory policies in a supply chain. It could also reduce the effects of the perishability of items by increasing the inventory turnover. For instance, seat inventory is an expensive resource for an airline 
company, and it should be utilized to its fullest capacity. Loyalty programs may help airline companies in improving the seat occupancy on their fleet.

Loyalty programs also affect the liability of the firms. From a risk management point of view, the number of time customers redeem their stockpiled rewards is very important as well as the value of the redeemed rewards. Finally, future research can include other factors such as the firms' uncertainty about the competing firms' strategies in an incomplete information setting or customers' satisfaction with the product. For example, customer satisfaction can be modeled by adding a variable between 0 (not satisfied) and 1 (fully satisfied) to characterize consumer groups in our model. 


\section{Appendix A}

This Appendix presents the firms' optimal decision variables and profits under three scenarios of S1 (both firms offer LP), S2 (only Firm $a$ offers LP), and S3 (none of the firm offers LP), where there is outside goods, for different combinations of parameters of $\alpha_{v}$ and $\alpha_{d}$.

Table A.1: Optimal reward timing (required number of purchases before redemption) in Scenario S1 of the game between LP and No-LP with an outside good

\begin{tabular}{c|ccccccccc}
$\alpha_{v} \alpha_{d}$ & 0.1 & 0.2 & 0.3 & 0.4 & 0.5 & 0.6 & 0.7 & 0.8 & 0.9 \\
\hline 0.1 & 10 & 10 & 10 & 10 & 10 & 10 & 10 & 10 & 10 \\
0.2 & 6 & 5 & 5 & 5 & 5 & 6 & 7 & 10 & 10 \\
0.3 & 5 & 4 & 4 & 3 & 3 & 3 & 3 & 4 & 4 \\
0.4 & 5 & 3 & 3 & 3 & 3 & 3 & 3 & 3 & 3 \\
0.5 & 4 & 3 & 3 & 3 & 3 & 2 & 2 & 2 & 2 \\
0.6 & 5 & 3 & 3 & 3 & 2 & 2 & 2 & 2 & 2 \\
0.7 & 5 & 4 & 3 & 3 & 2 & 2 & 2 & 2 & 2 \\
0.8 & 6 & 4 & 3 & 3 & 3 & 2 & 2 & 2 & 2 \\
0.9 & 6 & 4 & 4 & 3 & 3 & 3 & 2 & 2 & 2 \\
\hline
\end{tabular}


Table A.2: Optimal price in Scenario S1 of the game between LP and No-LP with outside goods for combinations of mental parameters

\begin{tabular}{|c|c|c|c|c|c|c|c|c|c|}
\hline$\alpha_{d}$ & 0.1 & 0.2 & 0.3 & 0.4 & 0.5 & 0.6 & 0.7 & 0.8 & 0.9 \\
\hline 0.1 & 1.510 & 1.479 & 1.462 & 1.452 & 1.445 & 1.441 & 1.437 & 1.435 & 1.433 \\
\hline 0.2 & 1.666 & 1.621 & 1.581 & 1.553 & 1.533 & 1.501 & 1.479 & 1.451 & 1.447 \\
\hline 0.3 & 1.841 & 1.769 & 1.702 & 1.702 & 1.666 & 1.639 & 1.617 & 1.560 & 1.546 \\
\hline 0.4 & 2.023 & 1.965 & 1.867 & 1.797 & 1.746 & 1.706 & 1.675 & 1.651 & 1.630 \\
\hline 0.5 & 2.272 & 2.117 & 1.984 & 1.891 & 1.823 & 1.863 & 1.821 & 1.786 & 1.757 \\
\hline 0.6 & 2.410 & 2.245 & 2.085 & 1.972 & 1.986 & 1.926 & 1.878 & 1.838 & 1.804 \\
\hline 0.7 & 2.537 & 2.263 & 2.149 & 2.031 & 2.021 & 1.962 & 1.912 & 1.870 & 1.835 \\
\hline 0.8 & 2.546 & 2.287 & 2.157 & 2.050 & 1.964 & 1.962 & 1.918 & 1.879 & 1.845 \\
\hline 0.9 & 2.484 & 2.241 & 2.102 & 2.030 & 1.958 & 1.897 & 1.896 & 1.864 & 1.835 \\
\hline
\end{tabular}

Table A.3: Optimal profit in Scenario S1 of the game between LP and No-LP with outside goods for combinations of mental parameters

\begin{tabular}{|c|c|c|c|c|c|c|c|c|c|}
\hline$\alpha_{d}$ & 0.1 & 0.2 & 0.3 & 0.4 & 0.5 & 0.6 & 0.7 & 0.8 & 0.9 \\
\hline 0.1 & 0.406 & 0.398 & 0.394 & 0.391 & 0.389 & 0.388 & 0.387 & 0.386 & 0.386 \\
\hline 0.2 & 0.431 & 0.412 & 0.403 & 0.396 & 0.391 & 0.390 & 0.389 & 0.391 & 0.390 \\
\hline 0.3 & 0.466 & 0.438 & 0.422 & 0.406 & 0.398 & 0.392 & 0.387 & 0.388 & 0.385 \\
\hline 0.4 & 0.511 & 0.465 & 0.444 & 0.429 & 0.417 & 0.408 & 0.401 & 0.396 & 0.391 \\
\hline 0.5 & 0.557 & 0.501 & 0.472 & 0.451 & 0.436 & 0.417 & 0.409 & 0.401 & 0.396 \\
\hline 0.6 & 0.611 & 0.534 & 0.498 & 0.473 & 0.447 & 0.434 & 0.424 & 0.416 & 0.409 \\
\hline 0.7 & 0.653 & 0.567 & 0.519 & 0.491 & 0.461 & 0.447 & 0.436 & 0.427 & 0.420 \\
\hline 0.8 & 0.682 & 0.585 & 0.532 & 0.503 & 0.482 & 0.456 & 0.445 & 0.436 & 0.428 \\
\hline 0.9 & 0.690 & 0.590 & 0.544 & 0.509 & 0.488 & 0.471 & 0.449 & 0.440 & 0.433 \\
\hline
\end{tabular}


Table A.4: Firm $a$ 's optimal reward timing (required number of purchases before redemption) in Scenario S2 of the game between LP and No-LP with an outside good for combinations of mental parameters

\begin{tabular}{c|ccccccccc}
\hline$\alpha_{v} \alpha_{d}$ & 0.1 & 0.2 & 0.3 & 0.4 & 0.5 & 0.6 & 0.7 & 0.8 & 0.9 \\
\hline 0.1 & 10 & 10 & 10 & 10 & 10 & 10 & 10 & 10 & 10 \\
0.2 & 7 & 5 & 5 & 5 & 5 & 6 & 8 & 10 & 10 \\
0.3 & 5 & 4 & 4 & 3 & 3 & 3 & 4 & 4 & 4 \\
0.4 & 5 & 4 & 3 & 3 & 3 & 3 & 3 & 3 & 3 \\
0.5 & 4 & 3 & 3 & 3 & 3 & 2 & 2 & 2 & 2 \\
0.6 & 5 & 3 & 3 & 3 & 2 & 2 & 2 & 2 & 2 \\
0.7 & 5 & 4 & 3 & 3 & 3 & 2 & 2 & 2 & 2 \\
0.8 & 6 & 4 & 3 & 3 & 3 & 2 & 2 & 2 & 2 \\
0.9 & 6 & 4 & 4 & 3 & 3 & 3 & 2 & 2 & 2 \\
\hline
\end{tabular}

Table A.5: Firm $a$ 's optimal price in Scenario S2 of the game between LP and No-LP outside goods for combinations of mental parameters

\begin{tabular}{c|ccccccccc}
\hline$\alpha_{v} \alpha_{d}$ & 0.1 & 0.2 & 0.3 & 0.4 & 0.5 & 0.6 & 0.7 & 0.8 & 0.9 \\
\hline 0.1 & 1.519 & 1.488 & 1.470 & 1.460 & 1.454 & 1.449 & 1.446 & 1.443 & 1.442 \\
0.2 & 1.664 & 1.639 & 1.599 & 1.571 & 1.551 & 1.516 & 1.481 & 1.460 & 1.456 \\
0.3 & 1.860 & 1.792 & 1.724 & 1.732 & 1.696 & 1.668 & 1.597 & 1.581 & 1.568 \\
0.4 & 2.041 & 1.928 & 1.897 & 1.827 & 1.775 & 1.736 & 1.705 & 1.679 & 1.659 \\
0.5 & 2.297 & 2.149 & 2.015 & 1.921 & 1.853 & 1.907 & 1.864 & 1.829 & 1.799 \\
0.6 & 2.433 & 2.279 & 2.118 & 2.004 & 2.031 & 1.970 & 1.921 & 1.880 & 1.846 \\
0.7 & 2.567 & 2.293 & 2.185 & 2.064 & 1.974 & 2.007 & 1.956 & 1.913 & 1.877 \\
0.8 & 2.582 & 2.324 & 2.198 & 2.087 & 1.999 & 2.009 & 1.962 & 1.922 & 1.888 \\
0.9 & 2.533 & 2.287 & 2.138 & 2.072 & 1.996 & 1.933 & 1.942 & 1.908 & 1.878 \\
\hline
\end{tabular}


Table A.6: Firm $a$ 's optimal profit in Scenario S2 of the game between LP and No-LP with outside goods for combinations of mental parameters

\begin{tabular}{c|ccccccccc}
\hline$\alpha_{v} \alpha_{d}$ & 0.1 & 0.2 & 0.3 & 0.4 & 0.5 & 0.6 & 0.7 & 0.8 & 0.9 \\
\hline 0.1 & 0.414 & 0.406 & 0.401 & 0.399 & 0.397 & 0.396 & 0.395 & 0.394 & 0.394 \\
0.2 & 0.444 & 0.427 & 0.417 & 0.410 & 0.405 & 0.402 & 0.400 & 0.399 & 0.398 \\
0.3 & 0.482 & 0.456 & 0.440 & 0.428 & 0.420 & 0.414 & 0.410 & 0.406 & 0.403 \\
0.4 & 0.526 & 0.489 & 0.467 & 0.451 & 0.440 & 0.431 & 0.424 & 0.418 & 0.413 \\
0.5 & 0.577 & 0.525 & 0.495 & 0.474 & 0.459 & 0.447 & 0.438 & 0.431 & 0.425 \\
0.6 & 0.629 & 0.560 & 0.523 & 0.497 & 0.477 & 0.464 & 0.454 & 0.445 & 0.438 \\
0.7 & 0.678 & 0.592 & 0.547 & 0.517 & 0.495 & 0.479 & 0.467 & 0.458 & 0.449 \\
0.8 & 0.717 & 0.617 & 0.565 & 0.533 & 0.509 & 0.490 & 0.478 & 0.468 & 0.459 \\
0.9 & 0.742 & 0.632 & 0.577 & 0.544 & 0.519 & 0.500 & 0.485 & 0.474 & 0.466 \\
\hline
\end{tabular}

Table A.7: Firm $b$ 's optimal price in Scenario S2 of the game between LP and No-LP with outside goods for combinations of mental parameters

\begin{tabular}{c|ccccccccc}
\hline$\alpha_{v} \alpha_{d}$ & 0.1 & 0.2 & 0.3 & 0.4 & 0.5 & 0.6 & 0.7 & 0.8 & 0.9 \\
\hline 0.1 & 1.393 & 1.393 & 1.393 & 1.393 & 1.393 & 1.393 & 1.393 & 1.393 & 1.393 \\
0.2 & 1.391 & 1.387 & 1.387 & 1.387 & 1.387 & 1.389 & 1.391 & 1.393 & 1.393 \\
0.3 & 1.388 & 1.385 & 1.384 & 1.380 & 1.380 & 1.379 & 1.384 & 1.384 & 1.384 \\
0.4 & 1.389 & 1.386 & 1.381 & 1.381 & 1.380 & 1.380 & 1.380 & 1.380 & 1.379 \\
0.5 & 1.388 & 1.383 & 1.382 & 1.381 & 1.381 & 1.374 & 1.373 & 1.373 & 1.373 \\
0.6 & 1.389 & 1.382 & 1.382 & 1.381 & 1.375 & 1.374 & 1.374 & 1.374 & 1.374 \\
0.7 & 1.386 & 1.384 & 1.380 & 1.380 & 1.380 & 1.374 & 1.374 & 1.374 & 1.374 \\
0.8 & 1.381 & 1.379 & 1.377 & 1.378 & 1.379 & 1.372 & 1.373 & 1.373 & 1.373 \\
0.9 & 1.372 & 1.373 & 1.378 & 1.374 & 1.376 & 1.377 & 1.371 & 1.371 & 1.372 \\
\hline
\end{tabular}


Table A.8: Firm $b$ 's optimal profit in Scenario S2 of the game between LP and No-LP with outside goods for combinations of mental parameters

\begin{tabular}{|c|c|c|c|c|c|c|c|c|c|}
\hline$\alpha_{d}$ & 0.1 & 0.2 & 0.3 & 0.4 & 0.5 & 0.6 & 0.7 & 0.8 & 0.9 \\
\hline 0.1 & 0.393 & 0.393 & 0.393 & 0.393 & 0.393 & 0.393 & 0.393 & 0.393 & 0.393 \\
\hline 0.2 & 0.391 & 0.387 & 0.387 & 0.387 & 0.387 & 0.389 & 0.391 & 0.393 & 0.393 \\
\hline 0.3 & 0.388 & 0.385 & 0.384 & 0.380 & 0.380 & 0.379 & 0.384 & 0.384 & 0.384 \\
\hline 0.4 & 0.389 & 0.386 & 0.381 & 0.381 & 0.380 & 0.380 & 0.380 & 0.380 & 0.379 \\
\hline 0.5 & 0.388 & 0.383 & 0.382 & 0.381 & 0.381 & 0.374 & 0.373 & 0.373 & 0.373 \\
\hline 0.6 & 0.389 & 0.382 & 0.382 & 0.381 & 0.375 & 0.374 & 0.374 & 0.374 & 0.374 \\
\hline 0.7 & 0.386 & 0.384 & 0.380 & 0.380 & 0.380 & 0.374 & 0.374 & 0.374 & 0.374 \\
\hline 0.8 & 0.381 & 0.379 & 0.377 & 0.378 & 0.379 & 0.372 & 0.373 & 0.373 & 0.373 \\
\hline 0.9 & 0.393 & 0.393 & 0.393 & 0.393 & 0.393 & 0.393 & 0.393 & 0.393 & 0.393 \\
\hline
\end{tabular}




\section{Appendix B}

This Appendix presents the scaled format of payoff matrices for different games of this thesis for different combinations of parameters of $\alpha_{v}$ and $\alpha_{d}$. Different regions of the games are shown by similar shading as the original tables in the body of chapters.

For each combination of $\alpha_{v}$ and $\alpha_{d}$, the payoff matrix is in the format shown below, where the firms decide about two policies (named 1 and 2), and $I_{i}^{x, y}$ is Firm $i$ 's profit when Firm $a$ 's and Firm $b$ 's choices are policies $x$ and $y$, respectively. In the applied scaling, 1 represents the lowest profit.

\begin{tabular}{c|cc}
\hline Firm $a$ & Policy 1 & Policy 2 \\
\hline Policy 1 & & \\
Policy 2 & $\left(I_{a}^{1,1}, I_{b}^{1,1}\right)$ & $\left(I_{a}^{1,2}, I_{b}^{1,2}\right)$ \\
& $\left(I_{a}^{2,1}, I_{b}^{2,1}\right)$ & $\left(I_{a}^{2,2}, I_{b}^{2,2}\right)$ \\
\hline
\end{tabular}


Table B.1: Scaled payoff matrices of the game between "LP" and "No-LP" policies for combinations of mental parameters

\begin{tabular}{|c|c|c|c|c|c|c|c|c|c|c|c|c|c|c|c|c|c|c|}
\hline & \multicolumn{2}{|c|}{0.1} & \multicolumn{2}{|c|}{0.2} & \multicolumn{2}{|c|}{0.3} & \multicolumn{2}{|c|}{0.4} & \multicolumn{2}{|c|}{0.5} & \multicolumn{2}{|c|}{0.6} & \multicolumn{2}{|c|}{0.7} & \multicolumn{2}{|c|}{0.8} & \multicolumn{2}{|c|}{0.9} \\
\hline \multirow{2}{*}{0.1} & 1,1 & 3,2 & 1,1 & 3,2 & 1,1 & 2,3 & 1,1 & 2,3 & 1,1 & 2,3 & 1,1 & 2,3 & 1,1 & 2,3 & 1,1 & 2,3 & 1,1 & 2,3 \\
\hline & 2,3 & 4,4 & 2,3 & 4,4 & 3,2 & 4,4 & 3,2 & 4,4 & 3,2 & 4,4 & 3,2 & 4,4 & 3,2 & 4,4 & 3,2 & 4,4 & 3,2 & 4,4 \\
\hline \multirow{2}{*}{0.2} & 3,3 & 4,1 & 2,2 & 4,1 & 1,1 & 3,2 & 1,1 & 3,2 & 1,1 & 3,2 & 1,1 & 3,2 & 1,1 & 2,3 & 1,1 & 2,3 & 1,1 & 2,3 \\
\hline & 1,4 & 2,2 & 1,4 & 3,3 & 2,3 & 4,4 & 2,3 & 4,4 & 2,3 & 4,4 & 2,3 & 4,4 & 3,2 & 4,4 & 3,2 & 4,4 & 3,2 & 4,4 \\
\hline \multirow{2}{*}{0.3} & 3,3 & 4,1 & 3,3 & 4,1 & 2,2 & 4,1 & 2,2 & 4,1 & 1,1 & 3,2 & 1,1 & 3,2 & 1,1 & 3,2 & 1,1 & 3,2 & 1,1 & 3,2 \\
\hline & 1,4 & 2,2 & 1,4 & 2,2 & 1,4 & 3,3 & 1,4 & 3,3 & 2,3 & 4,4 & 2,3 & 4,4 & 2,3 & 4,4 & 2,3 & 4,4 & 2,3 & 4,4 \\
\hline \multirow{2}{*}{0.4} & 3,3 & 4,1 & 3,3 & 4,1 & 3,3 & 4,1 & 2,2 & 4,1 & 2,2 & 4,1 & 1,1 & 3,2 & 1,1 & 3,2 & 1,1 & 3,2 & 1,1 & 3,2 \\
\hline & 1,4 & 2,2 & 1,4 & 2,2 & 1,4 & 2,2 & 1,4 & 3,3 & 1,4 & 3,3 & 2,3 & 4,4 & 2,3 & 4,4 & 2,3 & 4,4 & 2,3 & 4,4 \\
\hline \multirow{2}{*}{0.5} & 3,3 & 4,1 & 3,3 & 4,1 & 3,3 & 4,1 & 3,3 & 4,1 & 2,2 & 4,1 & 2,2 & 4,1 & 2,2 & 4,1 & 1,1 & 3,2 & 1,1 & 3,2 \\
\hline & 1,4 & 2,2 & 1,4 & 2,2 & 1,4 & 2,2 & 1,4 & 2,2 & 1,4 & 3,3 & 1,4 & 3,3 & 1,4 & 3,3 & 2,3 & 4,4 & 2,3 & 4,4 \\
\hline \multirow{2}{*}{0.6} & 3,3 & 4,1 & 3,3 & 4,1 & 3,3 & 4,1 & 3,3 & 4,1 & 3,3 & 4,1 & 2,2 & 4,1 & 2,2 & 4,1 & 2,2 & 4,1 & 1,1 & 3,2 \\
\hline & 1,4 & 2,2 & 1,4 & 2,2 & 1,4 & 2,2 & 1,4 & 2,2 & 1,4 & 2,2 & 1,4 & 3,3 & 1,4 & 3,3 & 1,4 & 3,3 & 2,3 & 4,4 \\
\hline \multirow{2}{*}{0.7} & 3,3 & 4,1 & 3,3 & 4,1 & 3,3 & 4,1 & 3,3 & 4,1 & 3,3 & 4,1 & 3,3 & 4,1 & 2,2 & 4,1 & 2,2 & 4,1 & 2,2 & 4,1 \\
\hline & 1,4 & 2,2 & 1,4 & 2,2 & 1,4 & 2,2 & 1,4 & 2,2 & 1,4 & 2,2 & 1,4 & 2,2 & 1,4 & 3,3 & 1,4 & 3,3 & 1,4 & 3,3 \\
\hline \multirow{2}{*}{0.8} & 3,3 & 4,1 & 3,3 & 4,1 & 3,3 & 4,1 & 3,3 & 4,1 & 3,3 & 4,1 & 3,3 & 4,1 & 2,2 & 4,1 & 2,2 & 4,1 & 2,2 & 4,1 \\
\hline & 1,4 & 2,2 & 1,4 & 2,2 & 1,4 & 2,2 & 1,4 & 2,2 & 1,4 & 2,2 & 1,4 & 2,2 & 1,4 & 3,3 & 1,4 & 3,3 & 1,4 & 3,3 \\
\hline \multirow{2}{*}{0.9} & 3,3 & 4,1 & 3,3 & 4,1 & 3,3 & 4,1 & 3,3 & 4,1 & 3,3 & 4,1 & 3,3 & 4,1 & 2,2 & 4,1 & 2,2 & 4,1 & 2,2 & 4,1 \\
\hline & 1,4 & 2,2 & 1,4 & 2,2 & 1,4 & 2,2 & 1,4 & 2,2 & 1,4 & 2,2 & 1,4 & 2,2 & 1,4 & 3,3 & 1,4 & 3,3 & 1,4 & 3,3 \\
\hline
\end{tabular}

Legend:

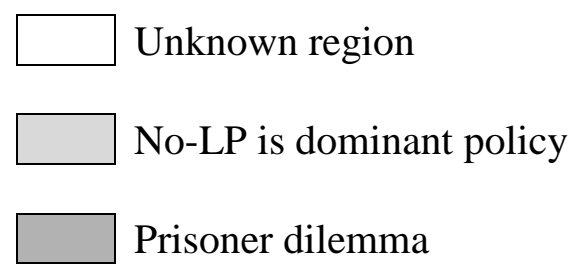

LP is dominant policy 
Table B.2: Scaled payoff matrices of the game between "LP" and "No-LP" policies with outside goods for combinations of mental parameters

\begin{tabular}{|c|c|c|c|c|c|c|c|c|c|c|c|c|c|c|c|c|c|c|}
\hline & \multicolumn{2}{|c|}{0.1} & \multicolumn{2}{|c|}{0.2} & \multicolumn{2}{|c|}{0.3} & \multicolumn{2}{|c|}{0.4} & \multicolumn{2}{|c|}{0.5} & \multicolumn{2}{|c|}{0.6} & \multicolumn{2}{|c|}{0.7} & \multicolumn{2}{|c|}{0.8} & \multicolumn{2}{|c|}{0.9} \\
\hline \multirow{2}{*}{0.1} & 3,3 & 4,1 & 2,2 & 4,1 & 2,2 & 4,1 & 1,1 & 3,2 & 1,1 & 3,2 & 1,1 & 3,2 & 1,1 & 3,2 & 1,1 & 3,2 & 1,1 & 3,2 \\
\hline & 1,4 & 2,2 & 1,4 & 3,3 & 1,4 & 3,3 & 2,3 & 4,4 & 2,3 & 4,4 & 2,3 & 4,4 & 2,3 & 4,4 & 2,3 & 4,4 & 2,3 & 4,4 \\
\hline \multirow{2}{*}{0.2} & 3,3 & 4,1 & 3,3 & 4,1 & 3,3 & 4,1 & 2,2 & 4,1 & 2,2 & 4,1 & 2,2 & 4,1 & 1,1 & 3,2 & 1,1 & 3,2 & 1,1 & 3,2 \\
\hline & 1,4 & 2,2 & 1,4 & 2,2 & 1,4 & 2,2 & 1,4 & 3,3 & 1,4 & 3,3 & 1,4 & 3,3 & 2,3 & 4,4 & 2,3 & 4,4 & 2,3 & 4,4 \\
\hline \multirow{2}{*}{0.3} & 3,3 & 4,1 & 3,3 & 4,1 & 3,3 & 4,1 & 3,3 & 4,1 & 2,2 & 4,1 & 2,2 & 4,1 & 2,2 & 4,1 & 2,2 & 4,1 & 2,2 & 4,1 \\
\hline & 1,4 & 2,2 & 1,4 & 2,2 & 1,4 & 2,2 & 1,4 & 2,2 & 1,4 & 3,3 & 1,4 & 3,3 & 1,4 & 3,3 & 1,4 & 3,3 & 1,4 & 3,3 \\
\hline \multirow{2}{*}{0.4} & 3,3 & 4,1 & 3,3 & 4,1 & 3,3 & 4,1 & 3,3 & 4,1 & 3,3 & 4,1 & 3,3 & 4,1 & 3,3 & 4,1 & 2,2 & 4,1 & 2,2 & 4,1 \\
\hline & 1,4 & 2,2 & 1,4 & 2,2 & 1,4 & 2,2 & 1,4 & 2,2 & 1,4 & 2,2 & 1,4 & 2,2 & 1,4 & 2,2 & 1,4 & 3,3 & 1,4 & 3,3 \\
\hline \multirow{2}{*}{0.5} & 3,3 & 4,1 & 3,3 & 4,1 & 3,3 & 4,1 & 3,3 & 4,1 & 3,3 & 4,1 & 3,3 & 4,1 & 3,3 & 4,1 & 3,3 & 4,1 & 2,2 & 4,1 \\
\hline & 1,4 & 2,2 & 1,4 & 2,2 & 1,4 & 2,2 & 1,4 & 2,2 & 1,4 & 2,2 & 1,4 & 2,2 & 1,4 & 2,2 & 1,4 & 2,2 & 1,4 & 3,3 \\
\hline \multirow{2}{*}{0.6} & 3,3 & 4,1 & 3,3 & 4,1 & 3,3 & 4,1 & 3,3 & 4,1 & 3,3 & 4,1 & 3,3 & 4,1 & 3,3 & 4,1 & 3,3 & 4,1 & 3,3 & 4,1 \\
\hline & 1,4 & 2,2 & 1,4 & 2,2 & 1,4 & 2,2 & 1,4 & 2,2 & 1,4 & 2,2 & 1,4 & 2,2 & 1,4 & 2,2 & 1,4 & 2,2 & 1,4 & 2,2 \\
\hline \multirow{2}{*}{0.7} & 3,3 & 4,1 & 3,3 & 4,1 & 3,3 & 4,1 & 3,3 & 4,1 & 3,3 & 4,1 & 3,3 & 4,1 & 3,3 & 4,1 & 3,3 & 4,1 & 3,3 & 4,1 \\
\hline & 1,4 & 2,2 & 1,4 & 2,2 & 1,4 & 2,2 & 1,4 & 2,2 & 1,4 & 2,2 & 1,4 & 2,2 & 1,4 & 2,2 & 1,4 & 2,2 & 1,4 & 2,2 \\
\hline \multirow{2}{*}{0.8} & 3,3 & 4,1 & 3,3 & 4,1 & 3,3 & 4,1 & 3,3 & 4,1 & 3,3 & 4,1 & 3,3 & 4,1 & 3,3 & 4,1 & 3,3 & 4,1 & 3,3 & 4,1 \\
\hline & 1,4 & 2,2 & 1,4 & 2,2 & 1,4 & 2,2 & 1,4 & 2,2 & 1,4 & 2,2 & 1,4 & 2,2 & 1,4 & 2,2 & 1,4 & 2,2 & 1,4 & 2,2 \\
\hline \multirow{2}{*}{0.9} & 3,3 & 4,1 & 3,3 & 4,1 & 3,3 & 4,1 & 3,3 & 4,1 & 3,3 & 4,1 & 3,3 & 4,1 & 3,3 & 4,1 & 3,3 & 4,1 & 3,3 & 4,1 \\
\hline & 1,4 & 2,2 & 1,4 & 2,2 & 1,4 & 2,2 & 1,4 & 2,2 & 1,4 & 2,2 & 1,4 & 2,2 & 1,4 & 2,2 & 1,4 & 2,2 & 1,4 & 2,2 \\
\hline
\end{tabular}

Legend:

No-LP is dominant policy

Prisoner dilemma

LP is dominant policy 
Table B.3: Scaled payoff matrices of the game between restricted and unrestricted redemption policies for combinations of mental parameters

\begin{tabular}{|c|c|c|c|c|c|c|c|c|c|c|}
\hline & \multicolumn{2}{|c|}{0.1} & \multicolumn{2}{|c|}{0.2} & \multicolumn{2}{|c|}{0.3} & \multicolumn{2}{|c|}{0.4} & \multicolumn{2}{|c|}{0.5} \\
\hline \multirow{2}{*}{0.1} & 2,2 & & 2,2 & 1,4 & 2,2 & 1,4 & 2,2 & 1,4 & 2,2 & 1,4 \\
\hline & 4,1 & 3,3 & 4,1 & 3,3 & 4,1 & 3,3 & 4,1 & 3,3 & 4,1 & 3,3 \\
\hline \multirow{2}{*}{0.2} & 3,3 & 1,4 & 2,2 & 1,4 & 2,2 & 1,4 & 2,2 & 1,4 & 2,2 & 1,4 \\
\hline & 4,1 & 2,2 & 4,1 & 3,3 & 4,1 & 3,3 & 4,1 & 3,3 & 4,1 & 3,3 \\
\hline \multirow{2}{*}{0.3} & 4,4 & 2,3 & 3,3 & 1,4 & 2,2 & 1,4 & 2,2 & 1,4 & 2,2 & 1,4 \\
\hline & 3,2 & 1,1 & 4,1 & 2,2 & 4,1 & 3,3 & 4,1 & 3,3 & 4,1 & 3,3 \\
\hline \multirow{2}{*}{0.4} & 4,4 & 3,2 & 4,4 & 2,3 & 3,3 & 1,4 & 2,2 & 1,4 & 2,2 & 1,4 \\
\hline & 2,3 & 1,1 & 3,2 & 1,1 & 4,1 & 2,2 & 4,1 & 3,3 & 4,1 & 3,3 \\
\hline \multirow{2}{*}{0.5} & 4,4 & 3,2 & 4,4 & 2,3 & 3,3 & 2,4 & 3,3 & 1,4 & 2,2 & 1,4 \\
\hline & 2,3 & 1,1 & 3,2 & 1,1 & 4,2 & 1,1 & 4,1 & 2,2 & 4,1 & 3,3 \\
\hline \multirow{2}{*}{0.6} & 4,4 & 3,2 & 4,4 & 3,2 & 4,4 & 2,3 & 3,3 & 2,4 & 3,3 & 1,4 \\
\hline & 2,3 & 1,1 & 2,3 & 1,1 & 3,2 & 1,1 & 4,2 & 1,1 & 4,1 & 2,2 \\
\hline \multirow{2}{*}{0.7} & 4,4 & 3,2 & 4,4 & 3,2 & 4,4 & 3,2 & 4,4 & 2,3 & 3,3 & 1,4 \\
\hline & 2,3 & 1,1 & 2,3 & 1,1 & 2,3 & 1,1 & 3,2 & 1,1 & 4,1 & 2,2 \\
\hline \multirow{2}{*}{0.8} & 4,4 & 3,2 & 4,4 & 3,2 & 4,4 & 3,2 & 4,4 & 3,2 & 4,4 & 2,3 \\
\hline & 2,3 & 1,1 & 2,3 & 1,1 & 2,3 & 1,1 & 2,3 & 1,1 & 3,2 & 1,1 \\
\hline \multirow{2}{*}{0.9} & 3,3 & 4,1 & 4,4 & 3,2 & 4,4 & 3,2 & 4,4 & 3,2 & 4,4 & 2,3 \\
\hline & 1,4 & 2,2 & 2,3 & 1,1 & 2,3 & 1,1 & 2,3 & 1,1 & 3,2 & 1,1 \\
\hline
\end{tabular}

Legend:

Restricted policy is dominant

Prisoner dilemma

Unrestricted policy is dominant 
Table B.4 : Scaled payoff matrices of the game between low restricted (without expiry) and highly restricted (with expiry) redemption policies for combinations of mental parameters

\begin{tabular}{|c|c|c|c|c|c|c|c|c|c|c|}
\hline $\begin{array}{r}\alpha_{d} \\
\alpha_{v}\end{array}$ & \multicolumn{2}{|c|}{0.1} & \multicolumn{2}{|c|}{0.2} & \multicolumn{2}{|c|}{0.3} & \multicolumn{2}{|c|}{0.4} & \multicolumn{2}{|c|}{0.5} \\
\hline \multirow{2}{*}{0.5} & 3,3 & 4,1 & 1,1 & 3,2 & 1,1 & 3,2 & 1,1 & 3,2 & 1,1 & 3,2 \\
& 1,4 & 2,2 & 2,3 & 4,4 & 2,3 & 4,4 & 2,3 & 4,4 & 2,3 & 4,4 \\
\hline \multirow{2}{*}{0.6} & 3,3 & 4,1 & 1,1 & 4,2 & 1,1 & 3,2 & 1,1 & 3,2 & 1,1 & 3,2 \\
& 1,4 & 2,2 & 2,4 & 3,3 & 2,3 & 4,4 & 2,3 & 4,4 & 2,3 & 4,4 \\
\hline \multirow{2}{*}{0.7} & 1,1 & 3,4 & 1,1 & 3,2 & 1,1 & 3,2 & 1,1 & 2,3 & 1,1 & 2,3 \\
\cline { 2 - 13 } & 4,3 & 2,2 & 2,3 & 4,4 & 2,3 & 4,4 & 3,2 & 4,4 & 3,2 & 4,4 \\
\hline \multirow{2}{*}{0.8} & 1,1 & 3,2 & 1,1 & 3,2 & 1,1 & 2,3 & 1,1 & 2,3 & 1,1 & 2,3 \\
\hline \multirow{2}{*}{0.9} & 2,3 & 4,4 & 2,3 & 4,4 & 3,2 & 4,4 & 3,2 & 4,4 & 3,2 & 4,4 \\
\cline { 2 - 12 } & 2,3 & 3,2 & 1,1 & 2,3 & 1,1 & 2,3 & 1,1 & 2,3 & 1,1 & 2,3 \\
\hline
\end{tabular}

Legend:

Unknown region

Setting expiry is dominant Nash equilibrium

Setting expiry is Pareto optimal policy 
Table B.5: Scaled payoff matrices of the game between unrestricted, low restricted, and highly restricted redemption policies for combinations of mental parameters

\begin{tabular}{|c|c|c|c|c|c|c|c|c|c|c|c|c|c|c|c|}
\hline & \multicolumn{3}{|c|}{0.1} & \multicolumn{3}{|c|}{0.2} & \multicolumn{3}{|c|}{0.3} & \multicolumn{3}{|c|}{0.4} & \multicolumn{3}{|c|}{0.5} \\
\hline \multirow{3}{*}{0.5} & 1,1 & 2,5 & 3,4 & 1,1 & 4,3 & 5,2 & 2,2 & 8,3 & 9,1 & 3,3 & 8,2 & 9,1 & 7,7 & 8,2 & 9,1 \\
\hline & 5,2 & 8,8 & 9,6 & 3,4 & 6,6 & 8,7 & 3,8 & 4,4 & 6,5 & 2,8 & 4,4 & 6,5 & 2,8 & 3,3 & 5,4 \\
\hline & 4,3 & 6,9 & 7.7 & 2,5 & 7,8 & 9,9 & 1,9 & 5,6 & 7,7 & 1,9 & 5,6 & 7,7 & 1,9 & 4,5 & 6,6 \\
\hline \multirow{3}{*}{0.6} & 1,1 & 2,5 & 3,4 & 1,1 & 2,5 & 3,4 & 1,1 & 4,3 & 5,2 & 2,2 & 8,3 & 9,1 & 3,3 & 8,2 & 9,1 \\
\hline & 5,2 & 8,8 & 9,6 & 5,2 & 6,6 & 9,7 & 3,4 & 6,6 & 8,7 & 3,8 & 4,4 & 6,5 & 2,8 & 4,4 & 6,5 \\
\hline & 4,3 & 6,9 & 7,7 & 4,3 & 7,9 & 8,8 & 2,5 & 7,8 & 9,9 & 1,9 & 5,6 & 7,7 & 1,9 & 5,6 & 7,7 \\
\hline \multirow{3}{*}{0.7} & 1,1 & 2,5 & 3,4 & 1,1 & 2,5 & 3,4 & 1,1 & 2,4 & 3,5 & 1,1 & 4,2 & 5,3 & 3,3 & 8,1 & 9,2 \\
\hline & 5,2 & 6,6 & 8,9 & 5,2 & 6,6 & 8,7 & 4,2 & 6,6 & 8,7 & 2,4 & 6,6 & 7,8 & 1,8 & 4,4 & 5,6 \\
\hline & 4,3 & 9,8 & 7,7 & 4,3 & 7,8 & 9,9 & 5,3 & 7,8 & 9,9 & 3,5 & 8,7 & 9,9 & 2,9 & 6,5 & 7,7 \\
\hline \multirow{3}{*}{0.8} & 1,1 & 2,4 & 3,5 & 1,1 & 2,4 & 3,5 & 1,1 & 2,4 & 3,5 & 1,1 & 2,3 & 4,6 & 1,1 & 3,2 & 6,4 \\
\hline & 4,2 & 6,6 & 8,7 & 4,2 & 6,6 & 8,7 & 4,2 & 6,6 & 7,8 & 3,2 & 5,5 & 7,8 & 2,3 & 5,5 & 7.8 \\
\hline & 5,3 & 7,8 & 9,9 & 5,3 & 7,8 & 9,9 & 5,3 & 8,7 & 9,9 & 6,4 & 8,7 & 9,9 & 4,6 & 8,7 & 9,9 \\
\hline \multirow{3}{*}{0.9} & 2,2 & 1,5 & 3,7 & 1,1 & 2,4 & 3,6 & 1,1 & 2,4 & 3,6 & 1,1 & 2,3 & 5,6 & 1,1 & 3,2 & 5,6 \\
\hline & 5,1 & 4,4 & 8,6 & 4,2 & 5,5 & 7,8 & 4,2 & 5,5 & 7,8 & 3,2 & 4,4 & 7,8 & 2,3 & 4,4 & 7,8 \\
\hline & 7,3 & 6,8 & 9,9 & 6,3 & 8,7 & 9,9 & 6,3 & 8,7 & 9,9 & 6,5 & 8,7 & 9,9 & 6,5 & 8,7 & 9,9 \\
\hline
\end{tabular}

Legend:

High restricted policy is dominant

Prisoner dilemma; unrestricted policy is the equilibrium

Prisoner dilemma; low restricted policy is the equilibrium 


\section{Bibliography}

Ben-Akiva, M. \& Lerman, S., 1985. Discrete choice analysis: Theory and application to travel demand. 1st ed. Boston:The MIT Press.

Berry, J., 2015. The 2015 loyalty census, big numbers, big hurdles. Technical report. Cincinnati: COLLOQUY.

Besanko, D. \& Winston, W. L., 1990. Optimal price skimming by a monopolist facing rational consumers. Management Science, 36(5), pp. 555-567.

Bijmolt, T. H., Verhoef, P. C. \& Dorotic, M., 2012. Loyalty programmes: Current knowledge and research directions. International Journal of Management Reviews, 14(3), pp. 217-237.

Blattberg, R. \& Sen, S., 1974. Market segmentation using models of multidimensional purchasing behavior. Journal of Marketing, 38(4), pp. 17-28.

Breugelmans, E., Bijmolt, T. H. A., Zhang, J., Basso, L. J., Dorotic, M., Kopalle, P., Minnema, A., Mijnlieff, W. J. \& Wnderlich, N. V., 2015. Advancing research on loyalty programs: A future research agenda. Marketing Letters, 26(2), pp. 127-139.

Bustos-Reyes, C. \& González-Benito, O., 2008. Store and store format loyalty measures based on budget allocation. Journal of Business Reseach, 61(9), pp. 1015-1025.

Butcher, K., Sparks, B. \& O'Callaghan, F., 2001. Evaluative and relational influences on service loyalty. International Journal of Service Industry Management, 12(4), pp. 310-327. 
Byrd, R. H., Gilbert, J. C. \& Nocedal, J., 2000. A trust region method based on interior point techniques for nonlinear programming. Mathematical Programming, 89(1), pp. 149-185.

Caminal, R. \& Matutes, C., 1990. Endogenous switching costs in a duopoly model. International Journal of Industrial Organization, 8(3), pp. 353-373.

Cao, Y., Nasakanda, A. L. \& Diaby, M., 2015. Planning the supply of rewards with cooperative promotion considerations in coalition loyalty programmes management. Journal of the Operational Research Society, 66(7), pp. 1140-1154.

Chun, S. Y., Iancu, D. A. \& Trichakis, N., 2015. Setting the Optimal Value of Loyalty Points. Stanford Graduate School of Business Research Paper Series, pp. 15-32.

Crosson, S. V. \& Needles, B. E., 2008. Managerial Accounting. Boston: Cengage Learning.

Dekay, F., Toh, R. S. \& Raven, P., 2009. Loyalty programs: airlines outdo hotels. Cornell Hospitality Quarterly, 50(3), pp. 371-382.

DeWulf, K., Odekerken-Schroder, G. \& Lacobucci, D., 2001. Investments in consumer relationships: A crosscountry and cross-industry exploration. Journal of Marketing, 65(4), pp. 33-50.

Dick, A., 1994. Customer loyalty: towards an integrated conceptual framework. Journal of the Academy of Marketing Science, 22(2), pp. 99-113.

Dorotic, M., Verhoef, P., Fok, D. \& Bijmolt, T., 2014. Reward redemption effects in a loyalty program when customers choose how much and when to redeem. International Journal of Research in Marketing, 31(4), pp. 339-355. 
Dowling, G. \& Uncles, M., 1997. Do customer loyalty programs really work? Sloan Management Review, 38(4), pp. 71-82.

Drèze, X. \& Nunes, J. C., 2009. Feeling superior: The impact of loyalty program structures on consumer's perceptions of status. Journal of Consumer Research, 35(6), pp. 890-905.

Ehenberg, A., Googhardt, G. \& Barwise, T., 1990. Double jeopardy revisited. The Journal of Marketing, 54(3), pp. 82-91.

Gandomi, A., 2012. An analytical investigation of the effectiveness of customer loyalty programs. Toronto: Ph.D. thesis, Ryerson University.

Gandomi, A. \& Zolfaghari, S., 2011. A stochastic model on the profitability of loyalty programs. Computers \& Industrial Engineering, 61(3), pp. 482-488.

Gandomi, A. \& Zolfaghari, S., 2013. Profitability of loyalty reward programs: An analytical investigation. Omega, 41(4), pp. 797-807.

Haurie, A., Tavoni, M. \& van der Zwaan, B. C. C., 2012. Modeling uncertainty and the economics of climate change: Recommendations for robust energy policy. Environmental Modeling \& Assessment, 17(1), pp. 1-5.

Haurie, . A. \& Zaccour, G., 2005. Dynamic Games: Theory and Applications. New York: Springer.

Henderson, C., Joshua, T. \& Palmatier, R., 2011. Review of the theoretical underpinnings of loyalty programs. Journal of Consumer Psychology, 21(3), pp. 256-276. 
Hongmin, L. \& Woonghee Tim, H., 2011. Pricing multiple products with the multinomial logit and nested logit models: Concavity and Implications. Manufacturing \& Service Operations Management, 13(2), pp. 549-563.

Jones, M., Reynolds, K. \& Arnold, M., 2006. Hedonic and utilitarian shopping value: Investigating differential effects on retail outcomes. Journal of Business Research, 59(9), pp. 974-981.

Kahn, B., Kalwani, M. \& Morrison, D., 1988. Niching versus change-of-pace brands: using purchase frequencies and penetration rates to infer brand positionings. Journal of Marketing Research, 25(4), pp. 384-390.

Kim, B., Shi, M. \& Srinivasan, K., 2001. Reward programs and tacit collusion. Marketing Science, 20(2), pp. 99-120.

Kim, S., 1987. A product differentiation model with outside goods and price bargaining. Economics Letters, 24(4), pp. 305-309.

Kivets, R., 2005. Promotion reactance: The role of effort-reward congruity. Journal of Consumer Research, 31(4), pp. 725-736.

Kivetz, R., 2003. The effects of effort and intrinsic motivation on risky choice. Marketing Science, 22(4), pp. 477-502.

Kivetz, R. \& Simonson, I., 2002. Earning the right to indulge: Effort as a determinant of customer preferences toward frequency program rewards. Journal of Marketing Research, 39(2), pp. 155-70. 
Kivetz, R., Urminsky, O. \& Zheng, Y., 2006. The goal-gradient hypothesis resurrected: Purchase acceleration, illusionary goal progress and customer retention. Journal of Marketing Research, 43(1), pp. 39-58.

Klemperer, P., 1987b. The competitiveness of markets with switching costs. RAND Journal of Economics, 18(1), pp. 138-150.

Kopalle , P. \& Neslin, S., 2003. The economic viability of frequency reward programs in a strategic competitive environment. Review of Marketing Science, 1(1), pp. 1-42.

Kopalle, P. K., Sun, Y., Neslin, S.A.; Sun, B. \& Swaminathan, V., 2012. The joint sales impact of frequency reward and customer tier components of loyalty programs. Marketing Science, 31(2), pp. 216-235.

Kumar, V., 2008. Managing customers for profit: Strategies to increase profits and build Loyalty. Philadelphia: Wharton School Publishing.

Kumar, V., Pozza, I. \& Ganesh, J., 2013. Revisiting the satisfaction-loyalty relationship: Empirical generalizations and directions for future research. Journal of Retailing, 89(3), pp. 246-262.

Kumar, V. \& Reinartz, W., 2006. Customer Relationship Management: A Database Approach. Hoboken: John Wiley \& Sons.

Kumar, V. \& Shah, D., 2004. Building and sustaining profitable customer loyalty for the $21 \mathrm{st}$ century. Journal of Retailing, 80(4), pp. 317-330. 
Lal, R. \& Bell, D. E., 2003. The impact of frequent shopper programs in grocery retailing. Quantitative Marketing and Economics, 1(2), pp. 179-202.

Leenheer, J. \& Bijmolt, T. H., 2008. Which retailers adopt a loyalty program? An empirical study. Journal of Retailing and Consumer Services, 15(6), pp. 429-442.

Leenheer, J., Van Heerde, H. J. \& Bijmolt, T. H. A., 2007. Do loyalty programs really enhance behavioral loyalty? An empirical analysis accounting for self selecting members. International Journal of Research in Marketing, 24(1), pp. 31-47.

Lewis, M., 2004. The influence of loyalty programs and short-term promotions on customer retention. Journal of Marketing Research, 41(3): 281-292.

Liu, Q. \& van Ryzin, G. J., 2008. On the choice-based linear programming model for network revenue management. Manufacturing \& Service Operations Management, 10(2), pp. 288310.

Liu, Y., 2007. The long-term impact of loyalty programs on consumer purchase behavior and loyalty. Journal of Marketing, 71(4), pp. 19-35.

Liu, Y. \& Yang, R., 2009. Competing loyalty programs: Impact of market saturation, market share, and category expandability. Journal of Marketing , 73(1), pp. 93-108.

Mägi, A. W., 2003. Share of wallet in retailing: The effects of customer satisfaction, loyalty cards and shopper characteristics. Journal of Retailing, 79(2), pp. 97-106.

Mauri, C., 2003. Card loyalty: A new emerging issue in grocery retailing. Journal of Retailing and Consumer Services, 10(1), pp. 13-25. 
Mayer-Waarden, L., 2007. The effects of loyalty programs on customer lifetime duration and share of wallet. Journal of Retailing, 83(2), pp. 223-236.

Maynard, M. \& Dash, E., 2005. Fliers find that mileage points only go so far. New York Times, 13 March.

McCall, M. \& Voorhees, C., 2010. The drivers of loyalty program success: An organizing framework and research agenda. Cornell Hospitality Quarterly, 51(1), pp. 35-52.

Meissner, J. \& Strauss, A. K., 2012. Network revenue management with inventory-sensitive bid prices and customer choice. European Journal of Operational Research, 216(2), pp. 459468.

Meissner, J., Strauss, A. \& Talluri, K., 2012. An enhanced concave program relaxation for choice network revenue management. Production and Operations Management, 22(1), pp. 71-87.

Meyer-Waarden, L., 2008. The influence of loyalty programme membership on customer purchase behaviour. European Journal of Marketing , 42(1/2), pp. 87-114.

Meyer-Waarden, L. \& Benavent, C., 2006. The impact of loyalty programs on repeat purchase behavior. Journal of Marketing Management, 22(1), pp. 61-88.

Mimouni-Chaabane, A. \& Volle, P., 2010. Perceived benefits of loyalty programs: scale development and implications for relational strategies. Journal of Business Research, 63(1), pp. 32-37. 
Morales, A., 2005. Giving firms an "E" for effort: Consumer responses to high-effort firms. Journal of Consumer Research, 31(4), pp. 806-812.

Nash, J., 1950. Equilibrium points in n-person games. Proceedings of the National Academy of Sciences, 36(1), pp. 48-49.

Nash, J. 1951. Non-cooperative games. The Annals of Mathematics, 54(2), pp. 286-295.

Noble, S. M., Esmark, C. L. \& Noble, C. H., 2014. Accumulation versus instant loyalty programs: The influence of controlling policies. Journal of Business Research, 67(3), pp. 361-368.

Nunes, J. C. \& Dréze, X., 2006. Your loyalty program is betraying you. Harvard Business Review, 84(4), pp. 124-131.

Oliver, R., 1999. Whence consumer loyalty?. Journal of Marketing, 63(Special Issue), pp. 33-44.

Ott, B., 2011. Making loyalty programs work. [Online] Available at: http://www.gallup.com/businessjournal/149570/Making-Loyalty-Programs-Work.aspx [Accessed 24 Nov 2016].

Palmatier, R. W., Jarvis, C. B., Bechkoff, J. R. \& Kardes, F. R., 2009. The role of customer gratitude in relationship marketing. Journal of Marketing, 73(5), pp. 1-18.

Pauler, G. \& Dick, A., 2006. Maximizing profit of a food retailing chain by targeting and promoting valuable customers using loyalty card and scanner data. European Journal of Operational Research, 174(2), pp. 1260-1280. 
Roehm, M. L., Pullins, E. B. \& Roehm Jr., A. H., 2002. Designing loyalty-building programs for packaged goods brands. Journal of Marketing Research, 39(2), pp. 202-213.

Roehm, M. L. \& Roehm Jr., H. A., 2010. The influence of redemption time frame on responses to incentives. Journal of the Academy of Marketing Science, pp. 1-13.

Rosenbaum, M. S., Ostrom, A. L. \& Kuntze, R., 2005. Loyalty programs and a sense of community. Journal of Services Marketing, 19(4), pp. 222-33.

Rusmevichientong, P., Shmoys, D. \& Topaloglu, H., 2014. Assortment optimization under the multinomial logit model with random choice parameters. Production and Operations Management, 23(11), pp. 2023-2039.

Salop, S. C., 1979. Monopolistic competition with outside goods. The Bell Journal of Economics, 10(1), pp. 141-156.

Sharp, B. \& Sharp, A., 1997. Loyalty programs and their impact on repeat-purchase loyalty patterns. International of Research in Marketing, 14(5), pp. 473.

Shugan, S., 2005. Brand loyalty programs: Are they shams?. Marketing Science, 24(2), pp. 18593.

Singh, S. S., Jain, D. C. \& Krishnan, T. V., 2008. Customer loyalty programs: Are they profitable?. Management Science, 54(6), pp. 1205-1211.

Soman, D., 2003. The effect of payment transparency on consumption: Quasi experiments from the field. Marketing Letters, 14(3), pp. 173-183. 
Stauss, B., Schmidt, M. \& Schoeler, A., 2005. Customer frustration in loyalty programs. International Journal of Service Industry Management, 16(3), pp. 229-252.

Stourm, V., Bradlow, E. \& Fader, P., 2015. Stockpiling points in linear loyalty programs. Journal of Marketing Research, 52(2), pp. 253-267.

Supermaket News, 2010. Wal-mart scores highest in shopper loyalty study. [Online] Available at: http://supermarketnews.com/news/walmart_loyalty_0329/?cid=upd

Talluri, K. \& Van Ryzin, G., 2004. The theory and practice of revenue management. Boston, MA, Kluwer Academic Publishers.

Taylor, G. A. \& Neslin, S. A., 2005. The current and future sales impact of a retail frequency reward program. Journal of Retailing , 81(4), pp. 293-305.

Thaler, R., 1985. Mental accounting and consumer choice. Marketing Science, 4(3), pp. 199-214.

Topaloglu, H., 2013. Joint stocking and product offer decisions under the multinomial logit model. Production and Operations Management, 22(5), pp. 1182-1199.

Uncles, M., 2003. Customer loyalty and customer loyalty programs. Journal of Consumer Marketing, 20(4), pp. 294-316.

van Ryzin, G. \& Vulcano, G., 2008. Computing virtual nesting controls for network revenue management under customer choice behavior. Manufacturing \& Service Operations Management, 10(3), pp. 448-467. 
Verhoef, P., 2003. Understanding the effect of customer relationship management efforts on customer retention and customer share development. Journal of Marketing, 67(4), pp. 3045.

Wagner, T., Henning-Thurau, T. \& Rudolph, T., 2009. Does customer demotion jeopardize loyalty?. Journal of Marketing, 73(3), pp. 69-85.

Yahoo News, 2013. [Online] Available at: http://news.yahoo.com/jetblue-ends-expirationloyalty-program-213901141.html

Yi, Y. \& Jeon, H., 2003. Effects of loyalty programs on value perception, program loyalty, and brand loyalty. Journal of the Academy of Marketing Science, 31(3), pp. 229-240.

Zhang, J. \& Breugelmans, E., 2012. The impact of an item-based loyalty program on consumer purchase behavior. Journal of Marketing Research, 49(1), pp. 50-65.

Zhang, J., Dixit, A. \& Friedmann, R., 2010. Customer loyalty and lifetime value: An empirical investigation of consumer packaged goods. The Journal of Marketing Theory and Practice, 18(2), pp. 127-140. 